\begin{tabular}{|c|l|}
\hline Title & Experimental Studies of Coupled Heat and Moisture Transfer in Soils During Freezing \\
\hline Author(s) & FUKUDA, Masami \\
\hline Citation & Contributions from the Institute of Low Temperature Science, A 31, 35-91 \\
\hline Issue Date & 1983-03-28 \\
\hline Doc URL & http://hdl.handle.net/2115/20245 \\
\hline Type & bulletin (article) \\
\hline File Information & A 31_p35-91.pdf \\
\hline
\end{tabular}

Instructions for use 


\title{
Experimental Studies of Coupled Heat and Moisture Transfer in Soils During Freezing*
}

\author{
by \\ Masami FuKudA \\ 福 田 正 已 \\ The Institute of Low Temperature Science \\ Received February 1983
}

\begin{abstract}
The author attempted to verify the mechanism and model of heat and moisture transfer in a soil during freezing which he proposed.

He conducted verificatory experiments to show moisture flows both in the frozen and the unfrozen layer of a freezing soil as well as making a mathematical analysis of the model using the computer simulation method. A discussion of the results led to a conclusion, which is summarized as follows :

(1) Measurements of pore-water pressure in the unfrozen layer during freezing showed that the pore-water pressure profile remains constant and water is transported upward to the freezing front when the freezing front is stationary.

(2) Observations of the growth of ice lenses indicated that they are formed at temperatures below $0^{\circ} \mathrm{C}$ and suggested that a considerable amount of moisture flows through the frozen layer.

(3) Being the dual gamma beam attenuation method an ideal technique for the monitoring of moisture flows both in a frozen and an unfrozen soil, the author applied it to a soil freezing experiment, whereby he obtained a number of reproducible results; he measured moisture flows in the frozen layer directly as well as obtaining information on temperature distribution in it.

(4) The results of the dual gamma beam attenuation method allowed to estimate the hydraulic conductivity of a frozen and unsaturated soil.

(5) A numerical analysis was also conducted using the computer simulation method, with the results reinforcing the results of the experiments in verifying the model proposed by the author concerning heat and moisture transfer in a soil during freezing.
\end{abstract}

* Contribution No. 2528 from the Institute of Low Temperature Science.

北海道大学番查学位諭文 


\section{Contents}

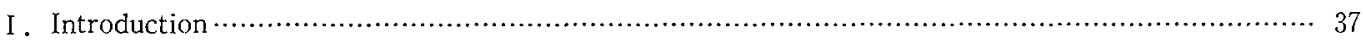

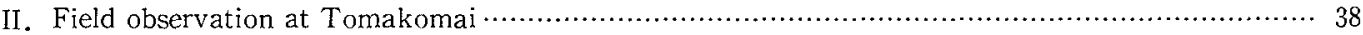

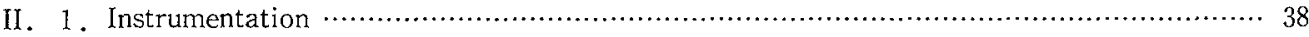

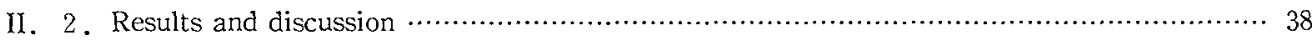

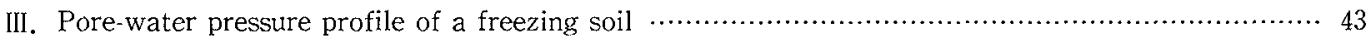

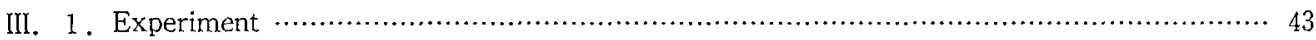

III. 2. Measurement of hydraulic conductivity ……...................................................... 44

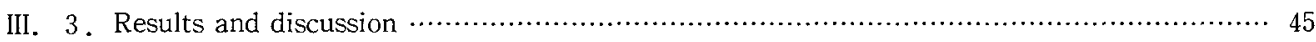

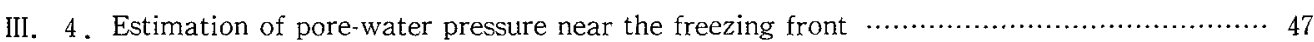

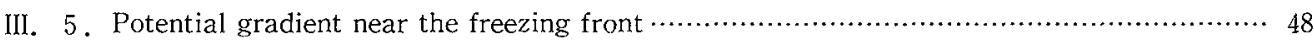

III. 6. Field observations of pore-water pressure profile at Tomakomai …........................ 50

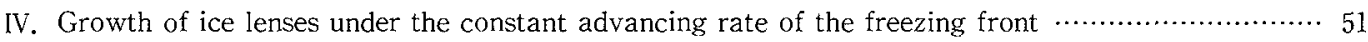

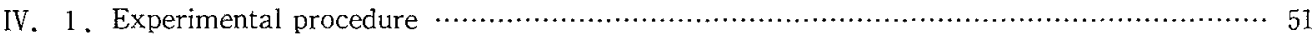

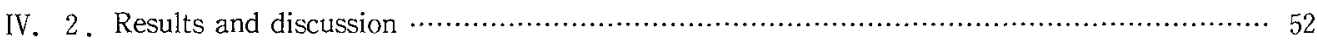

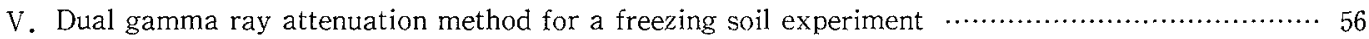

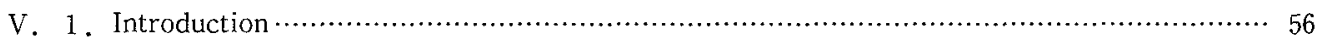

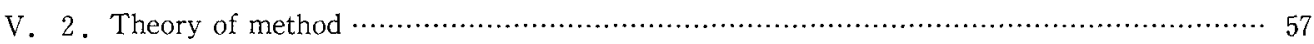

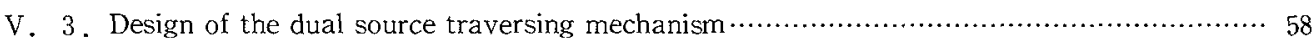

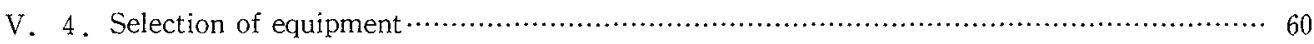

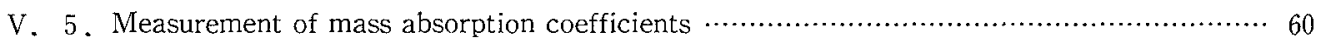

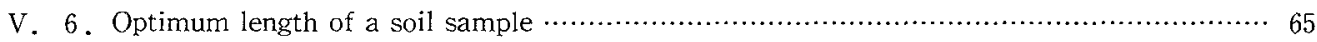

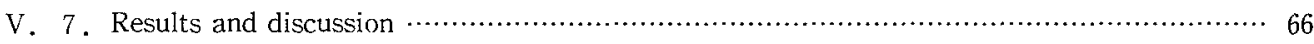

VI. Numerical analysis of coupled heat and moisture transfer in a soil during freezing $\ldots \ldots \ldots \ldots \ldots \ldots \ldots \ldots \ldots$

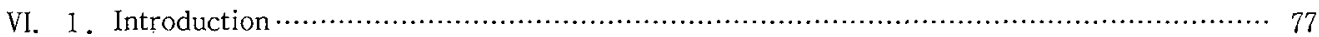

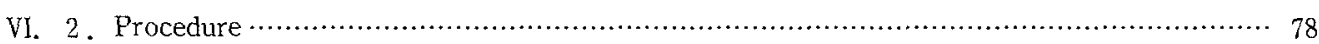

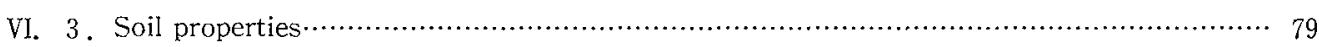

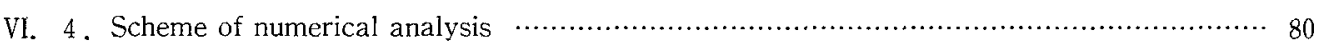

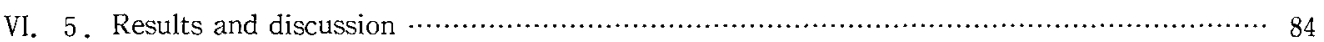




\section{I . Introduction}

The theory and experimental verification of frost heaving have well developed recently. During the freezing of a soil, water in the soil migrates to the freezing front. Concerning driving forces of this migration a number of attempts have been made to account for them. The first explanation drew on a model based on capillarity (Everett, 1961) according to which the capillary pressure is given for an unsaturated, unfrozen soil as follows:

$$
P_{a}-P_{w}=2 \sigma_{u a} / r_{w a}
$$

where $\mathrm{P}_{\mathrm{a}}$ is the pressure in the air phase, $P_{w}$ is the pressure inside water, $\sigma_{\mathrm{ua}}$ is the surface tension of air-water, and $r_{w a}$ is the effective pore radius of the soil. Such a difference in pressure between water and ice at their interface pulls water toward the interface. Below the layer of the interface it forms a hydraulic pressure gradient. Water migrates along it toward the interface, forming a "freezing front" (Chalmirs and Jackson, 1970).

Secondly, generalizing Clapeyron equation, Edlefsen and Anderson (1943) defined another model concerning the suction of water in a frozen soil. This second concept treated the flow of water to the freezing front similarly to the first model.

Thirdly, it is a well-known fact that, when a soil freezes, not all the amount of water freezes simultaneously (Anderson and Morgenstern, 1973) and that the amount of unfrozen water in the frozen soil decreases with lowering temperature. Thus, if a temperature gradient exists in a frozen layer, unfrozen water inside the frozen soil is different in chemical potential from unfrozen water inside the unfrozen soil. Under this condition a differentiated chemical potential may be defined as a differentiated pore-water pressure. Then, it is likely that water flows to the lower side of pore-water pressure. This third concept is shown by a simplified schematic figure in Fig. 1 Models of the coupled heat and moisture transFig. 1.

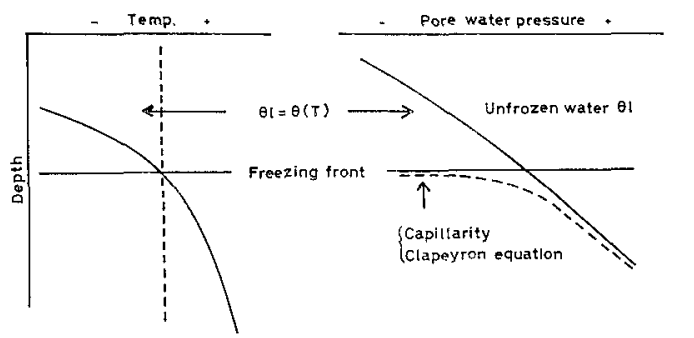
fer in soil durig freezing.

Generalized and called the coupled heat

and moisture transfer in soil during freezing, the third concept has been experimented with recently in a variety of attempts to explain the water transport, which is the dominant process in frost heaving (Guymon and Luthin, 1974 ; Taylor and Luthin, 1976, 1978 ; Jame and Norum, 1977 ; Sheppard, Kay and Loch, 1978). It may be said, however, that no adequate verification has been given to the model based on this concept.

Accordingly, aiming at providing verificatory data, the author conducted experiments, with the results suggesting water migration in both the frozen and the unfrozen soil (chapters 
II, III, IV, V), whereby he verifited the model by comparing the results with the numerical analyses obtained by the computer simulation method (chapter VI).

\section{Field observations at Tomakomai}

The objective of this chapter is to show the characteristic phenomena due to soil freezing and frost heaving observed in field environments. The observations gave us general ideas of frost heaving with complex features resulting from it.

\section{1. Instrumentation}

For the studies of frost heaving a field site was selected in the Tomakomai experimental forest, Hokkaido. A concrete waterproof basin $(5 \times 5 \mathrm{~m}$ wide, $2 \mathrm{~m}$ deep) was filled with a test soil (Tomakomai silt). A water level within the basin was controlled artificially so that a sufficient amount of water was supplied to the soil to cause a large frost heaving to occur.

Daily changes were recorded in air temperature, soil temperatures at several depths, heave amount of the ground surface and the depth of ground freeze. Heat flow sensors were installed at various depths, and tensiometers were also inserted within soil layers. Core samples were taken out of the frozen ground several times throughout the period of the experiment, and obtained samples were used to measure their water contents and densities.

\section{2. Results and discussion}

Two sets of observed results are shown in Fig. 2-a, 2-b and Fig. 3-a, 3-b. Shown in the first set are changes in level of the surface and in depth of the freezing front with the lapse of time in the 1976-1977 season. Two different types of soils were tested. These differences effected the total heave amounts and the maximum depths of ground freeze. Type I soil (Fig. 2-a) is more frost susceptible than Type II soil (Fig. 2-b). Water content profiles of the frozen soils of both types showed an identical tendency, so, the water was accumulated in some frozen layers. For example, in Fig. 2-b, water content profiles of Type II soil on 7th Jan. and 8th Mar. had the maximum peaks at the depths between 10 and $20 \mathrm{~cm}$; the similar tendency in case of Type I soil was also shown. Down below the freezing front, water contents were considerably smaller than in the upper frozen layer. It means that water in the soil redistributed after freezing and that the water accumulated layers were formed at the upmost layer. The cross-sectional photos of the frozen samples are shown in Fig. 4-a and 4-b. If one compares the redistributed water content profile and the photos, it is obvious that the water accumulated layers correspond to the ice lenses in the frozen layers.

Such features in the frozen soil as the formation of ice lenses were observed in other winter seasons. Another set of examples are shown in Fig. 3-a, 3-b and 5. For improving or verifying the model to explain such a water redistribution, two trial experiments were carried out in the field. The heat flow measurement was one of them. A typical result is 

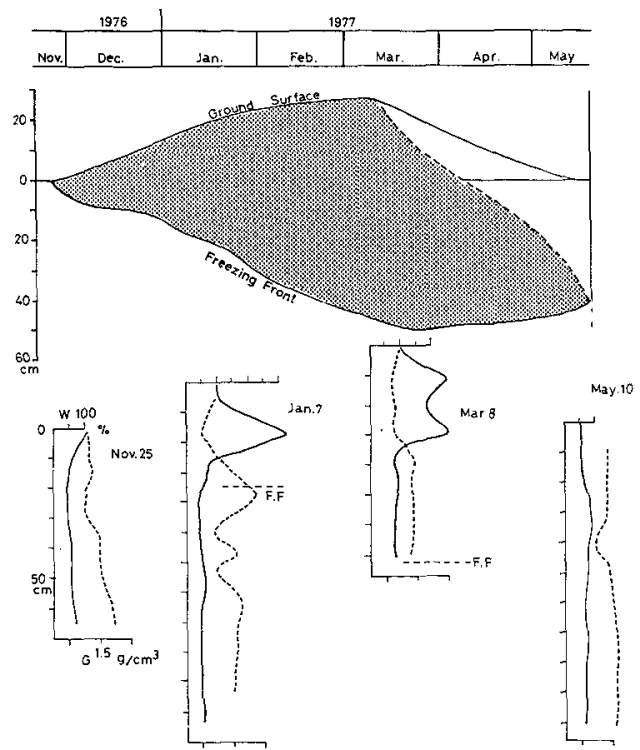

W: WATER CONTENT

Fig. 2-a Results of soil freezing and heaving at test site I , 1976-77 season.
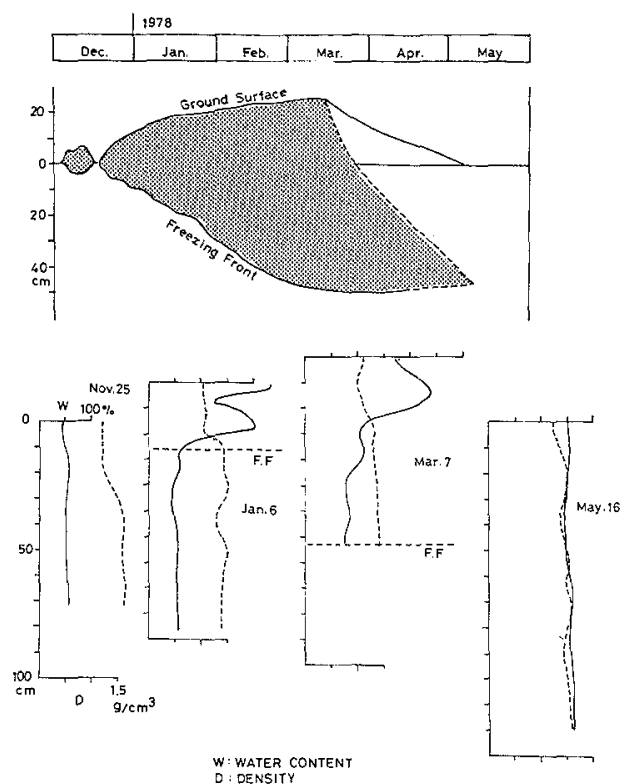

Fig. 3-a Results of soil freezing and heaving at test site I , $1977-78$ season.

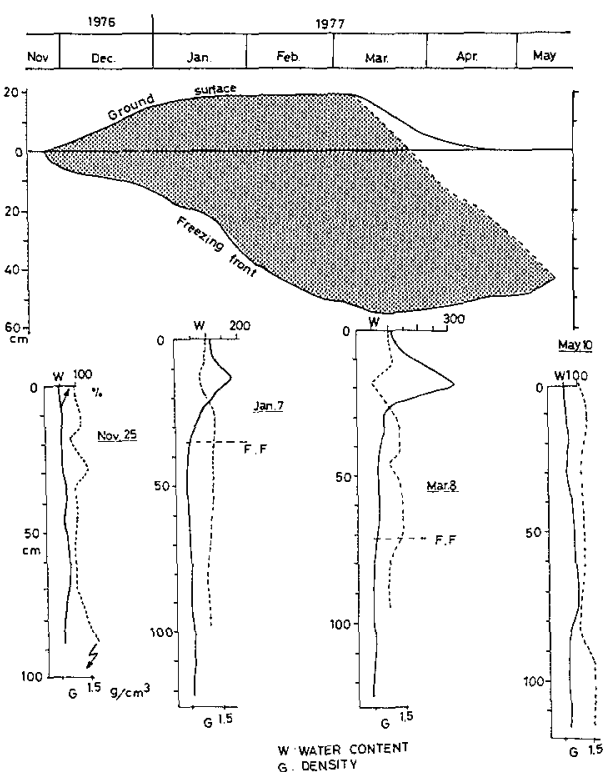

Fig. 2-b Results of soil freezing and heaving at test site II, 1976-77 season
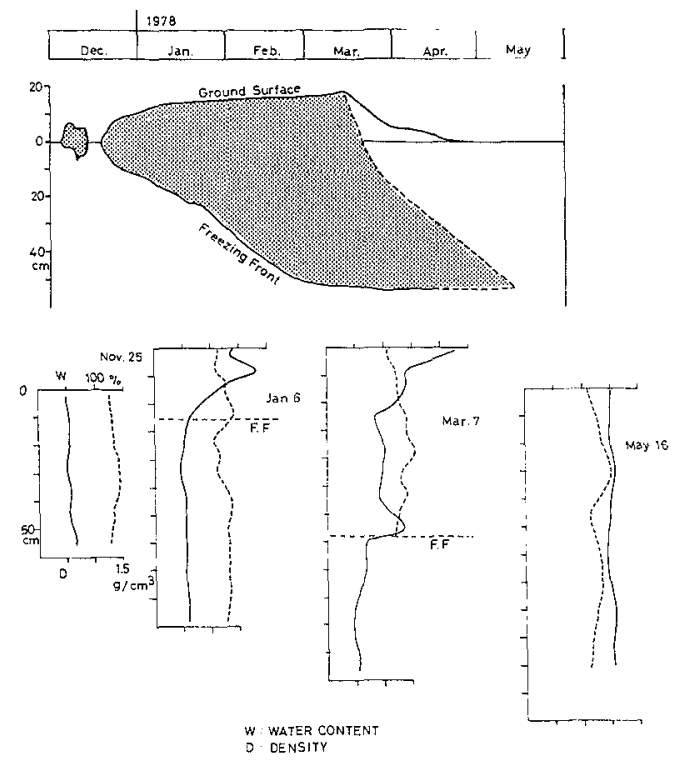

Fig. 3-b Results of soil freezing and heaving at test site II, $1977-78$ season. 
M. FukudA
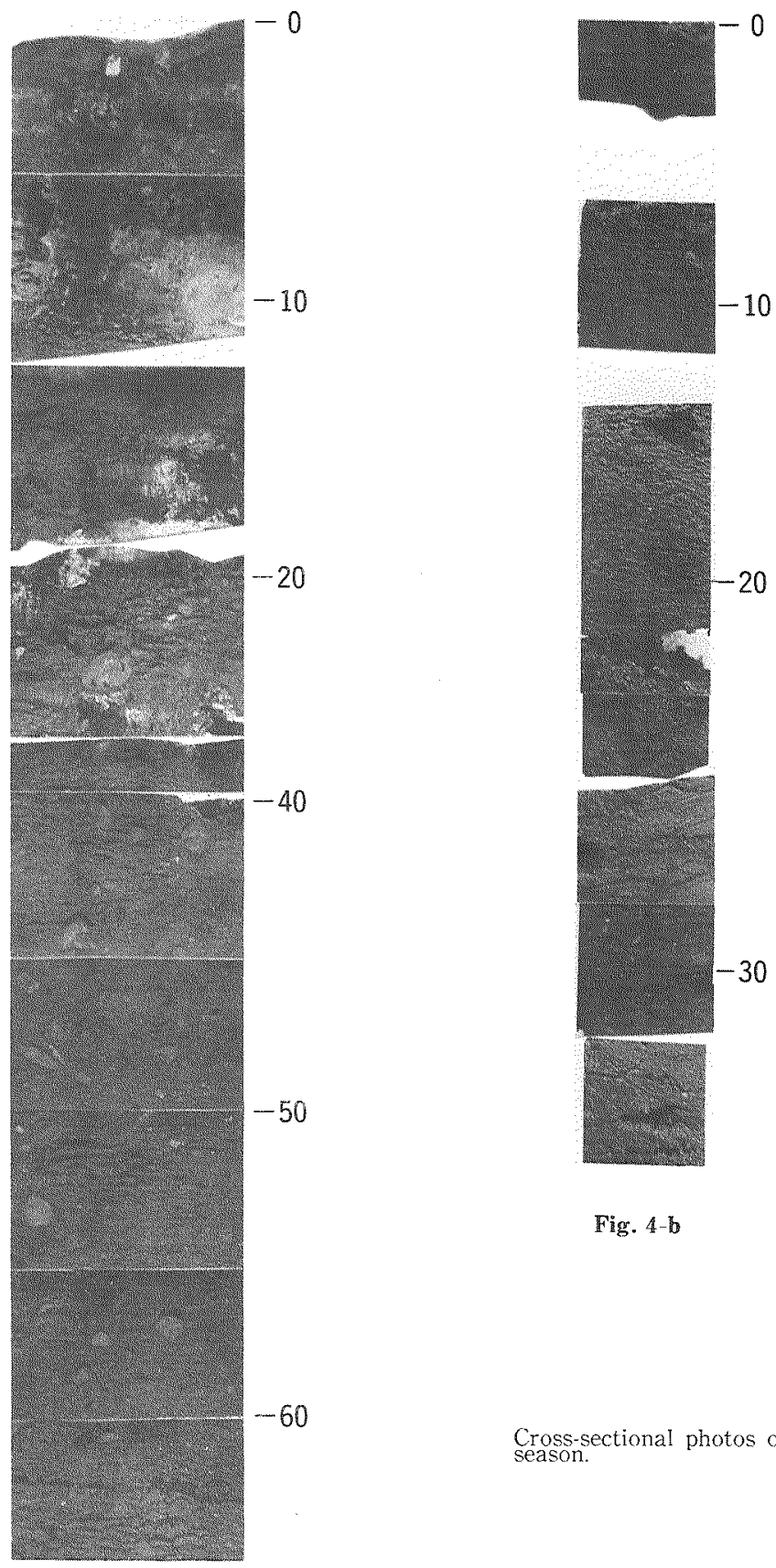

Fig. 4-b

Fig. 4-a Cross-sectional photos of frozen soil, 1976-77
season. 


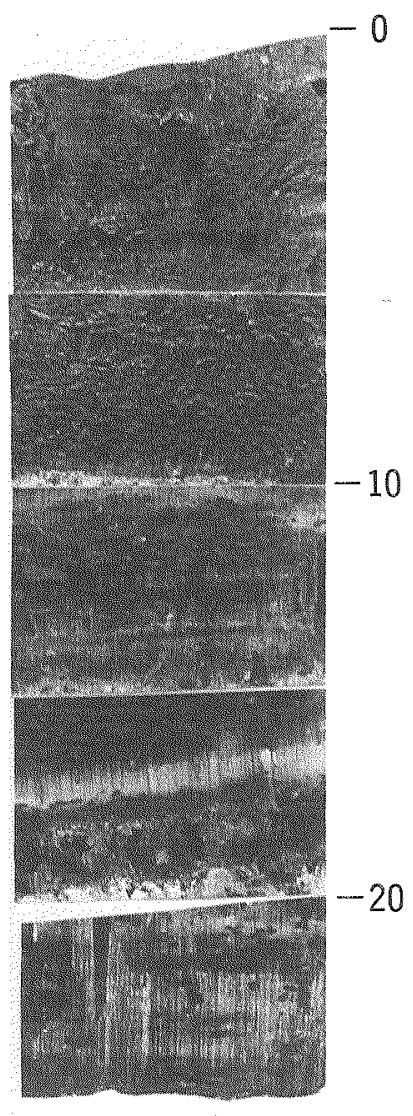

Fig. 5-a

Cross-sectional photos of frozen soil, 1977.78 season.

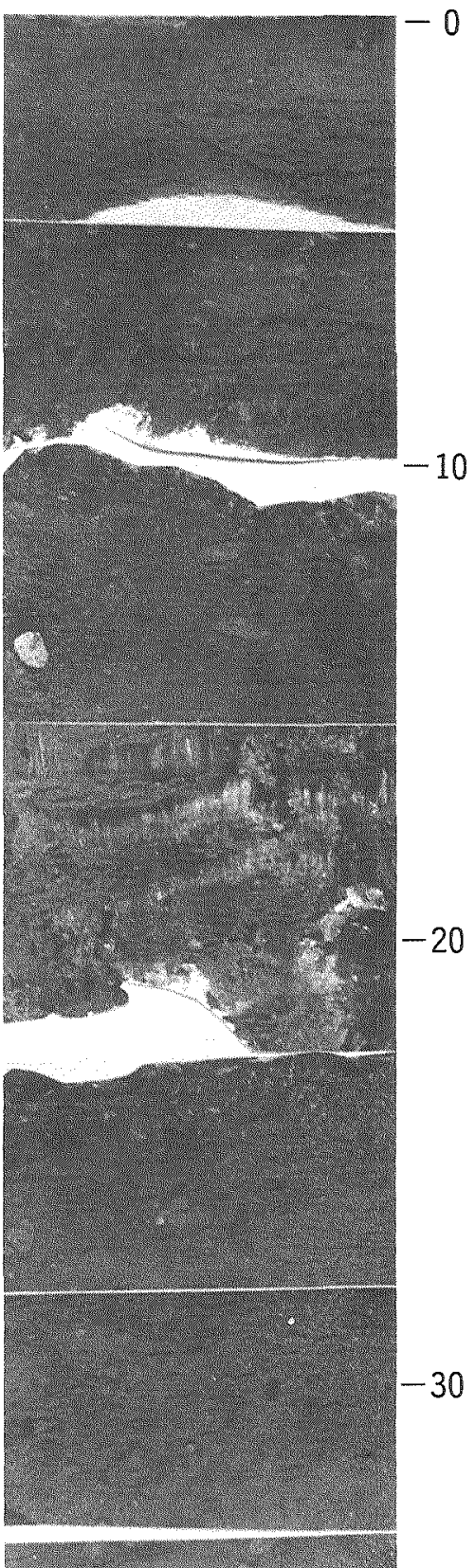

Fig. 5 b 


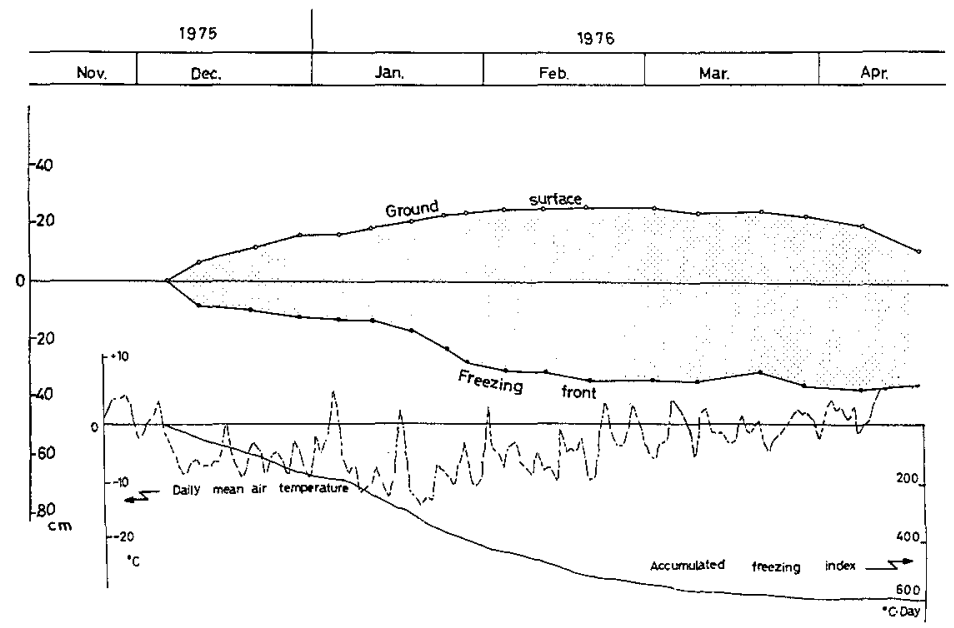

Fig. 6 Results of soil freezing and heaving at test site III, 1975-76 season.

\begin{tabular}{l|l|l|l|l}
1975 & \multicolumn{4}{|c}{1976} \\
\hline DEC. & JAN. & FEB & MAR. & \\
\hline
\end{tabular}

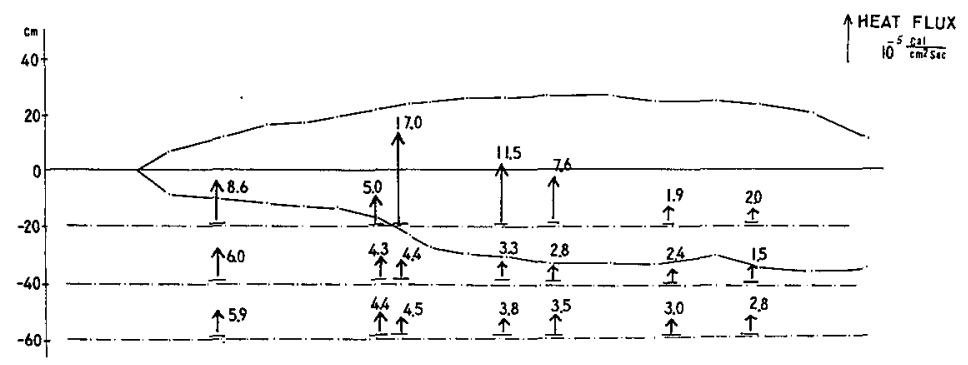

Fig. 7 Heat flow measurement at test site III, 1977.78 season.

selected in case of the 1975-1976 season in Fig. 6 and 7 . At the depth of $20 \mathrm{~cm}$, the value of heat flow was measured as $5.0 \times 10^{-5} \mathrm{cal} / \mathrm{cm}^{2} \mathrm{sec}$ on 15 th Jan. On the next day the value of heat flow increased up to $17.0 \times 10^{-5} \mathrm{cal} / \mathrm{cm}^{2} \mathrm{sec}$. The data of the depth of the freezing front indicated that during these periods the freezing front passed at the depth of $20 \mathrm{~cm}$. Hence, an increase in heat flow was due to the released latent heat at the freezing front and two measured flux values corresponded to the heat flux into and out of the freezing front. It is expressed by the following heat balance equation :

$$
K_{f} \frac{\partial \theta_{f}}{\partial x}-K_{u} \frac{\partial \theta_{u}}{\partial x}=\rho_{w} L_{w} v+\rho_{s} L_{s} \cdot \frac{\mathrm{d} x}{\mathrm{~d} t}
$$

where $L_{w} ; L_{s}=$ latent heat of water and soil, respectively

$K_{f} ; K_{u}=$ thermal conductivities of the frozen and the unfrozen soil, respectively $\frac{\partial \theta_{f}}{\partial x}, \frac{\partial \theta_{u}}{\partial x}=$ temperature gradients in the frozen and the unfrozen soil layer, respect- 
ively

$\rho_{w}, \rho_{i}=$ densities of water and ice, respectively

$$
\begin{aligned}
v & =\text { rate of flux of water transferred to the freezing front } \\
\frac{\mathrm{d} x}{\mathrm{~d} t} & =\text { advancing rate of the freezing front }
\end{aligned}
$$

One may assume that two sets of the left side of the equation represent the residual of the conducted heat out of and into the freezing front, which is equal to the latent heat. The released latent heat is separeted into two parts. The first part is due to the latent heat of water which flowed into the freezing front. The second part is due to the latent heat of water frozen in situ. The measured two values were substituted into the left side, and the value of $1.2 \times 10^{-4} \mathrm{cal} / \mathrm{cm}^{2} \cdot \mathrm{sec}$ was obtained. The heaving rate and the advancing rate of the freezing front during this period were estimated as $1 \times 10^{-6} \mathrm{~cm} / \mathrm{sec}$ and $6 \times 10^{-6} \mathrm{~cm} / \mathrm{sec}$, respectively. Hence, estimated values of latent heat of water both migrated and frozen insitu were $8 \times 10^{-5}$, and $1.2 \times 10^{-4} \mathrm{cal} / \mathrm{cm}^{2} \cdot \mathrm{sec}$. These two values correspond to two terms of the right side of the equation. Consequently, the estimated value does not agree with the measured value. This is mainly due to the lack of the values of water content and migrated flux of water at that time period. For the verification of the model, the field observations gave us general features of soil heaving such as the water accumulation or ice lenses. From this point of view, the relevant laboratory experiments of soil freezing are called for.

\section{Pore-water pressure profile of a freezing soil}

\section{1. Experiment}

Tomakomai silt was used in the experiment. The soil was first wetted to the desired moisture content and then was packed in a soil column. The soil column consisted of a plexiglas pipe $54 \mathrm{~cm}$ long (Fig. 8). The upper half of the column had double side wall and evacuated to insulate the column. The formation of ice lenses and the depth of the freezing front were visually observed through the walls. The inside diameter of the soil column was $15.2 \mathrm{~cm}$. Tensiometers and thermistors were inserted at 5, 10, 15, 30, 40 and $50 \mathrm{~cm}$ from the surface of the soil column. A

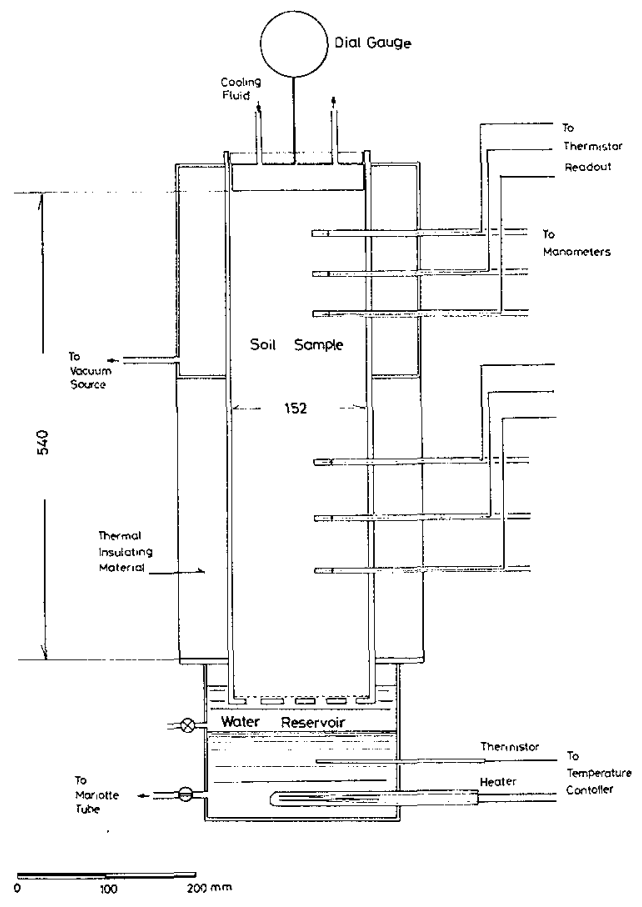

Fig. 8 Diagram of the apparatus used to measure pressure in freezing soil. 
brass circulation plate was placed on the top of the soil column to control the temperature. The soil column was mounted on a water reservoir. The temperature of the water in the reservoir was maintained constant with a fluctuation of $\pm 0.1^{\circ} \mathrm{C}$. It was possible to apply a negative pressure to the water reservoir so that water tables at various depths could be simulated. The flow of water from the reservoir into soil was controlled by a mariotte tube. The amount of heave during the freezing process was measured by a dial gauge at the top of the soil column. At one hour intervals, the pore-water pressure at each tensiometer, the temperature, the amount of heave, and the depth of freezing front were measured.

\section{2. Measurement of hydraulic conductivity}

The unsaturated hydraulic conductivity of the Tomakomai silt was measured by a method described by Klute (1965). A plexiglas pipe $15 \mathrm{~cm}$ long was used as a pressure cell (Fig. 9). Porous plates were attached to both ends to regulate the water transport through the column. The column was perforated with a number of holes and a semicylindrical piece of plexiglas was attached over these holes. This was for the purpose of applying air pressure to the gas phase in the soil. Tensiometers were inserted at $2.5 \mathrm{~cm}$ and $7.5 \mathrm{~cm}$ from

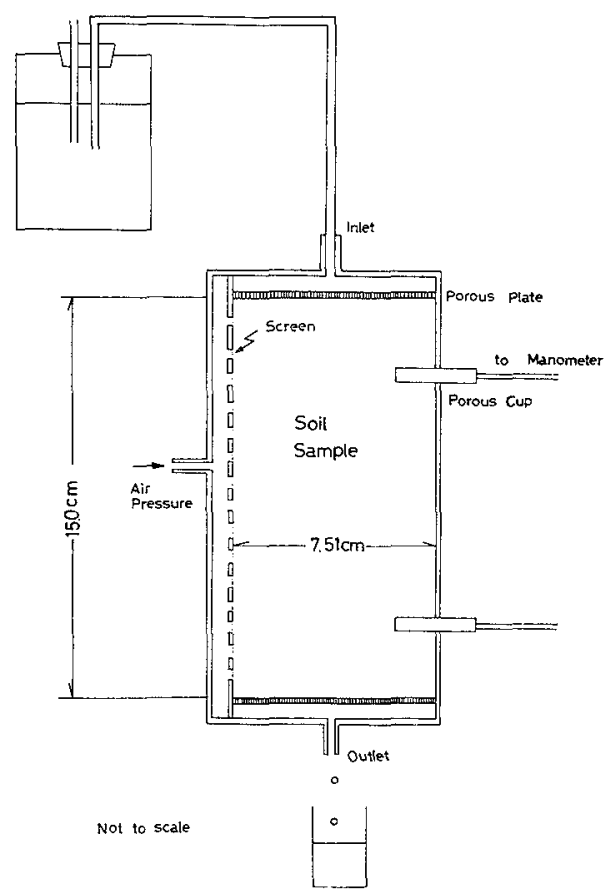

Fig. 9 Diagram of the apparatus used to measure hydraulic conductivity of soil as a function of negative moisture pressure.

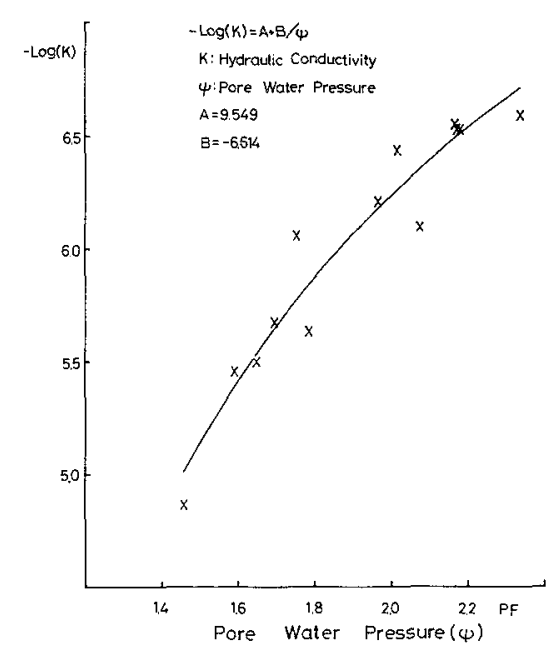

Fig. 10 Plots of experimental data relating negative soil moisture pressure to hydraulic conducti. vity. 
the suface. The flow rates through the soil were monitored by the levels of the water reservoir at the top and by a burette at the bottom. The length of the pressure cell used in this experiment is longer than the $5 \mathrm{~cm}$ suggested by Klute, since, if the distance between the two tensiometers is too small, it may cause a fairly larger error in estimation of the potential gradients in the pressure cells. In this experiment, it took two weeks to reach equilibrium after increasing the applied air pressure at $2 \mathrm{cmHg}$ increments. The measurement took eleven months to perform. The author started with a near saturated condition and proceeded to desaturate the soil by increasing the air pressure. From the results, the following empirical equation that related the hydraulic conductivity to the pore-water pressure was obtained (Fig. 10) :

$$
-\log _{10} K=A+B / \varphi
$$

where $K=$ hydraulic conductivity, $\mathrm{cm} / \mathrm{sec}$

$\varphi=\mathrm{PF}$ of pore water

$A, B=$ constants

III. 3. Results and discussion

More than 10 freezing experiments were conducted. The temperatures of the cooling fluids were set at $-6^{\circ} \mathrm{C}$ and $-10^{\circ} \mathrm{C}$. Negative pressures were applied to the water reservoir from 0 to $-200 \mathrm{cmH}_{2} \mathrm{O}$ pressure head. Once an hour changes in reading of the manometers, temperature and frost heave amount were measured. The soil column was located in a large refrigerator with near $0^{\circ} \mathrm{C}$ temperature. Through a window on the door the ice lens formation and the position of the freezing front were visually observed. A typical result of the experiment is shown in Fig. 11. In this case, $100 \mathrm{~cm}$ of negative pressure head was applied at the temperature of the cooling fluid which was $-6^{\circ} \mathrm{C}$. During the freezing, the rate of heaving was $3.4 \times 10^{-5}$ $\mathrm{cm} / \mathrm{sec}$ at the beginning and decreased to 1 . $8 \times 10^{-5} \mathrm{~cm} / \mathrm{sec}$. The pore-water pressure increased at the freezing front which was at a short distance from the porous cup ; the pore-water pressure rose and then dropped sharply due to the entry of air through the

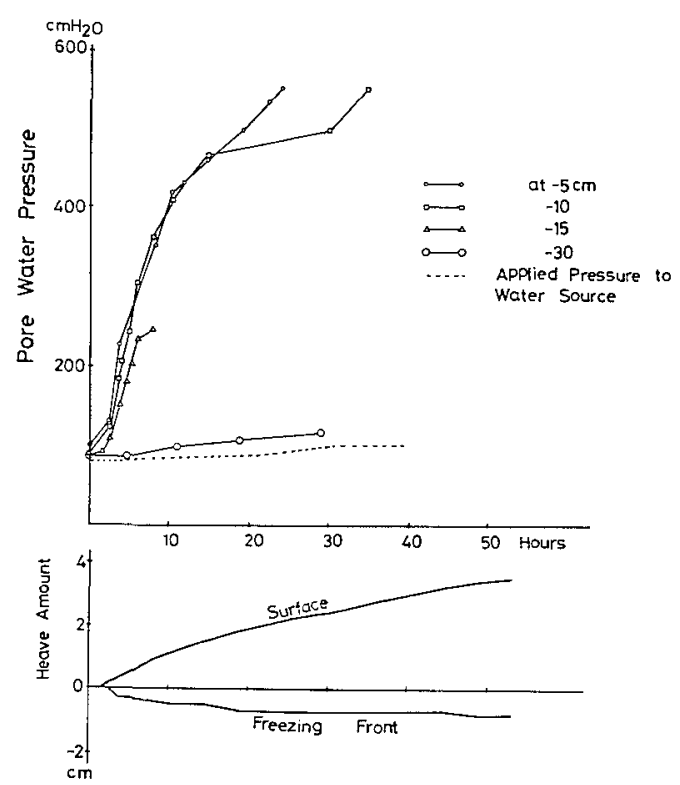

Fig. 11 Typical result of an experiment applying a pressure of $-100 \mathrm{~cm} \mathrm{H} \mathrm{H}_{2} \mathrm{O}$ to the reservoir, cooling fluid temperature at $-6^{\circ} \mathrm{C}$. 
porous cup wall. In other words, the air entry value was exceeded. The potential gradients indicated the amount of water flow to the freezing front and also the change in water content at each location. For the purpose of comparing the influence of the applied negative pressure, two different experiments were run, as shown in Figs. 12 and 13. In Fig. 13, a 100 $\mathrm{cmH}_{2} \mathrm{O}$ negative pressure was applied to the water reservoir. The initial pore-water pres-
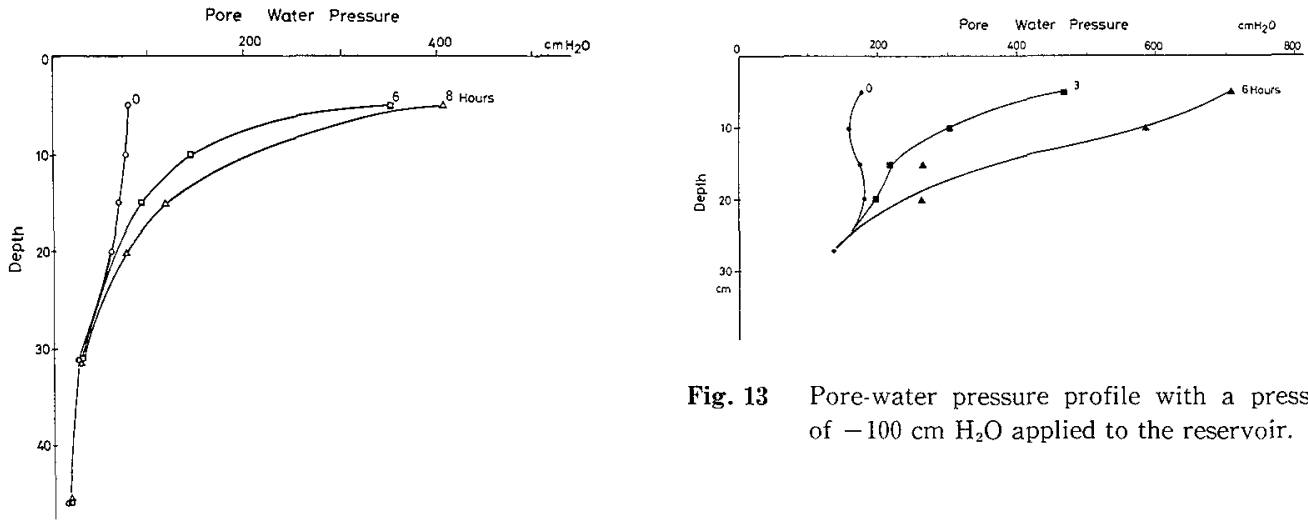

Fig. 13 Pore-water pressure profile with a pressure of $-100 \mathrm{~cm} \mathrm{H}_{2} \mathrm{O}$ applied to the reservoir.

Fig. 12 Pore-water pressure profile with a pressure of $0 \mathrm{~cm} \mathrm{H}_{2} \mathrm{O}$ applied to the reservoir.

sure at $5 \mathrm{~cm}$ was greater than the case where no negative pressure was applied. An increase in pore-water pressure at $5 \mathrm{~cm}$ was very large, especially during the first 3 to 6 hours. It is possible to be seen from Fig. 11 that during the period from 6 to 8 hours, the heaving rate was $2.08 \times 10^{-5} \mathrm{~cm} / \mathrm{sec}$. The speed of advance of the freezing front was $1.38 \times 10^{-5} \mathrm{~cm} / \mathrm{sec}$. After six hours the freezing front had advanced $2.3 \mathrm{~cm}$ and after eight hours it had reached $2.45 \mathrm{~cm}$. If the empirical equation of hydraulic conductivity given above is used, the flux due to this gradient is estimated. The estimated flux was $6.6-4.5 \times 10^{-6} \mathrm{~g} / \mathrm{sec}$. The increase in porewater pressure corresponded to a decrease in water content. In a previous experiment, porewater pressures versus moisture content curves were obtained. Thus it is possible to estimate a decrease in water content. During the two hours, a decrease in water content at $5 \mathrm{~cm}$ was estimated as $1.8 \times 10^{-6} \mathrm{~g} / \mathrm{cm}^{3} \cdot \mathrm{sec}$. The frost heaving due to the volume increase from ice to water was also estimated according to the following procedure : the speed of the freezing front advance during these two hours was $1.38 \times 10^{-5} \mathrm{~cm} / \mathrm{sec}$. This is the increase in volume of the frozen layer per unit time. If heave takes place under saturated conditions, the volume expansion of the water results. The saturated water content is $65 \%$; thus, the heave by the volumetric expansion of water in soil may be calculated as $1.38 \times 10^{-8} \times 0.65 \times$ $0.1=8.97 \times 10^{-10} \mathrm{~cm} / \mathrm{sec}$. This is very small value in comparison with the observed heaving rate. Thus, heaving due to the volume expansion of water is negligible. The flow of water out of a unit layer at a $5 \mathrm{~cm}$ depth is called $Q_{1}$ where $Q_{1}=Q_{g}+Q_{s}$ and where $Q_{g}$ is the water 
transported by the potential gradient between 5 and $10 \mathrm{~cm}$ in depth. $Q_{\mathrm{s}}$ is the water that flowed from the unit layer at a $5 \mathrm{~cm}$ depth. $Q_{\mathrm{g}}=6.6-4.5 \times 10^{-6} \mathrm{~g} / \mathrm{sec}$. Thus, $\mathrm{Q}_{1}=8.4-6.3 \times$ $10^{-6} \mathrm{~g} / \mathrm{sec}$. The observed heave rate is $2.08 \times 10^{-5} \mathrm{~cm} / \mathrm{sec}$ and this is due to the water transported by the hydraulic gradient. The difference between the flux from a $5 \mathrm{~cm}$ layer and the flux observed due to the surface heave rate is $1.63 \times 1.24 \times 10^{-5} \mathrm{~cm} / \mathrm{sec}$. This water must be supplied from the zone between the depth of $5 \mathrm{~cm}$ and the freezing front location, which is $2.45 \mathrm{~cm}$ below the top of the soil. It means, then, that a large amount of water is extracted from the zone adjacent to the freezing front. This means that a dry soil moisture zone will form immedietly below the freezing front.

\section{4. Estimation of pore-water pressure near the freezing front}

The hydrodynamic model assumes that the two transport equations for heat and water are coupled by the relationship between the pore-water pressure and the temperature below $0^{\circ} \mathrm{C}$ as given by the Clausius-Clapeyron equation,

$$
\mathrm{d} T=(\mathrm{T} / \mathrm{L})\left(V_{w} \mathrm{~d} p_{w}-V_{i} \mathrm{~d} p_{i}\right)
$$

where $\mathrm{T}=$ temperature, Kelvin

$$
\mathrm{L}=\text { heat } \text { of fusion }
$$

$p_{\mathrm{i}}, p_{\mathrm{w}}=$ pressure of ice and water, respectively

$V_{\mathrm{i}}, V_{\mathrm{w}}=$ specific volume of ice and water, respectively.

When there is no load on the soil surface, the pressure of the ice in the unsaturated soil is nearly zero. Thus, the equation can be modified as follows :

$$
\triangle T=0.081 P
$$

where $\triangle T$ is the freezing point depression at $0^{\circ} \mathrm{C}$ and $P$ is the pore-water pressure in bars.

Koopmans and Miller (1966) suggested a different empirical equation which was based upon experiments. In this case by experiments the following empirical coupling equation was obtained:

$$
T=0.061 P-0.0012
$$

Thus, near the freezing front, if water freezes at depressed temperatures, there will be very large negative pore-water pressures.

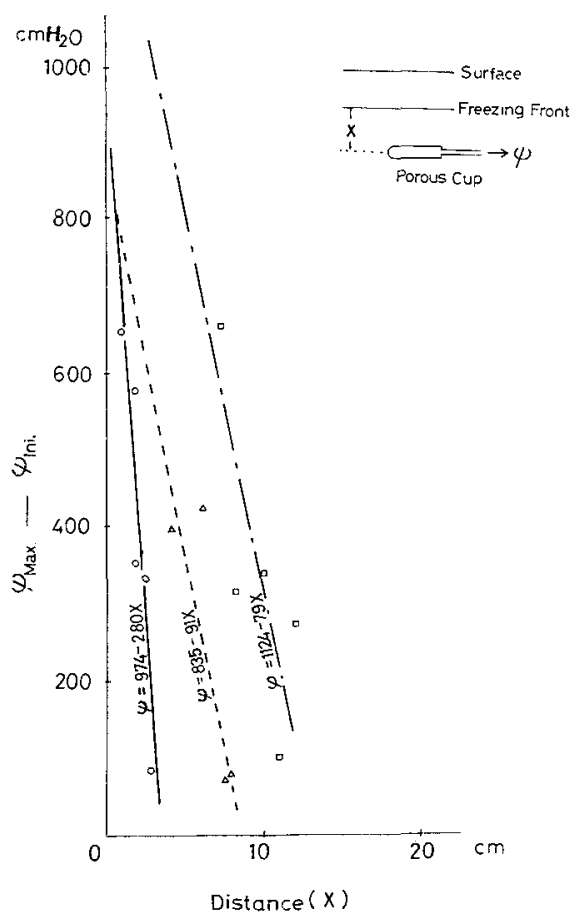

Fig. 14 Increase in pore-water pressure as a function of distance from the freezing front. 
This large pore-water pressure is the driving force for water to move to the freezing front. The equations given above are based upon the thermodynamics of an equilibrium water-ice situation. The actual freezing process is a non-equilibrium process.

The author attempted to estimate the pore-water pressures near the freezing front from these experimental results and these values may possibly be of use in developing additional computer simulation model. In Fig. 14, the author has plotted increases in pore-water pressure as a function of distance between the freezing front and the tensiometers. As the freezing front descends, the pore-water pressures increase graduially. The estimated porewater pressure at the freezing front ranges from 835 to $1124 \mathrm{~cm}$ of water. This was obtained by fitting a least-square line at three locations, 5,10 , and $15 \mathrm{~cm}$ apart from the freezing front in the initial condition. If this pore-water pressure value is substituted into the empirical coupling equation, $0.047^{\circ} \mathrm{C}$ for a freezing point depression is obtained at the freezing front.

\section{5. Potential gradient near the freezing front}

In order to estimate the flow rate of water to the freezing front through the unfrozen layer, the hydraulic gradients at various locations were calculated. The estimation was done as follows: the hydraulic gradients between 5 and $10 \mathrm{~cm}$ depths were calculated from a measurement of the pore-water pressures during the freezing. Figure 15 gives typical curves of potential gradients as a function of time. Two different conditions of initial water profiles are shown. At the beginning of soil freezing, the total potential gradient increased very sharply. When pore-water pressures at the $5 \mathrm{~cm}$ depth reached a maximum, then the
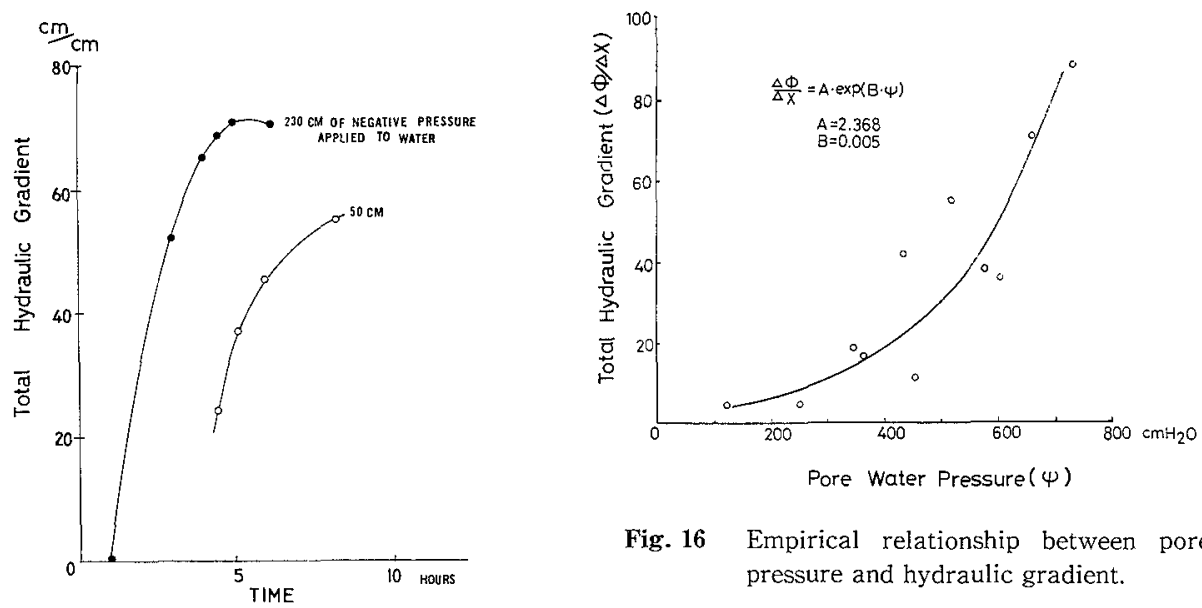

Fig. 16 Empirical relationship between pore-water pressure and hydraulic gradient.

Fig. 15 Rate of change in hydraulic gradient as a function of negative pressure applied to the reservoir. The negative pressure is equivalent to a water table at a depth below the end of the column. 
potential gradient increased. The maximum potential gradients of each initial condition were selected with a mean pore-water pressure, which was obtained from the measured porewater pressures at each depth. All the data are plotted on Fig. 16. A simple regression having an exponential form was performed. This fitted curve was the best fit among other simple regressions. The regression coefficient is 0.899 . Thus, it indicates the following empirical relation between pore-water pressures and potential gradients in the unfrozen soil during the experiment :

$$
\frac{\partial \phi}{\partial x}=A \exp (B . \varphi)
$$

where $\frac{\partial \phi}{\partial x}=$ total hydraulic gradient $\mathrm{cm} / \mathrm{cm}$

$$
\begin{aligned}
\varphi & =\text { pore-water pressure } \mathrm{cmH}_{2} \mathrm{O} \\
A, B & =\text { constants } \\
x & =\text { distance } \mathrm{cm}
\end{aligned}
$$

Using this empirical equation it is possible to derive an equation involving the distance from the ground surface and the pore-water pressure profile in the unfrozen layer under freezing conditions. This empirical equation is a first-order linear differential equation. The author can solve this equation by integrating each variable.

$$
\int \frac{\partial \phi}{A \cdot \exp (B \cdot \varphi)}=x+C
$$

Wher $C$ is the integration constant and can be determined at the water table where the porewater pressure is 0 . If this value is substituted, a constant $C$ is obtained as follows :

$$
C=-(A \cdot B)
$$

Using values for $A$ and $B$, then $C$ is equal to $-84.4 \mathrm{~cm}$. Further the final form of the equation is obtained as follows:

$$
\varphi=\frac{1}{B} \log (-\mathrm{A} \cdot \mathrm{B}(x+C))-x
$$

where $\varphi$ is the pore-water pressure and $x$ is the distance from the water table.

It is possible to obtain the pore-water pressure profile in the unfrozen layer of the freezing soil (Fig. 17). It means that if the freezing front is assumed at $84.4 \mathrm{~cm}$ above the water table, there will be infinitely large pore-water pressures near the freezing front. If the freezing front is stationary, then there will be a steady state pore-water pressure

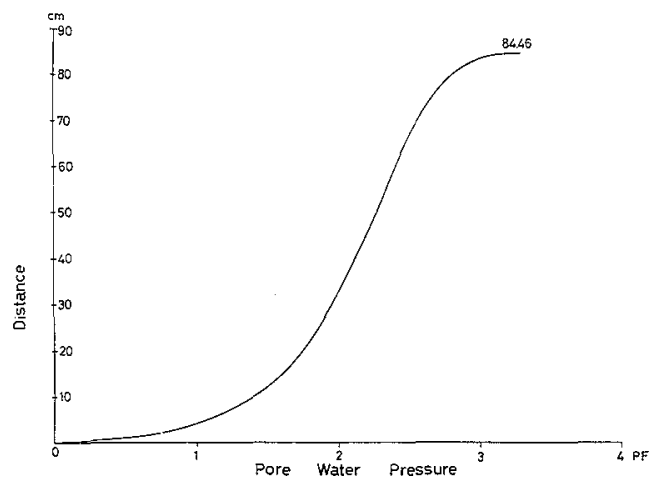

Fig. 17 Pore-water pressure profile in soil under the advancing rate of the constant freezing front. profile with constant water movements to the 
freezing front.

From these experiments, it is concluded that the pore-water pressure movements in the unfrozen soils can be used to indicate the maximum pore-water pressure causing the movement of water to the freezing front. If there exists a stationary freezing front, then the pore-water pressure profile remains constant and wather is transported upward to the freezing front.

\section{6. Field observations of pore-water pressure profile at Tomakomai}

At Tomakomai frost heave observatory, pore-water pressures were observed by the similar methods described above using tensiometers. The results of the experiment were applied to the field observations. In the 1976-1977 season, tensiometers were installed at the depths of $20,40,60,80$ and $100 \mathrm{~cm}$ in the soil. The measured pore-water pressure profiles are shown in Fig. 18.

On 13th Dec. the freezing front was located at the depth of $10 \mathrm{~cm}$ from the ground surface ; the advancing rate of the freezing front was $0.2 \mathrm{~mm} /$ hour. Under this condition, it may be assumed that the water flow is stationary, and it is possible to apply equation (6) to this case. The equilibrium porewater pressure line is fitted into this case. The result is shown as solid lines in Fig. 18, where a broken line represents "estimated"

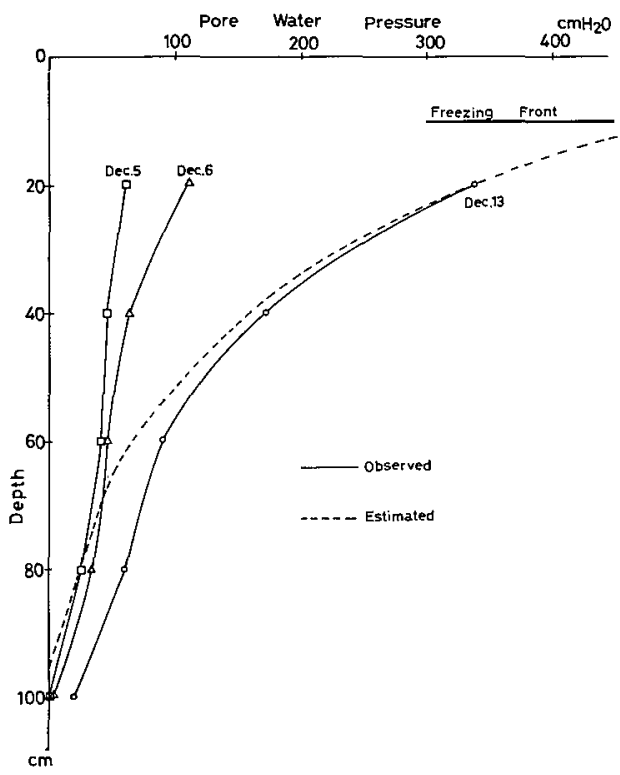

Fig. 18 Field measurement of pore-water pressure profile during freezing.

plots. The two profiles in the figure are identical. It means that the stationary pore-water pressure profile was established in field condition under the similar condition such as the very slow advancing speed of the freezing front. The hydraulic potential gradient between 20 and $40 \mathrm{~cm}$ on $13 \mathrm{th}$ Dec. was measured as $9.25 \mathrm{~cm} / \mathrm{cm}$. The average pore-water pressure between these locations was $252.2 \mathrm{cmH}_{2} \mathrm{O}$. This value is substituted into empirical equation (5), whereby the estimated hydraulic potential gradient is obtained as $8.37 \mathrm{~cm} / \mathrm{cm}$. These two values of hydraulic potential gradient are almost equal. Thus, the experimental results are applicable to field observations at Tomakomai. 


\section{Growth of ice lenses under the constant advancing rate of the freezing}

\section{1. Experimental procedure}

Hoekstra (1969) observed the growth of ice lenses in the frozen layers of freezing soil, whereby he pointed out that water migrated through the frozen soil and accumulated at a certain position forming visible ice lenses. However, in his experiments, temperature profiles were not accurate enough to relate the growth rate of ice lenses with thermal conditions. In this experiment, the cooling rate of the cold end of soil column is controlled to establish the constant advancing rate of the freezing front. Under this condition, one can relate the growth rate of ice lenses with the heat flow through the freezing front.

The experimental procedure is as follows : temperature profiles of the soil column are measured at a certain time intervals. Applying the linear regression or multiple regression to the temperature profile, the $0^{\circ} \mathrm{C}$ position is estimated. The movement of the $0^{\circ} \mathrm{C}$ position is monitored and the rate of movement is calculated. If the rate of movement is greater than the value at which it is initially set, the cooling rate on the cold end is changed. The cooling rate is controlled by the on-off of the magnetic valve through which the cold brine is supplied to the cooling plate.

The monitored rate of movement is compared with the desired value, and the results of the comparison are fed back to the adjuster of the valve.

The system diagram is shown in Fig. 19. A small computer is employed as the controller.

For the test of the system, wather is used as a freezing material.

To eliminate the convected heat transfer, one percent agar solute with the dye of Metyleneblue is added. The boundary of the frozen and the unfrozen layer is clearly visible, and the rates of movement are measured by both computer estimation and observation by the naked eyes.

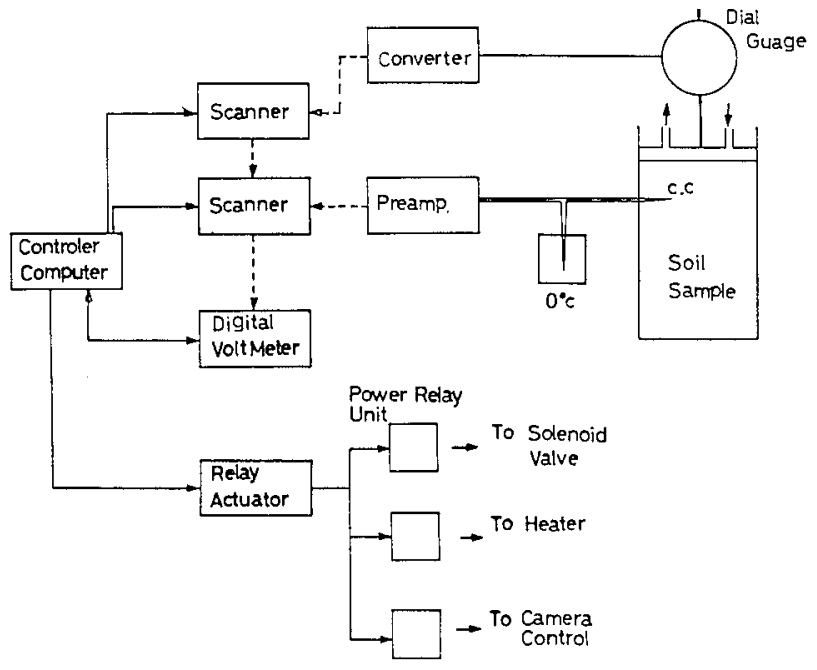

Fig. 19 Diagram of the controlling system of the experiment. 
The result of the test is shown in Fig. 20. The position of $0^{\circ} \mathrm{C}$ thermal line was plotted according to elapsed time. If the advancing rate is constant, a simple regression line can be drawn. Both the estimated and the observed line are drawn as straight lines, which indicates that the control system works properly.

The soil column consisted of transparent plexiglas. The column had double side walls and the space between the walls was evacuated to insulate the column thermally. The inside shape of column tappered downward. This treatment allowed to reduce the adhesion of the frozen soil to the column (Fig. 21). The formation of ice lenses and the depth of the freezing front were visually observed through the walls. The advancing rates of the freezing front were measured and time-lapse photos were taken every hour.

\section{2. Results and discussion}

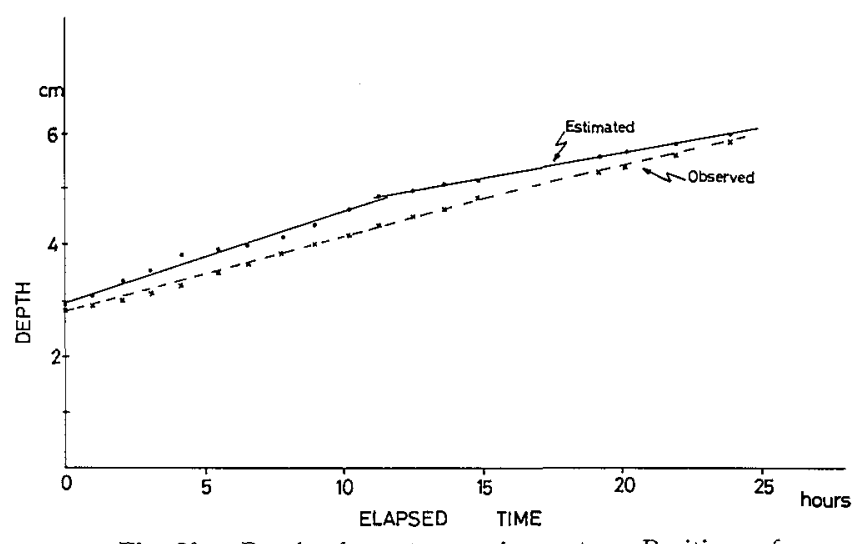

Fig. 20 Result of a test run using water. Positions of the $0^{\circ} \mathrm{C}$ line are plotted.

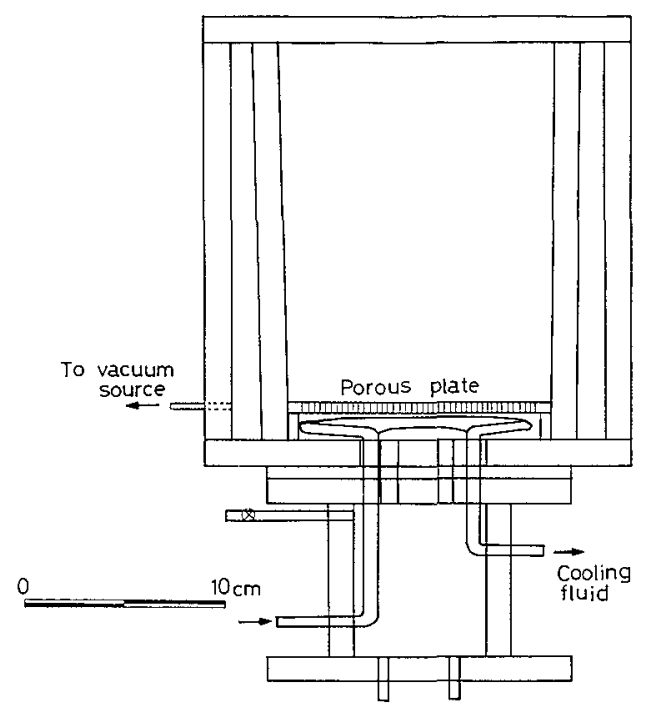

Fig. 21 Diagram of the soil column used for the experiment.

Soil freezing experiments were carried out at the constant advancing rate of freezing front. A series of the time-lapse photos were taken. Each experimental result showed that the ice lenses formed at temperatures below $0^{\circ} \mathrm{C}$, and even at $-1^{\circ} \mathrm{C}$ or below. The growth of ice lenses continued to grow. For example, in Fig. 22 the advancing rate of the freezing front is shown. The values are scattered around $0.15 \mathrm{~cm} /$ hour, which was close to the initially set value. And it might be assumed that the constant advancing rate of the freezing front was established under the controlled system. Time-lapse photos were taken at the times, which were marked by small arrows on the abscissa (the elapsed time) with the 


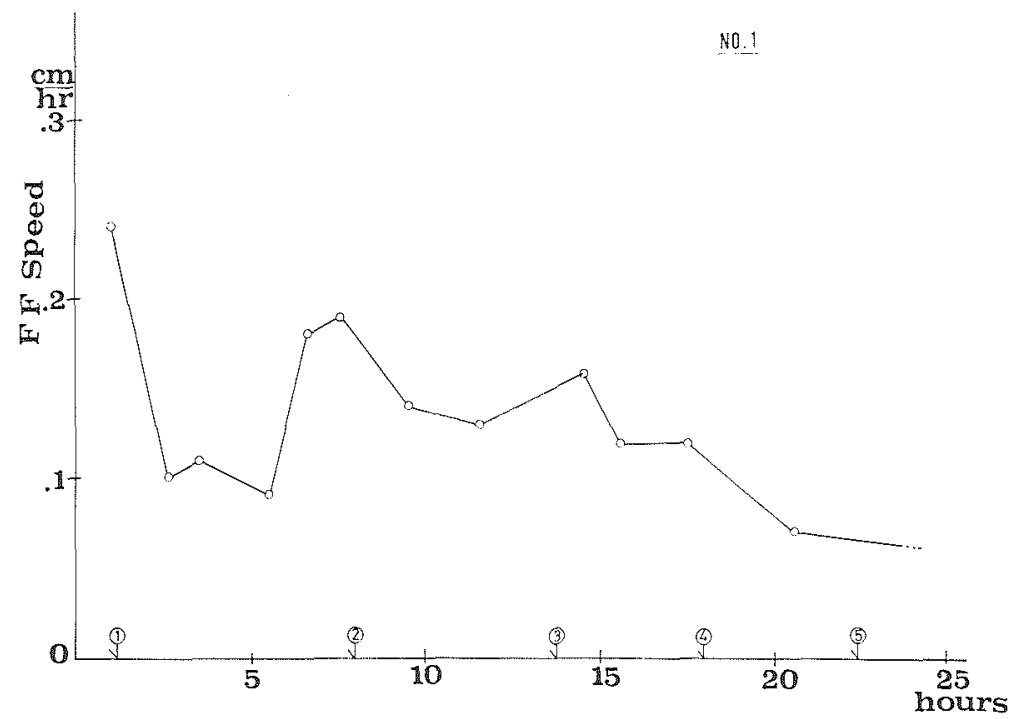

Fig. 22 Result of a freezing experiment with the constant advancing rate of the freezing front, test No. 1.

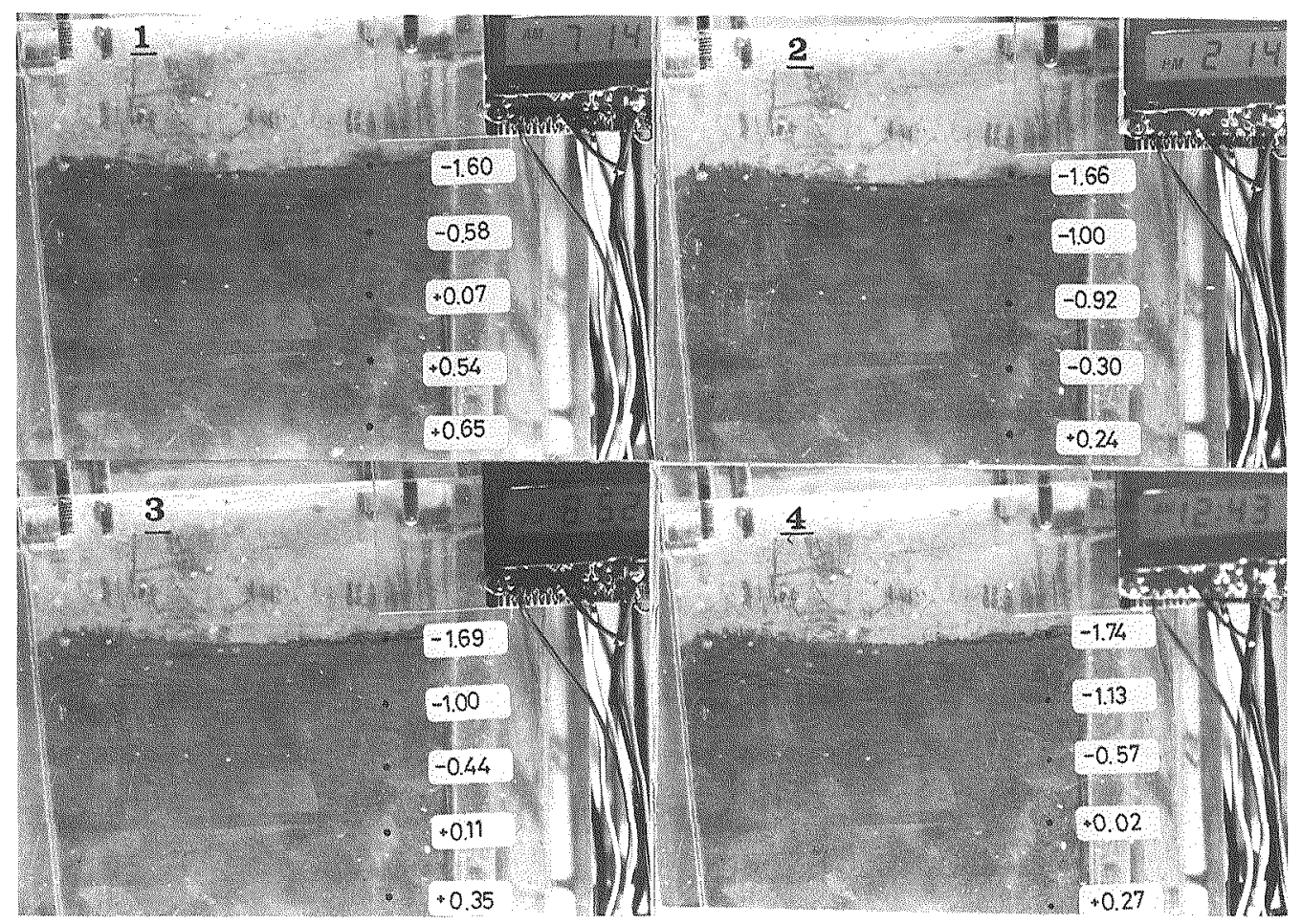

Fig. 23 Time-lapse photos showing the growth of ice lenses, test No. 1. 
numbers indicating orders. These ordering numbers correspond to the index numbers of the series of the photos (Fig. 23). At time 1, there were no visible ice lenses formed. At time 2 , the obvious ice lenses were distinguished near the surface ( 1 to $2 \mathrm{~cm}$ below the surface). If one compared the temperatures in cases 1 and 2 , the ice lenses were formed under $-0.5^{\circ} \mathrm{C}$ or below. Further, comparing with other photos, No. 3 and 4 , the ice lenses were formed successively in a range of temperatures from $-1^{\circ} \mathrm{C}$ to $-1.13^{\circ} \mathrm{C}$. During the time period between 1 and 3 , the heave rate and the growth rate of an ice lens, which was arbitrally selected from lenses, are shown in Fig. 24. At time 3, this ice lens stopped growing. However, measured heave rates still maintained the similar values after the end of growth of this ice lens. And the photo taken at 4 indicates that ice lenses were growing at different positions.

Other experimental results are shown in Figs 25, 26, and 27. If one compares the series of the photos, $1-4$, it is also obvious that the ice lenses grew under a range of temperatures from -0 . $76^{\circ} \mathrm{C}$ to $-1.42^{\circ} \mathrm{C}$. Both results indicated that the ice lenses were formed not at the temperature of $0^{\circ} \mathrm{C}$ but below $0^{\circ} \mathrm{C}$, that a considerable amount of unfrozen water existed, and that it migrated through the frozen layer to the ice lenses. Hoekstra derived similar conclusions from his experiment (1969).

For the understanding of the mechanism of water transfer in soils during the freezing, water migration in the frozen layer must be directly measured. The results of the experiments in this chapter led to to the initiation of experiments using a

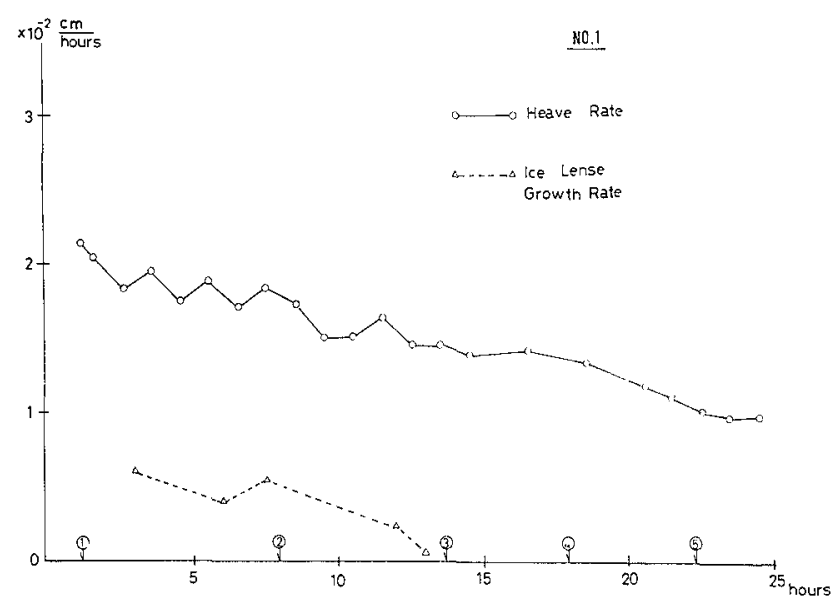

Fig. 24 Heave rate and growth rate of ice lenses, test No. 1.

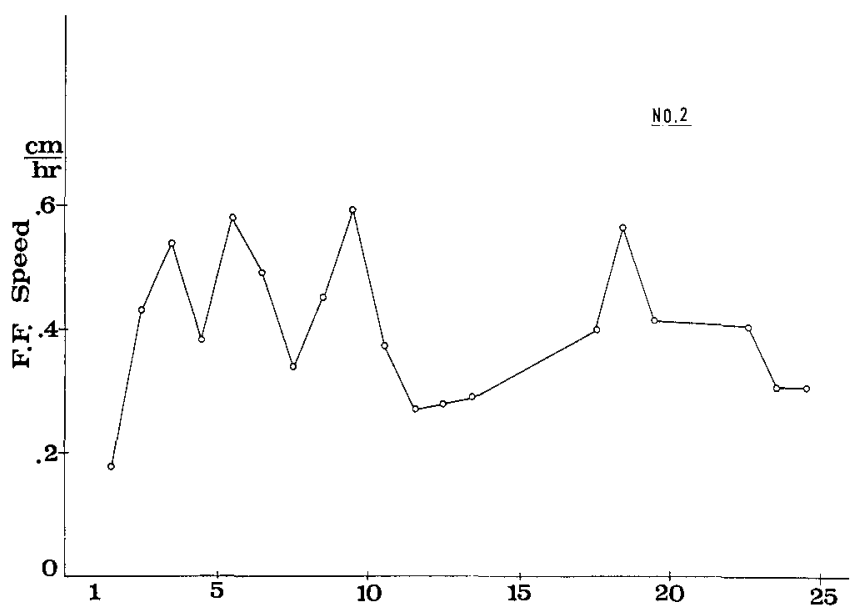

Fig. 25 Result of a freezing experiment with the cons- hours tant advancing rate of the freezing front, test No. 2. 


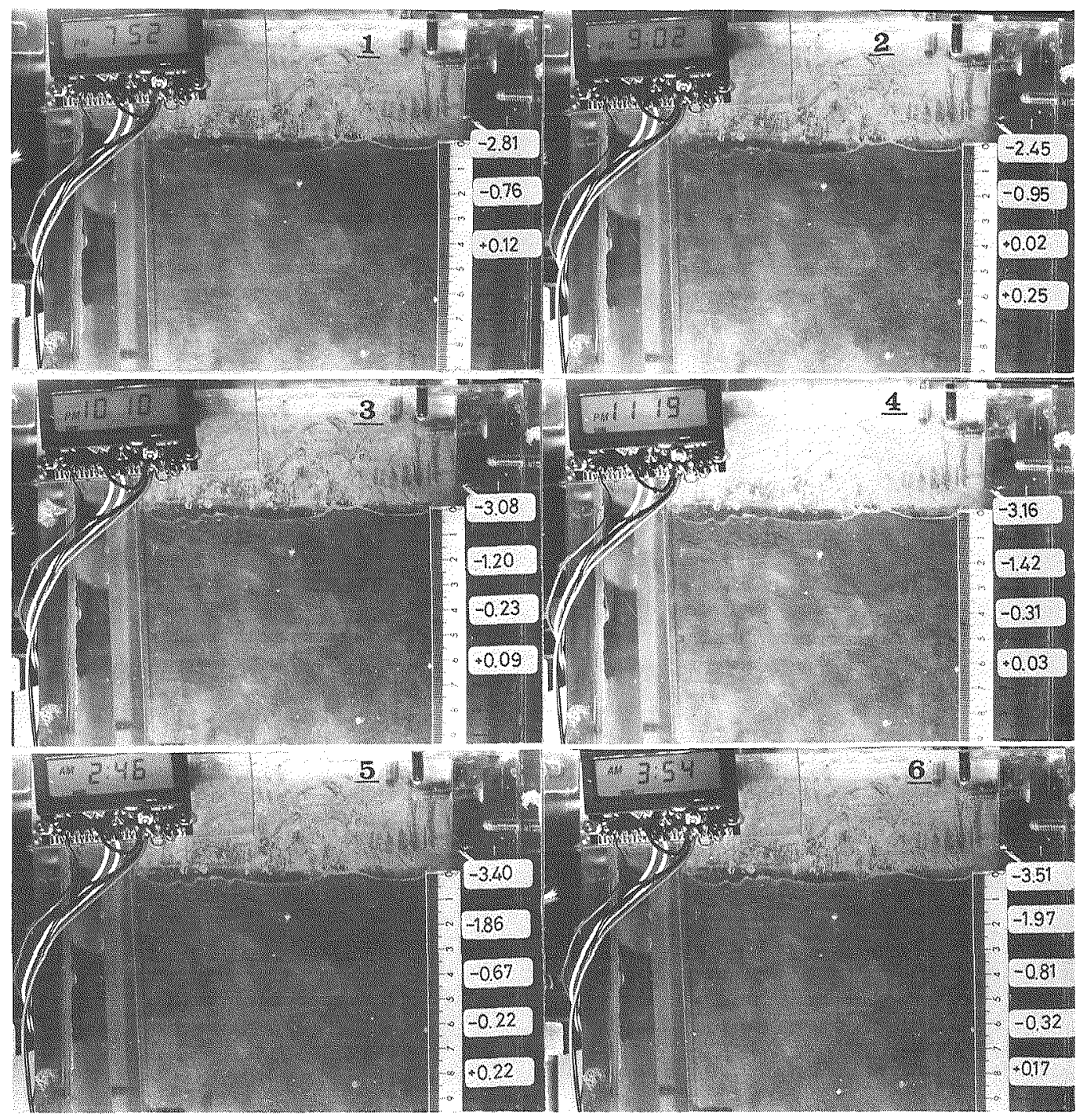

Fig. 26 Time-lapse photos showing the growth of ice lenses, test No. 2.

dual gamma ray attenuation method, which is described in the following chapter. 


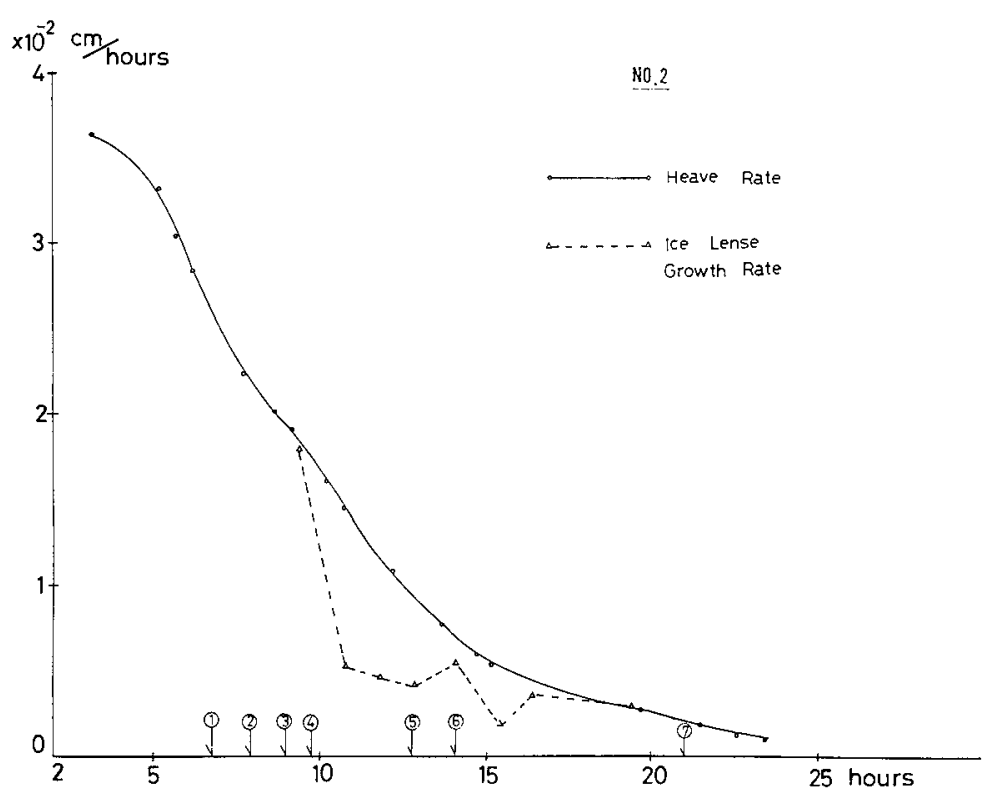

Fig. 27 Heave rate and growth rate of ice lenses, test No. 2.

\section{Dual gamma ray attenuation method for a freezing soil experiment}

\section{1. Introduction}

The attenuation of a dual gamma beam is the most powerful technique for studying the frost heaving phenomena associated with soil freezing. Attenuation of gamma radiation during transmission through soil has been developed and used for these three decades as a nondestructive method for determining water content and dry bulk density in other study fields such as swelling processes of clay soil. In early $1960^{\prime} \mathrm{s}$, a single gamma source was most commonly used such as ${ }^{137} \mathrm{Cs}$. However the application of this single source method was limited in only determining water, content under the known and constant dry bulk soil density.

During the soil freezing, both water content and density may change. From this viewpoint, a single source method was only applied to the nonswelling sandy soil and was not applicable for frost heaving experiments. In case of the swelling processes of clayish soil, both dry density and water content change. And the dual beam gamma ray attenuation method was successfully employed by Nofzinger and Swartzendruber (1976).

In the field of freezing of soil, only two experiments were reported by Jame and Norum (1976) and Loch and Kay (1978). Jame and Norum used a single gamma source ${ }^{137} \mathrm{Cs}$ on the 
assumption of constant dry bulk density throughout the freezing processes. This assumption might be critical when they observed the considerable water accumulation to the freezing front. Accumulated ice caused a decrease in density near ice lenses. Loch and Kay employed a dual beam gamma source, using ${ }^{241} \mathrm{Am}$ and ${ }^{137} \mathrm{Cs}$ with a slit collimator. They observed accumulation of water and sharp decrease of bulk dry density at the same layer in the soil column. This result emphasizes the limitation of a single gamma source method.

\section{2. Theory of method}

The attenuation of a collimated beam of a single gamma source by wet soil to the detector is decribed by the following equation :

$$
I=I_{o} \exp \left(-\mu_{s} \rho_{s} X-\mu_{w} \rho_{w} X \theta-\mu_{c} \rho_{c} X^{\prime}\right)
$$

where $I_{o}$ is the gamma ray intensity through air ; $\rho_{s}, \rho_{w}, \rho_{c}$ are the densities of the soil, water and soil container respetively $; \mu_{s}, \mu_{w}, \mu_{c}$ are the mass attenuation coefficients for the soil, water and soil container, respectively ; $\theta$ is the volumetric water content, and $X$ and $X^{\prime}$ are the lengths of the soil column and thickness of the column case, respectively.

If two gamma sources of different energy spectra are used, one will obtain two equations for each case.

$$
\begin{aligned}
& I_{a}=I_{o a} \exp \left(-\mu_{s a} \rho_{s} X-\mu_{w a} \rho_{w} X \theta-\mu_{c a} \rho_{c} X^{\prime}\right) \\
& I_{b}=I_{o b} \exp \left(-\mu_{s b} \rho_{s} X-\mu_{w b} \rho_{w} X \theta-\mu_{c b} \rho_{c} X^{\prime}\right)
\end{aligned}
$$

where the subscript $a$ refers to the lower energy radiation and the subscritp $b$ refers to the

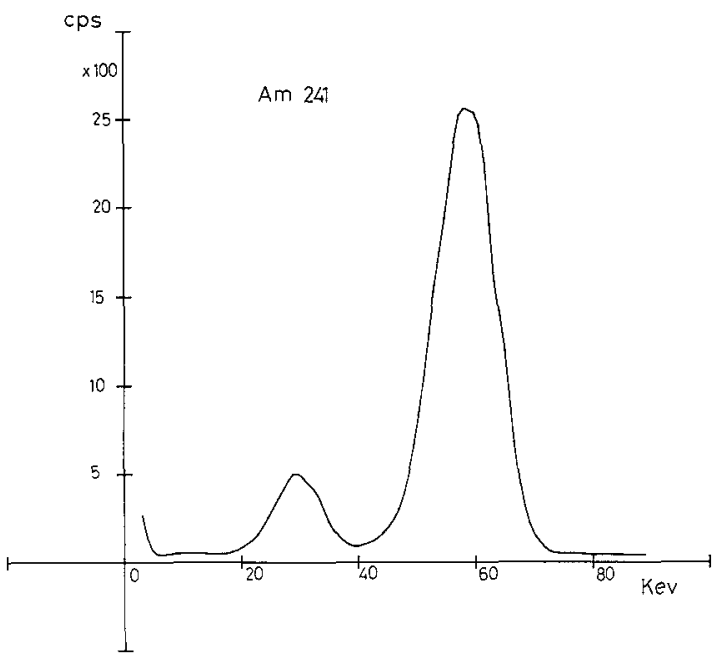

Fig. 28 Energy spectra of gamma source ${ }^{241} \mathrm{Am}$.

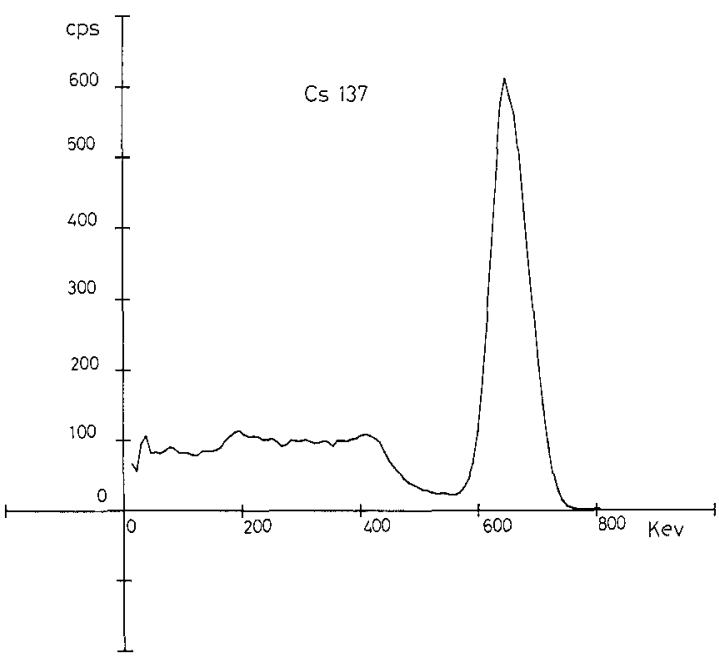

Fig. 29 Energy spectra of gamma source ${ }^{137} \mathrm{Cs}$. 
high energy radiation. In each equation $\rho_{s}$ and $\theta$ are unknown. Thus, if we apply the simultaneous equation to equation (8), we obtain $\theta$ and $\rho_{s}$ as follows :

$$
\begin{aligned}
& \theta=\frac{\operatorname{In}\left(I / I_{o}\right)_{b} \cdot \mu_{s a}-\operatorname{In}\left(I / I_{o}\right)_{a} \cdot \mu_{s b}-C_{a} \mu_{s b}-C_{b} \mu_{s a}}{X \cdot\left(\mu_{w a} \cdot \mu_{s b}-\mu_{w b} \cdot \mu_{s a}\right)} \\
& \rho=\frac{\operatorname{In}\left(I / I_{o}\right)_{b} \cdot \mu_{w a}-\operatorname{In}\left(I / I_{o}\right)_{a} \cdot \mu_{w b}-C_{b} \mu_{w a}+C_{a} \mu_{w b}}{X \cdot\left(\mu_{s a} \cdot \mu_{w b}-\mu_{s b} \cdot \mu_{w a}\right)} \\
& \begin{array}{l}
\text { In }\left(I / I_{o}\right)_{a} \\
\text { In }\left(I / I_{o}\right)_{b}
\end{array} \quad \text { ratio of gamma ray intensity column/air } \\
& C_{a}=\operatorname{In}\left(I / I_{o}\right)_{a} \quad \text { ratio of gamma ray intensity } \\
& C_{b}=\operatorname{In}\left(I / I_{o}\right)_{b} \quad \text { through column case and air }
\end{aligned}
$$

For these measurements, ${ }^{241} \mathrm{Am}$ and ${ }^{137} \mathrm{Cs}$ are suitable, as they have different energy spectra such as $59.6 \mathrm{Kev}$ and $662 \mathrm{Kev}$. It is found that $100 \mathrm{mci}^{241} \mathrm{Am}$ emits a large number of gamma rays of various energy (Fig. 28), and has a half-life of 458 years. This long half-life eliminates the need for decay correction. Meanwhile, $40 \mathrm{mci}{ }^{137} \mathrm{Cs}$ decays with a gamma ray of 662 Kev with a half-life of 30 years (Fig. 29).

\section{3. Design of the dual source traversing mechanism}

The traversing mechanism dimensions are shown in Figs. 30-a, 30-b, and 31. It was designed to accomodate up to a $15 \mathrm{~cm}$ diameter soil column and to traverse a length of 180 $\mathrm{cm}$. The source holder-collimator assembly was designed to hold commercially available $100 \mathrm{mci}{ }^{241} \mathrm{Am}$ and $40 \mathrm{mci}{ }^{137} \mathrm{Cs}$ line sources with an active length of $20 \mathrm{~mm}$ and diameter of
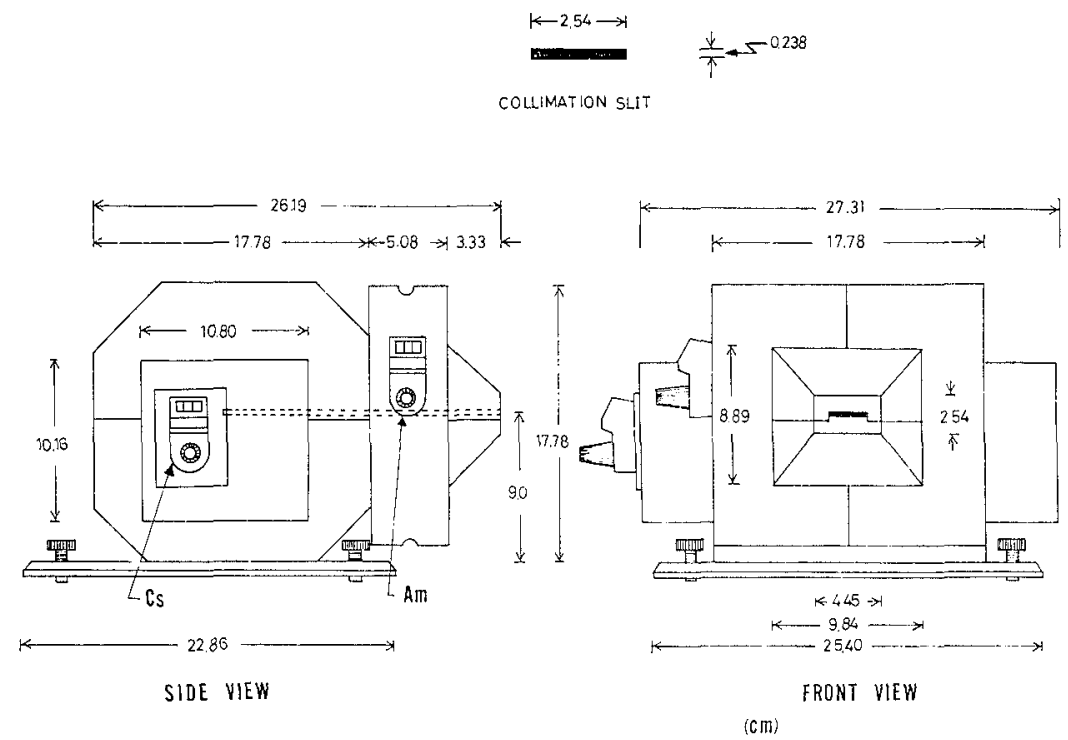

Fig. 30-a Diagram of a gamma source holder and a collimetor. 


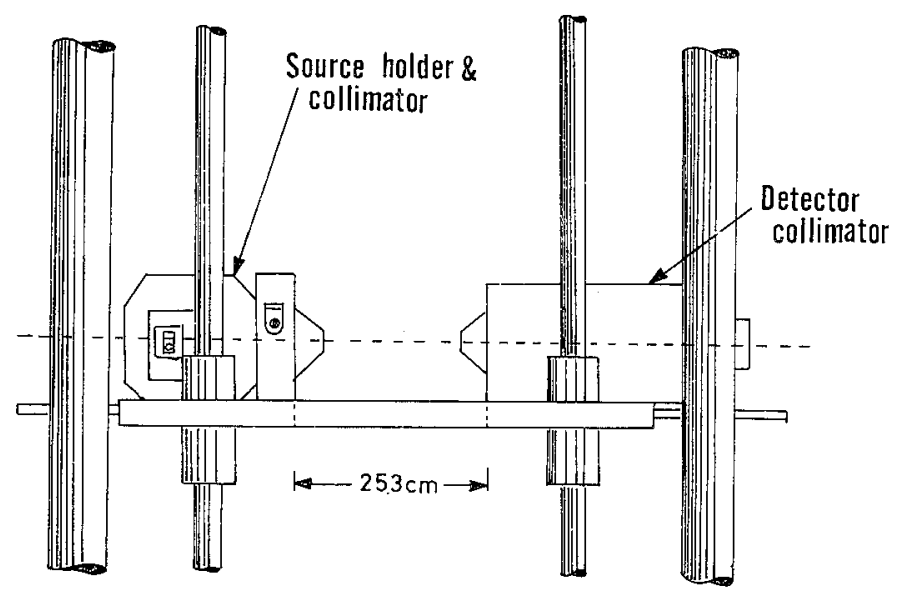

Fig. 30-b Diagram of a gamma source holder and a collimated detector.

$1.68 \mathrm{~mm}$. The source holder-collimator assembly dimensions are shown in Fig. 30-a. The sources are mounted, off center, on two alminum cylinders $7.5 \mathrm{~cm}$ long and $3 \mathrm{~cm}$ in diameter. The sources can be brought into the collimation slit level together and individually, with the aid of a gear train-counter dial combination. This unique design provides an essential safety operation. A 2 " $\times 2$ " sodium iodide ( $\mathrm{Nal}$ ) scintillation crystal detector is housed in a lead shield. The collimation slit of the detector is $10 \mathrm{~cm}$ long, and has the same cross-sectional dimensions as the source collimation slit, $2.38 \times 25.4 \mathrm{~mm}$. Both collimation slits are aligned with each other by three leveling screws on each assembly. The massive shielding around the detector reduces the background counts to a negligible level.

The elevator assembly consists of a tra-

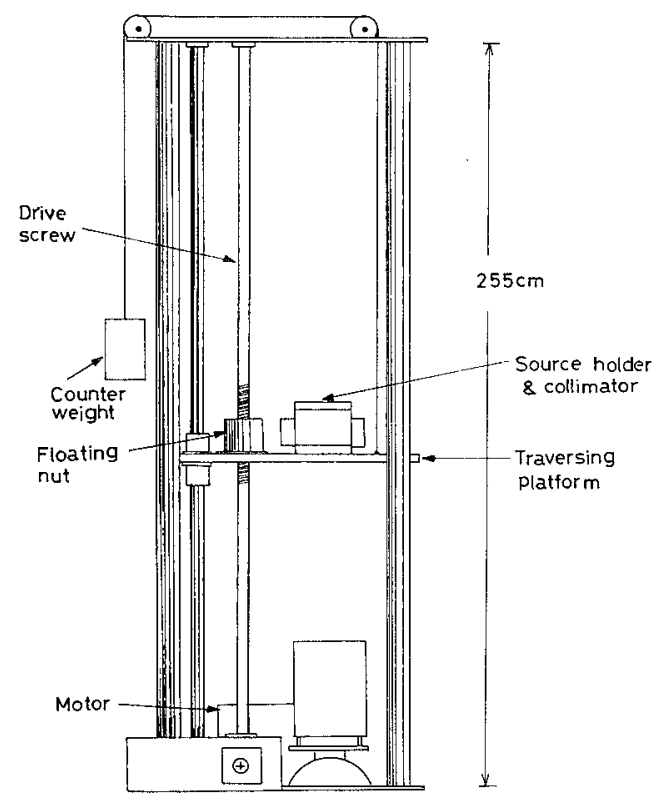

Fig. 31 Diagram of a dual source traversing mechanism.

veling platform that slides up and down four precision ground guide rods. The platform is driven by two drive screws. Uplift force is transmitted to the platform by two floating bronze nuts. Two counterweights are adjusted and attached to the platform such that, while the two driving screws are under normal loads at all times, any torque around them is 
eliminated. Power to the mechanism is provided by an adjustable speed gear motor. Magnetic breaks in the control circuit allows the platform to be stopped at any height without overriding. For discrete data acquistion, the platform is equipped with a collimated photo cell, a light source and an aluminum template in between, with pinholes at $1 \mathrm{~cm}$ intervals. The control circuit is activated by the light beam, passing through the collimation pinhole and enerizing the photo cell. The accuracy of the positioning by this system is \pm 0 . $05 \mathrm{~mm}$ at each run.

\section{4. Selection of equipment}

The electronic equipment associated with the dual source traversing Mechanism is shown as a block diagram in Fig. 32. The scintillation counter consists of a sodium iodide (Na I ) crystal mounted in front of a photomultiplier tube and a preamplifier. From the high

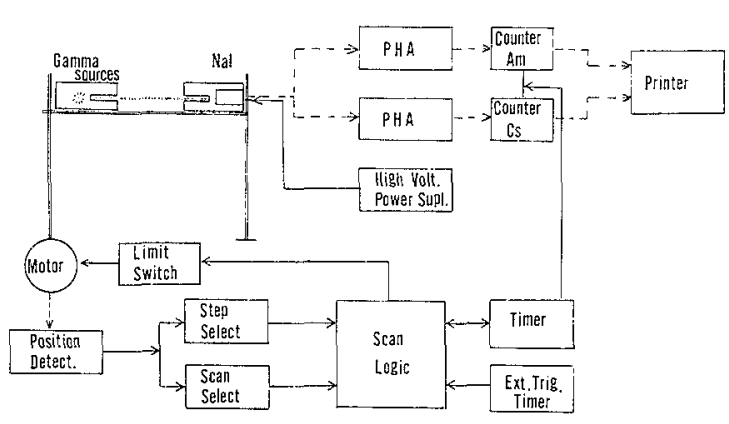

Fig. 32 Block diagram of the dual gamma beam method. voltage supply unit, a power is supplied to a photomultiplier. The output signal from the photomultiplier is connected to two pulse height analysers (PHA) with different window settings for ${ }^{241} \mathrm{Am}$ and ${ }^{137} \mathrm{Cs}$ energy spectra. The pulse counts per gamma source are measured by two separate pulse counters connected to the printer with a built-in clock.

The interval timer and the external triggering timer units control the measuring interval or counting interval. The position detector by a photocell transmits signals to stop at any desired levels. Traversing platform movements are fully controlled automatically by scanlogic unit.

The window and baseline of PHA are essentially important for the stable counting of the outcoming pulses. To avoid the interfacing of both ${ }^{241} \mathrm{Am}$ and ${ }^{137} \mathrm{Cs}$ energy spectra, two PHA windows are set as from $40 \mathrm{Kev}$ to $74 \mathrm{Kev}$ for ${ }^{241} \mathrm{Am}$ and from $590 \mathrm{Kev}$ to $740 \mathrm{Kev}$ for ${ }^{137} \mathrm{Cs}$. The applied high voltage DC to the photomultiplier is $900 \mathrm{~V}$ and well regulated.

\section{5. Measurement of mass absorption coefficients}

As defined by equation (8), the mass absorption coefficient of each material must be obtained prior to the experiments. The plexiglas is used as the material of the container of a soil column. Thus, the absorption coefficients of plexiglas for ${ }^{241} \mathrm{Am}$ and ${ }^{137} \mathrm{Cs}$ are determined as follows: acculately machined eight plexglas plates with a $10 \times 10 \mathrm{~cm}$ square shape were placed centrally in the gamma beam perpendicular to the beam. Count rates for a period of 120 seconds were determined successively, starting with all eight plates, removing 


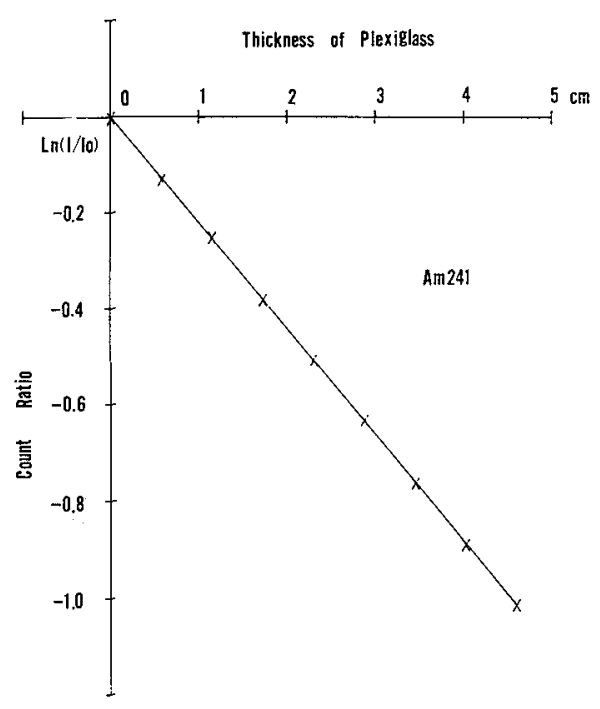

Fig. 33 Relationship between thickness of plexiglas and attenuated count. Slope of the linear regression line indicates the absorption coefficient.

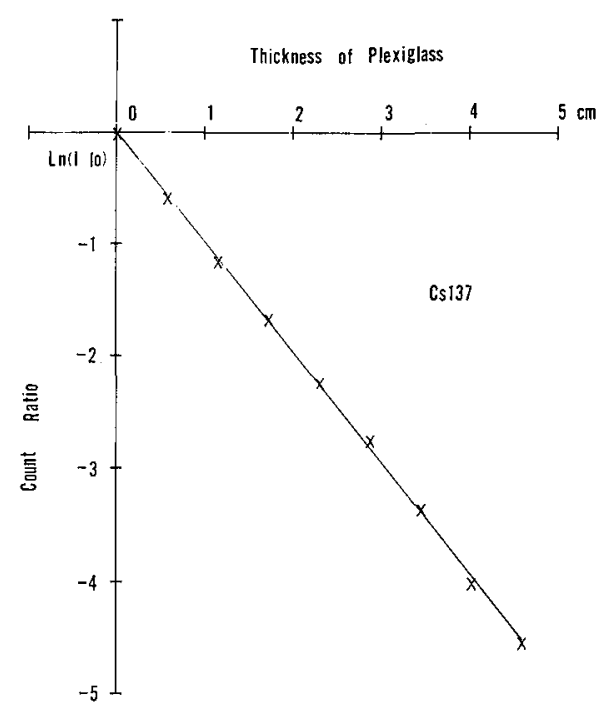

Fig. 34 Relationship between thickness of plexiglas and attenuated count.

one by one plate at each counting, and lastly no plate. The logarithmic count rates as a function of the thickness of plexiglas were shown in Figs. 33 and 34 for both ${ }^{241} \mathrm{Am}$ and ${ }^{137} \mathrm{Cs}$. Two linear regressions of the plots gave attenaution coefficients for plexiglas both for ${ }^{241} \mathrm{Am}$ and ${ }^{137} \mathrm{Cs}$.

$$
\begin{aligned}
& \mu_{c A m}=0.220 \mathrm{~cm}^{2} / \mathrm{g} \\
& \mu_{c c s}=0.098 \mathrm{~cm}^{2} / \mathrm{g}
\end{aligned}
$$

the suffixes of $\mathrm{Am}$ and $\mathrm{Cs}$ mean for ${ }^{241} \mathrm{Am}$ and ${ }^{137} \mathrm{Cs}$.

Fritton (1969) pointed out that if the count rate is greater than $10^{6} \mathrm{cpm}$, resolving time correction should be done. Resolving time of a gamma-ray counting system is the minimum time that can separate two consecutive recorded gamma-ray photons. If another photon arrives within the elapsed time of the recording of the previous photons, no count is measured. According to Fritton, an observed counting rate can be corrected for resolving time with the equation,

$$
I=I_{o} /\left(1-T \cdot I_{o}\right)
$$

where

$$
\begin{aligned}
I & =\text { true counting rate }(\mathrm{cpm}) \\
I_{o} & =\text { observed counting rate }(\mathrm{cpm}) \\
T & =\text { resolving time }(\mathrm{min} / \text { counts })
\end{aligned}
$$

The resolving time is determined by applying an appropriate value in equation (11), and obtaining a linear regression at each case. The result of calculation for ${ }^{241} \mathrm{Am}$ is shown in 
Table 1 Resolving time correction

\begin{tabular}{|c|c|c|}
\hline $\begin{array}{c}\text { Resolving time } \\
\mu \mathrm{sec} / \text { count }\end{array}$ & $\begin{array}{c}\text { Absorption Coefficent } \\
\mu_{\text {CAm }} \mathrm{cm}^{2} / \mathrm{g}\end{array}$ & R-square \\
\hline 0 & 0.2201 & 0.999984 \\
1 & 0.2210 & 0.999984 \\
2 & 0.2219 & 0.999985 \\
3 & 0.2220 & 0.999986 \\
4 & 0.2229 & 0.999986 \\
5 & 0.2238 & 0.999985 \\
\hline
\end{tabular}

Table 1. It is obvious there is no significant difference between nonadjusted and $3 \mu \mathrm{sec} /$ counts adjusted. Thus, in this experiment, resolving time correction was not considered for determining other absorption coefficients.

The plexiglas boxes having different internal dimensions filled with distilled de-aired water were placed between the gamma sources and the detector. Changes in count rate passing through the water were measured. A linear regression of the data gave the absorption coefficient for water. Both for ${ }^{241} \mathrm{Am}$ and ${ }^{137} \mathrm{Cs}$ are shown in Figs 35 and 36 . The values

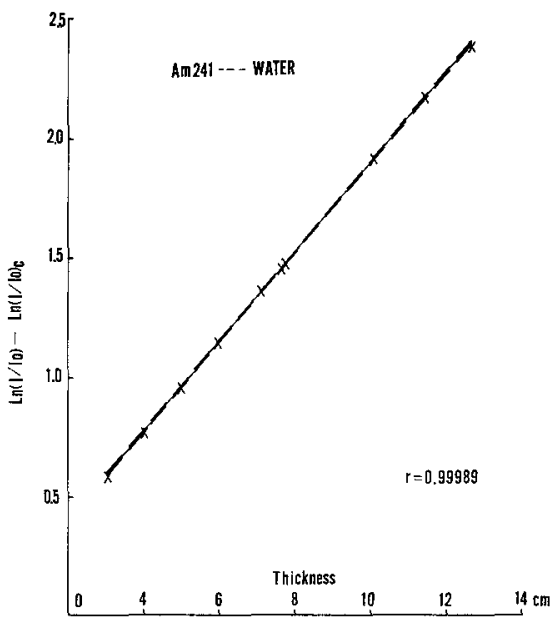

Fig. 35 Determination of mass absorption coefficient of water for ${ }^{241} \mathrm{Am}$.

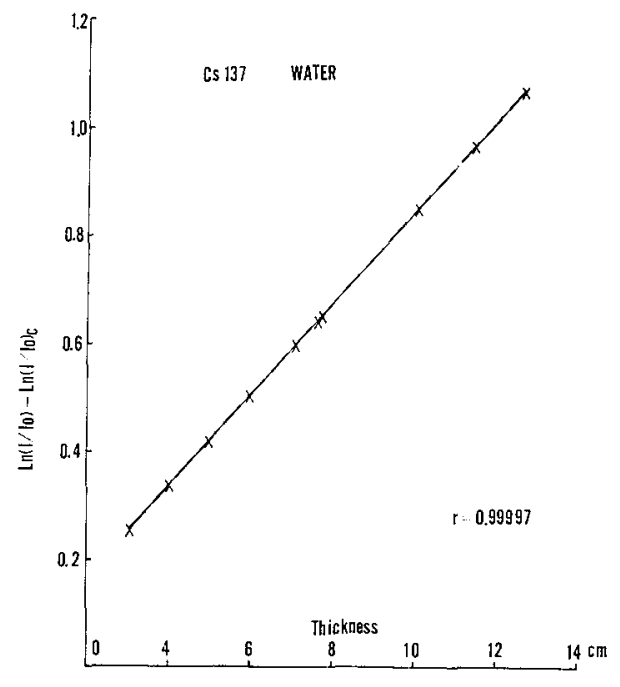

Fig. 36 Determination of mass absorption coefficient of water for ${ }^{137} \mathrm{Cs}$.

are as follows : $\mu_{W A_{m}}=0.1181 \mathrm{~cm}^{2} / \mathrm{g}$ with a regression coefficient of $0.99989 ; \mu_{W c_{s}}=0.0849$ $\mathrm{cm}^{2} / \mathrm{g}$ with a regression coefficient of 0.99997 .

In the case of the determination of mass absorption coefficients for soil, the methods described above are not adequate because of a variety of densities of dry soils. In order to determine the absorption coefficient for soil, the dry soil was packed into plexiglas boxes 
having various inside dimensions. The volumes of the boxes were carefully measured and the dry soils were weighed. After determining the density, each box filled with dry soil was placed in the gamma ray apparatus. The intensity of the gamma ray passing through the box was measured. In Figs. 37 and 38, the values obtained by dividing the count ratio by the

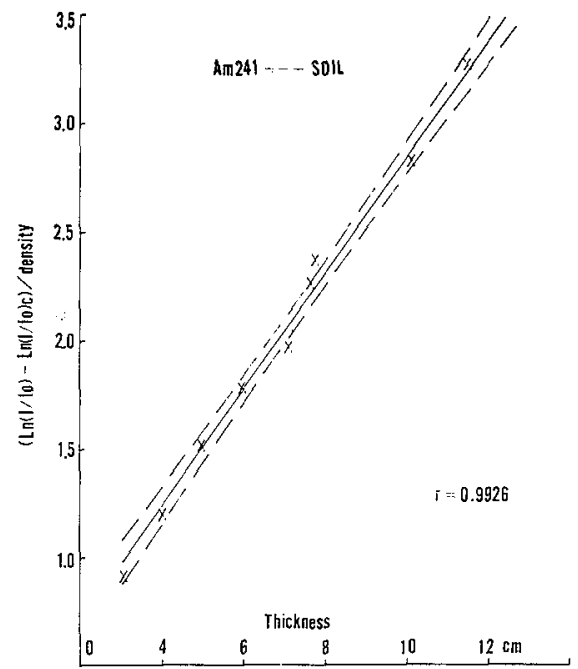

Fig. 37 Determination of mass absorption coefficient of soil for ${ }^{241} \mathrm{Am}$.

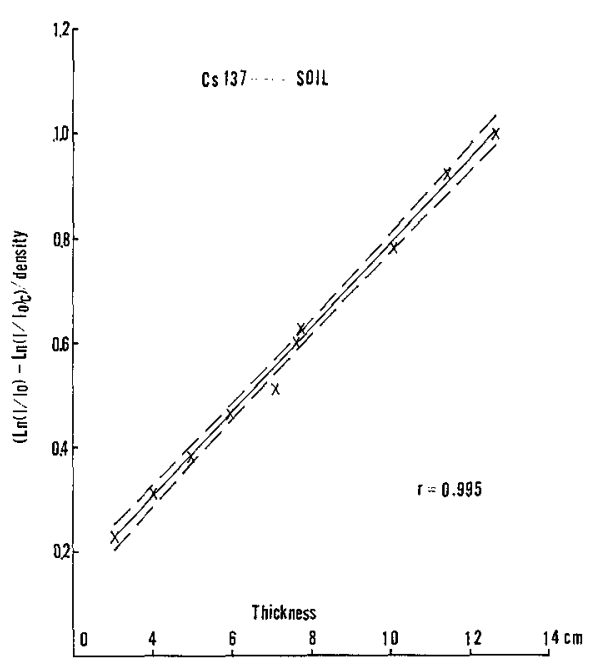

Fig. 38 Determination of mass absorption coefficient of soil for ${ }^{137} \mathrm{Cs}$.

measured density are plotted as a function of the length of the dry soil samples. The slopes of the fitted regression line indicate the absorption coefficient. The dashed line shows the $90 \%$ confidence zone of regression. Goit et al. (1978) indicated that errors, due to the variations in the absorption coefficient of soils, cause wide variations in measurements of water contents. They assumed that only one value of the mass absorption coefficient, due to the use of Am and Cs, varied. Actually, in the case of using the dual gamma ray system, both values may vary at the same time. The effect of a shift of the absorption coefficients on the calculation of water content were calculated for one pair of values of water content and soil dry density and given on Fig. 39. The

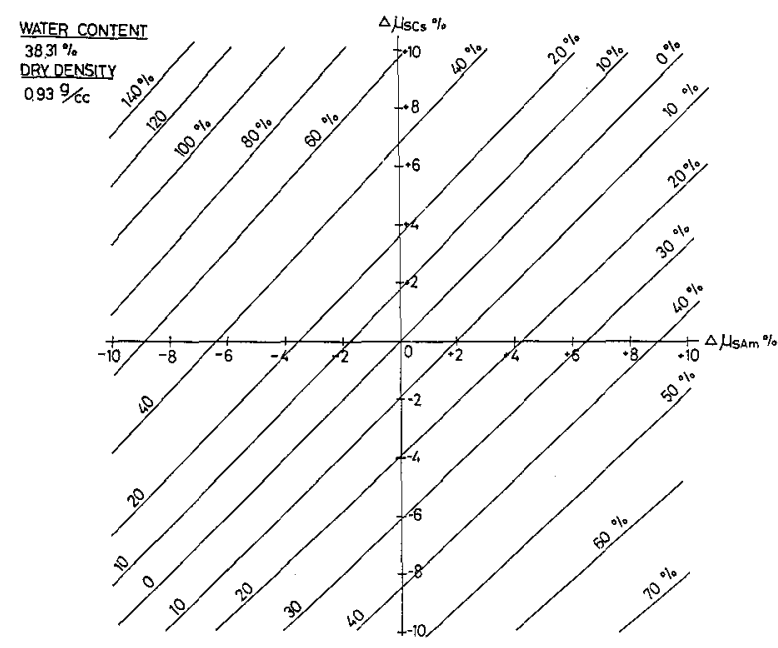

Fig. 39 Effect of shift of attenuation coefficient on calculation of water content. 
shift in water content is due to the deviation of the values of the absorption coefficient. In Fig. 39, the percentage numbers on the lines imply the shifts from the actual water content. If an accuracy of $1 \%$ or less of water content is desired, the attenuation coefficients for ${ }^{241}$ Am and ${ }^{137} \mathrm{Cs}$ must be determined within a deviation of less than $0.5 \%$.

Gardner (1972) suggested a way for determining the coefficient of dry soil. In this experiment, his method was employed. A dry soil was packed into a soil column container consisting of three sections held together by a masking tape. After packing the soil into the column, it was shaken for three hours. The top section was carefully removed; the middle section was also removed and the soil was scraped off with a straight edge. Both ends were covered with plexiglas plates. Then counts were taken through the middle section. After counting, the soil was weighed. This procedure was repeated six times. By this method, the following mass absorption coefficients were obtained :

$$
\begin{aligned}
& \mu_{S A_{m}}=0.2778 \pm 0.002 \mathrm{~cm}^{2} / \mathrm{g} \\
& \mu_{S C_{s}}=0.0752 \pm 0.002 \mathrm{~cm}^{2} / \mathrm{g}
\end{aligned}
$$

The absorption coefficient of a mixture of ice and water were also measured. The absorption coefficient for water should be equal for both the solid and liquid phases. During the melting process of ice, the intensity of a gamma ray passing a mixture of ice and water was measured. The equation for an ice water system is :

$$
\operatorname{In}\left(I / I_{o}\right)=\mu_{w} \cdot \rho_{w} \cdot X
$$

where $\operatorname{In}\left(I / I_{o}\right)$ is the count ratio, $\mu_{w}$ is the absorption coefficient and is constant for both ice and water, $\rho_{w}$ is the density of ice or water, $X$ is the length of the gamma path through the ice water. Dividing $\operatorname{In}\left(I / I_{o}\right)$ of water, the author obtained the following ratios:

$$
\begin{aligned}
& \mathrm{N} \cdot \mathrm{Am}=0.914256 \pm 0.00305 \\
& \mathrm{~N} \cdot \mathrm{Cs}=0.911389 \pm 0.00478
\end{aligned}
$$

These ratio are almost equal to 0.924 , the density ratio of ice to water, from the density at $0^{\circ} \mathrm{C}$ of 0.9168 and $0.9921 \mathrm{~g} / \mathrm{cm}^{3}$ for ice and water respectively, according to Dorsey (1940). In Fig. 40, the increase of $\operatorname{In}\left(I / I_{o}\right)$ indicates that the change of water-ice to water during the melting process agreed with Dorsey's data. Regardless of the water or

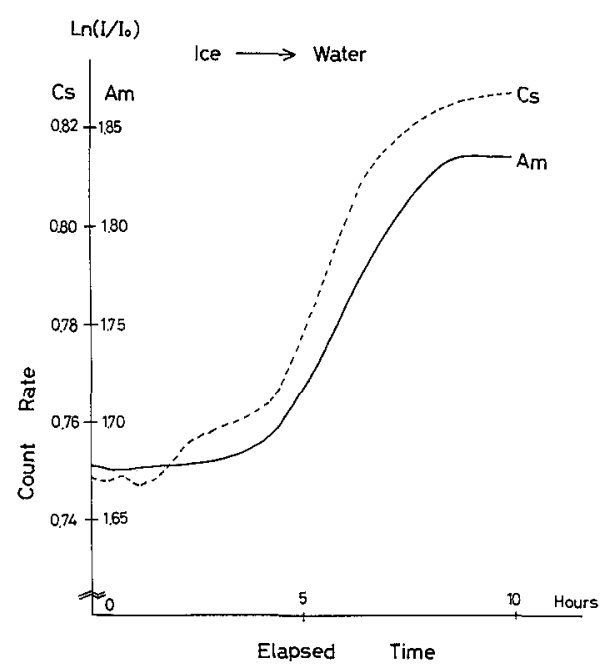

Fig. 40 Effect of phase change from ice to water on count rate. ice phase, the measured water content means the equivalent unfrozen water cotent. 


\section{6. Optimum length of a soil sample}

Gardner (1972) pointed out that the errors of water content and density measurements, due to the randomness of gamma ray emissdon, can be expressed as the summed variances of the various components. Using equation (9), the variance of water content measurement is expressed as the following equation :

$$
\begin{aligned}
\sigma_{\theta}^{2} & =\left(\frac{\partial \theta}{\partial I_{a}}\right)^{2} \sigma_{I_{a}}^{2}+\left(\frac{\partial \theta}{\partial I_{a_{0}}}\right)^{2} \sigma_{I_{a 0}}^{2}+\left(\frac{\partial \theta}{\partial I_{b}}\right)^{2} \sigma_{I_{b}}^{2}+\left(\frac{\partial \theta}{\partial I_{b 0}}\right)^{2} \sigma_{I_{b o}}^{2}+\left(\frac{\partial \theta}{\partial x}\right)^{2} \sigma_{x}^{2}+\left(\frac{\partial \theta}{\partial \mu_{s a}}\right)^{2} \sigma_{\mu_{s a}}^{2} \\
& +\left(\frac{\partial \theta}{\partial \mu_{s b}}\right)^{2} \sigma_{\mu_{s b}}^{2}+\left(\frac{\partial \theta}{\partial \mu_{w a}}\right)^{2} \sigma_{\mu_{w a}}^{2}+\left(\frac{\partial \theta}{\partial \mu_{w b}}\right)^{2} \sigma_{\mu_{w b}}^{2} \ldots \ldots \ldots \ldots \ldots \ldots \ldots \ldots \ldots \ldots \ldots \ldots \ldots \ldots \ldots \ldots \ldots \ldots \ldots \ldots \ldots \ldots \ldots \ldots \ldots \ldots \ldots \ldots \ldots \ldots \ldots \ldots \ldots \ldots \ldots
\end{aligned}
$$

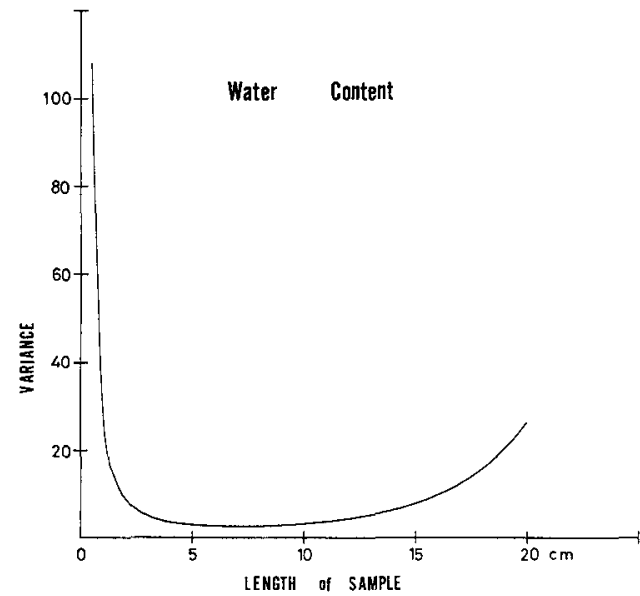

Fig. 41 Variance of gamma ray counts as a function of sample length for moisture content determination

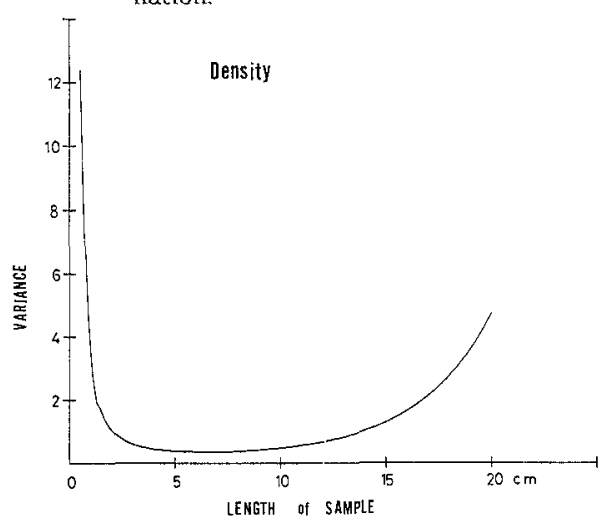

Fig. 42 Variance of gamma ray counts as a function of sample length for density determination.

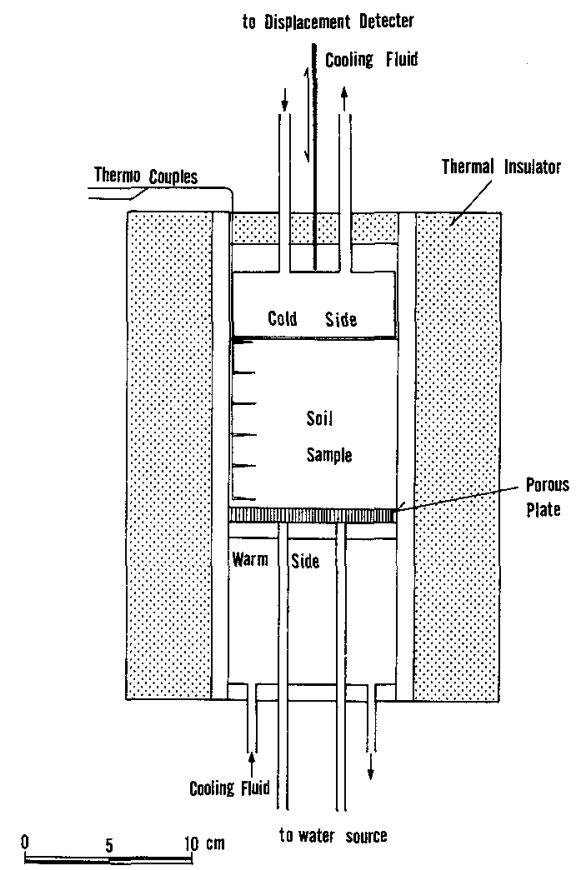

Fig. 43 Experimental apparatus of a soil column. 
where $\sigma^{2}$ is the variance in the mean value of the component indicated by the subscript.

Attainable precision is limited by random emission of the radio active sources; therefore, the limit in the absolute precision of the method is obtained from the first four terms of equation (13). Carrying out the partial differentiation of the equation, and replacing $\sigma N^{2}$ by $N$, which may be done for the poisson' s distribution of random emission, the following eqation was yielded :

$$
\sigma_{\theta}^{2}=\frac{1}{X^{2} K^{2}}\left(\frac{\mu_{s b}^{2}}{I_{a}}+\frac{\mu_{s_{b}}^{2}}{I_{a_{0}}}+\frac{\mu_{s a}^{2}}{I_{b}}+\frac{\mu_{s_{a}}^{2}}{I_{b_{a}}}\right)
$$

where $K=\mu_{s_{a}} \cdot \mu_{w_{b}}-\mu_{s_{b}} \cdot \mu_{w_{a}}$ and $X$ is the length of a sample.

Taking $I_{a_{o}}=I_{b_{o}}=I_{o}$, and substituting

$I_{a}=I_{o}\left(\exp \left(-X\left(\mu_{w_{a}} \theta+\mu_{s_{a}} \rho_{s}\right)\right)\right)$ and

$I_{b}=I_{o}\left(\exp \left(-X\left(\mu_{w_{b}} \theta+\mu_{s_{b}} \rho_{s}\right)\right)\right)$ into equation (14),

we obtain

$$
\sigma_{\theta}^{2}=\frac{\mu_{s b}^{2}}{X^{2} K^{2} I_{o}}\left\{1+\exp \left(X\left(\mu_{w_{c}} \theta+\mu_{s_{a}} \rho_{s}\right)\right)\right\}+\frac{\mu_{s a}^{2}}{X^{2} K^{2} I_{o}}\left\{1+\exp \left(X\left(\mu_{w_{b}} \theta+\mu_{s_{b}} \rho_{s}\right)\right\}\right.
$$

The count rates through air $I_{o}=10^{6} \mathrm{cpm}$, water content $\theta=30-50 \%$, and density $\rho_{s}=1.0 \mathrm{~g} /$ $\mathrm{cm}^{3}$ were taken into consideration into the calculation using the above equation.

The variances of water content and density as a function of the thickness of the soil column are shown in Figs. 41 and 42 . The $10 \mathrm{~cm}$ length of a soil column, which the author employed in this study, is adequate for the determination of water content and density by the dual gamma ray attenuation method. The temperature of the soil column thermally insulated is controlled by circulating cooling fluid inside the two plates at both ends (Fig. 43).

\section{7. Results and discussion}

A numeber of experiments were conducted using several different temperature gradients and at various initial moisture contents, which resulted in different advancing rates of the freezing front. As a result, it was observed that changes in moisture of a freezing soil in a closed system occur in both the frozen and the unfrozen zone.

At the freezing front, a sharp drop took place in water content inside the unfrozen soil layer. This discontinuity in the profile of water content means that the drying zone in the unfrozen side exists immediately beneath the freezing front. For example, in Fig. 44 at a 1 $\mathrm{cm}$ depth, the water content decreased sharply from the intial water content of $32 \%$ to $11.85 \%$ during the time period of 0 to 1 hour. Changes in water content at depths of $1,2,3$ and $4 \mathrm{~cm}$ are shown in Fig. 46 as the time functions. At depths of 1 and $2 \mathrm{~cm}$, the water content decreased, then again increased up to large values than the initial values.

Using Tomakomai silt, the unfrozen water contents at various degrees below $0^{\circ} \mathrm{C}$ were 


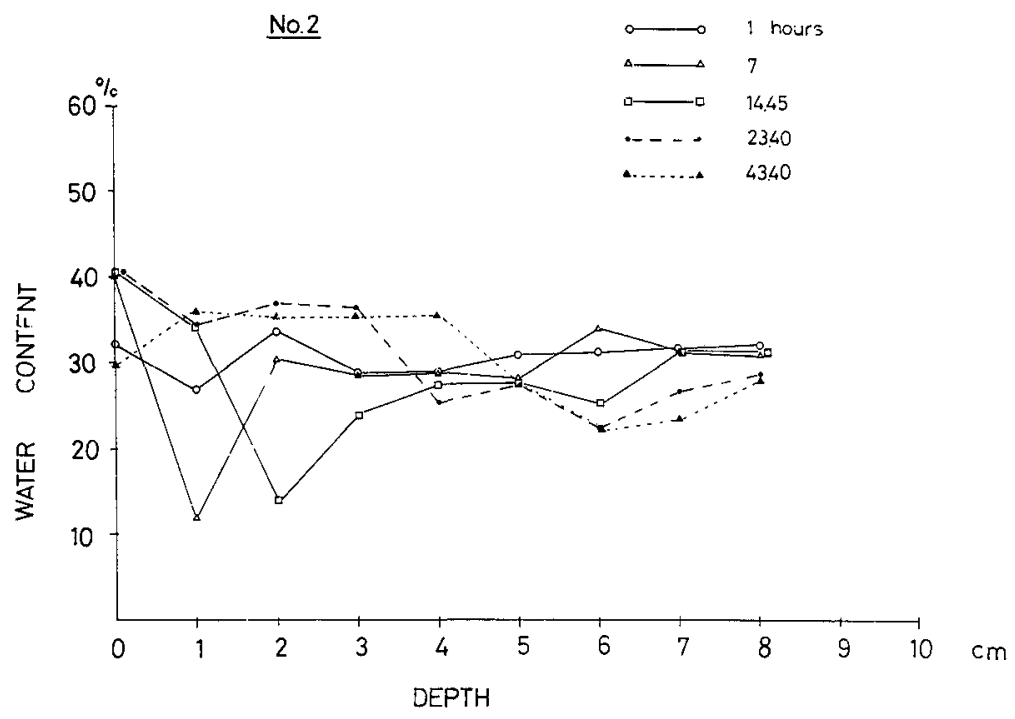

Fig. 44 Water content for various times after initiation of freezing.

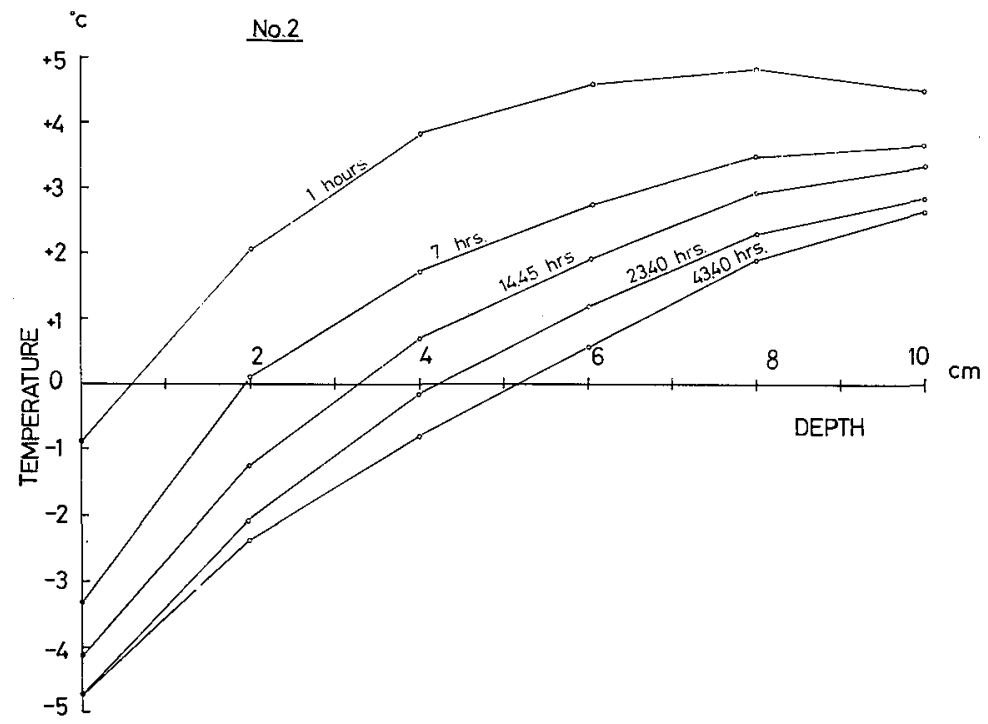

Fig. 45 Temperature distribution for experimental data in Fig. 44.

measured (Ishizaki and Kinosita, 1980). The following empirical equation was obtained from the measured data by the freezing point deprssion method (Fig. 47).

$$
w=a T^{b}
$$


where $w=$ volumetric unfrozen water content $\left(\mathrm{cm}^{3} / \mathrm{cm}^{3}\right), \quad a=$ constant $=0.19778, \quad b=$ constant $=-0.3046, \quad T=$ absolute value of freezing point depression $\left({ }^{\circ} \mathrm{C}\right)$.

In Fig. 48, the temperature gadients and water contents between depths of 1 and $2 \mathrm{~cm}$ are shown. Using equation (16), the unfrozen water content is calculated and shown as a tic mark on the line of water content at a $1 \mathrm{~cm}$ depth. The range shown by an arrow on the line indicates that water is unfrozen at a given temperature. The measured water content is plotted between these ranges of

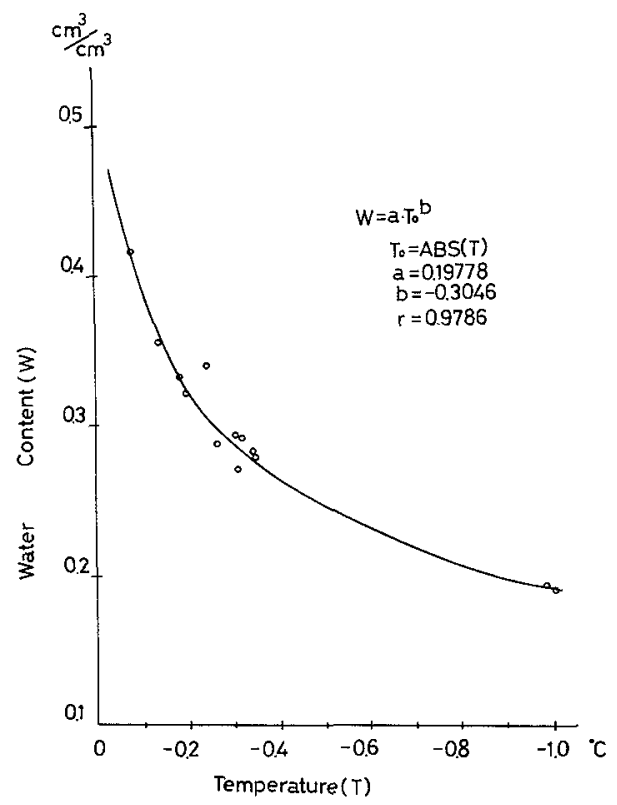

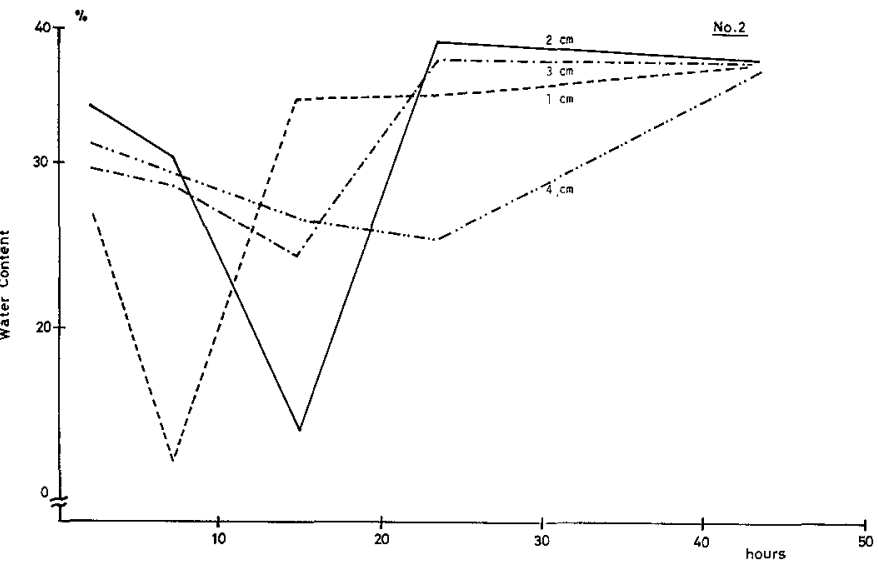

Fig. 46 Water content fluctuations as a function of elapsed time at $1-4 \mathrm{~cm}$ depths.

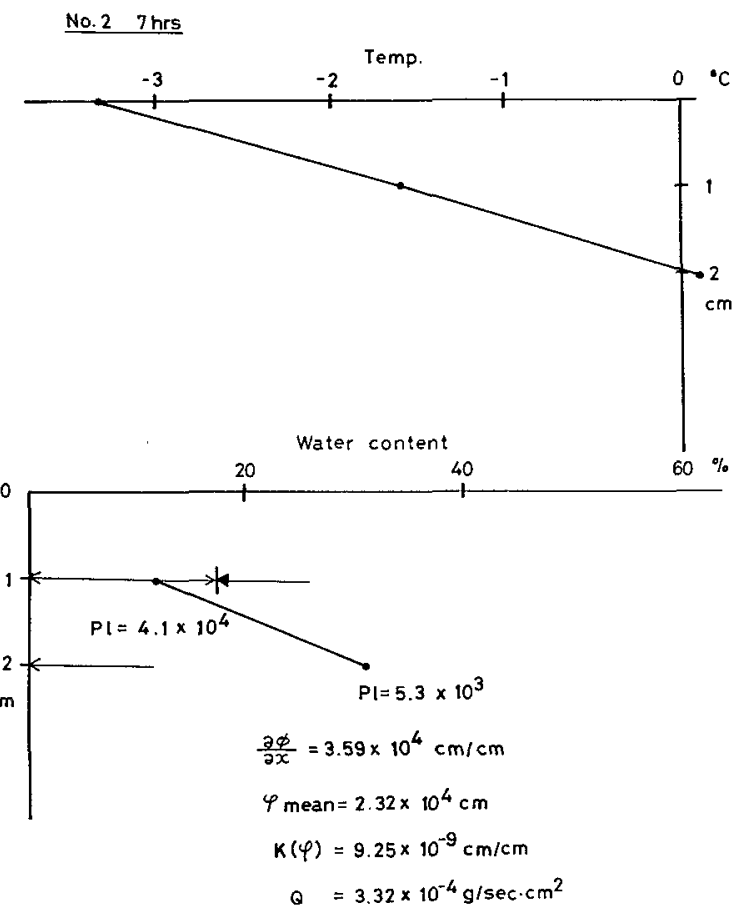

Fig. 48 Temperature and water content profiles at elapsed time of 7 hours in test No. 2.

Fig. 47 Relationship botween volumentric unfrozen water content and temperature below $0^{\circ} \mathrm{C}$. 


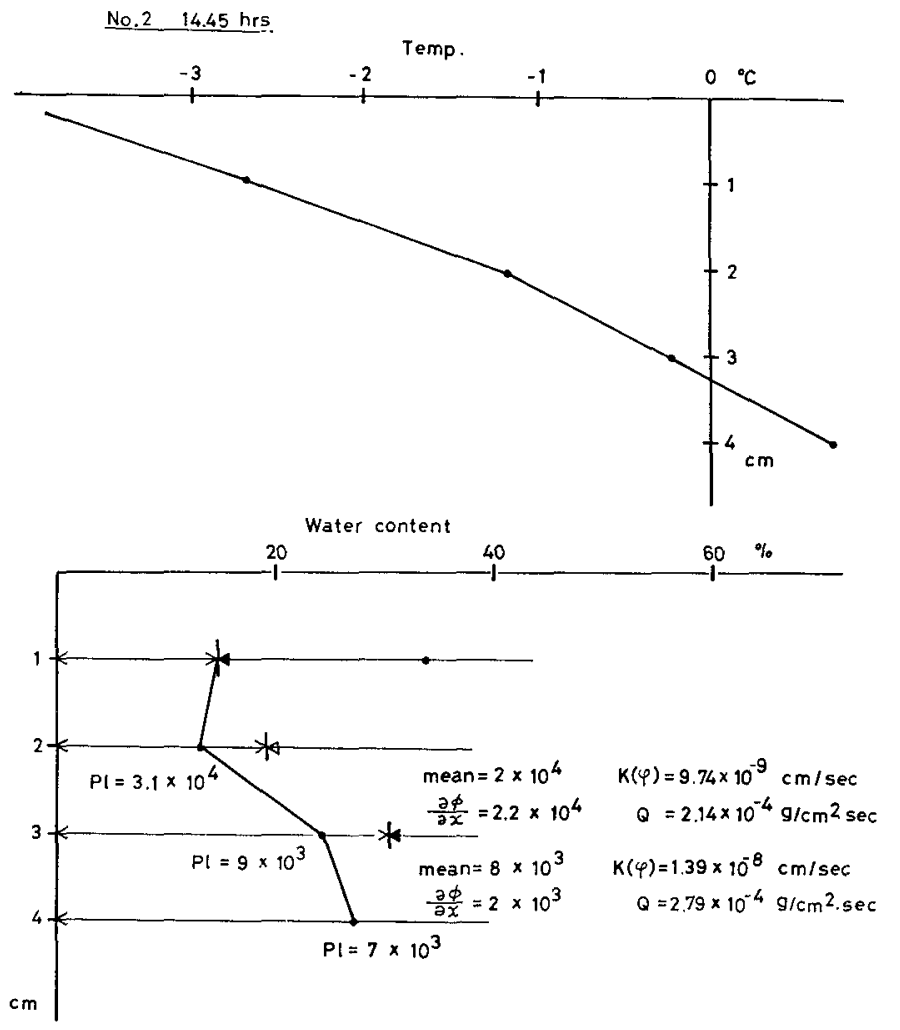

Fig. 49 Temperature and water content profiles at elapsed time of 14.45 hours in test No. 2 .

unfrozen water content. Thus, the water migrates in a liquid form from 2 to $1 \mathrm{~cm}$ in depth. In the previous experiment, the author obtained the relationship between water content and pore-water pressure. The characteristic curve is shown in Fig. 51. Using this relationship, a water content difference between 1 and $2 \mathrm{~cm}$ in depth is converted into a pore-water pressure gradient. The distance between two locations is considered as is subjected to the gravitational effect, and then the hydraulic potential gradient is obtained as $3.59 \times 10^{4} \mathrm{~cm} / \mathrm{cm}$. The average value of pore-water pressure, $2.32 \times 10^{4} \mathrm{~cm} / \mathrm{cm}$, between two positions is substituted into the empirical equation of the unsaturated hydraulic conductivity, which was previously obtained (equation (2)). Thus, the value of $9.25 \times 10^{-9} \mathrm{~cm} / \mathrm{sec}$ as the estimated hydraulic conductivity is obtained. The flux of liquid water transported along the porewater pressure profile is estimated as $Q=9.25 \times 10^{-9} \times 3.59 \times 10^{4}=3.32 \times 10^{-4} \mathrm{~g} / \mathrm{cm}^{2} \cdot \mathrm{sec}$. Similarly, at the elapsed time of 14.45 hours, the temperature gradients and water content profiles are shown (Fig. 49), and the unfrozen water contents at each layer are indicated by tic marks on each line. The measured water contents are smaller than the unfrozen water content except at a $1 \mathrm{~cm}$ depth. The values of $P_{l}$ in Fig. 49 indicate the pore-water pressures 


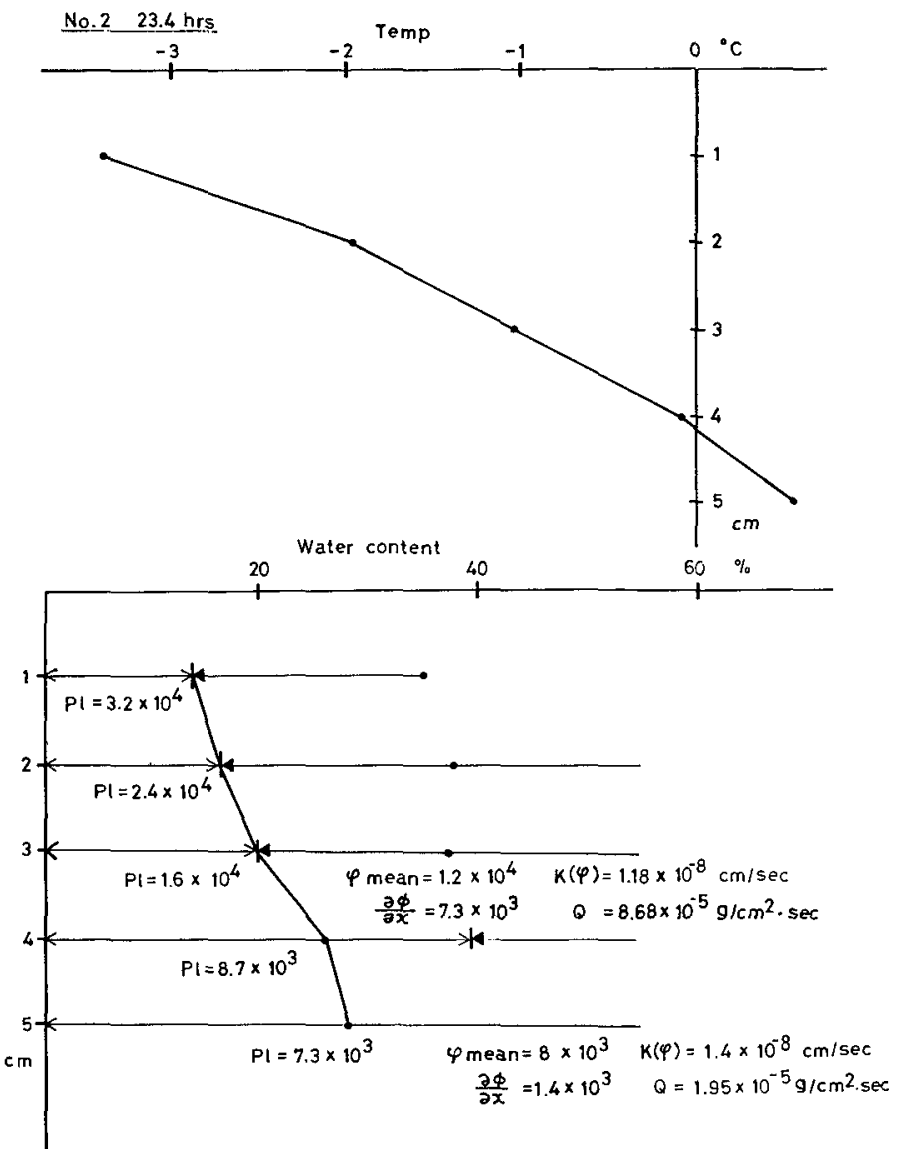

Fig. 50 Temperature and water content profiles at elapsed time of 23.4 hours in test No. 2.

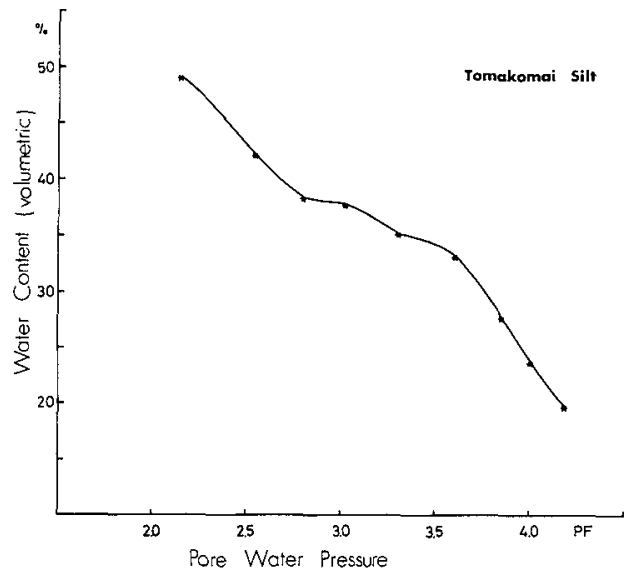

Fig. 5i Soil moisture characteristic curve for Tomakomai silt loam. 
converted from the water content. The fluxes between depths of 2 and $3 \mathrm{~cm}$, between 3 and $4 \mathrm{~cm}$ are calculated as $2.14 \times 10^{-4}$ and $2.79 \times 10^{-4} \mathrm{~g} / \mathrm{cm}^{2} \cdot \mathrm{sec}$, respectively.

At the elapsed time of 23.4 hours, the freezing front descended below a depth of $3 \mathrm{~cm}$ (Fig. 50). It means that the water contents at 1,2 and $3 \mathrm{~cm}$ in depth increased more than the unfrozen water content determined by the temperatures. The flux of liquid water between 4 and $5 \mathrm{~cm}$ in depth is estimated as $1.95 \times 10^{-5} \mathrm{~g} / \mathrm{cm}^{2} \cdot \mathrm{sec}$. However, at a depth of $3 \mathrm{~cm}$, as measured water content, the pore-water pressure is equal to the maximum unfrozen water content indicated by a tic mark on the line: Using these values, th flux of water is also calculated as $8.86 \times 10^{-5} \mathrm{~g} / \mathrm{cm}^{2} \cdot \mathrm{sec}$. This value is larger than the flux of underlying layers, and must be the same or nearly the same. These differences may be due to the overstimation of the hydraulic conductivity $\left(1.18 \times 10^{-8} \mathrm{~cm} / \mathrm{sec}\right)$. It is because at the depth of $3 \mathrm{~cm}$, the measured water content exceeds the unfrozen water content, and unfrozen water and ice may co-exist. The ice crystals between solid particles of soil and unfrozen water impeded the migration of water. This effect is called ice-impeding effect by Taylor and Luthin (1978). In experiment No. 6, temperatures of both the ends of the soil column dropped with increasing lapse of time, as shown in Fig. 52, and the temperature profiles dropped likewise, as shown in Fig. 54. In Fig. 53, at the depth of $1 \mathrm{~cm}$ in front of the freezing front advanced beyond this front, the water content increased. After the elapsed time of 42 hours, the estimated position of the freezing front was located at the depth of about $4 \mathrm{~cm}$. The temperature at the depth of 1 $\mathrm{cm}$, at the same time, was $-1.8^{\circ}$

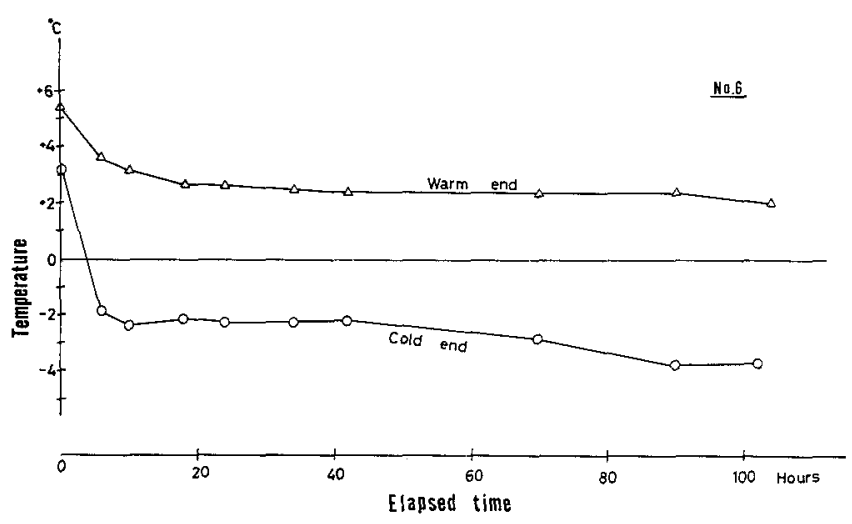

Fig. 52 Temperature changes at both ends of a soil sample in test No. 6 .

C. After 102 hours, the temperature dropped to $-3.0^{\circ} \mathrm{C}$. During the time period from 42 to 102 hours the moisture content increased even though the point in question was beneath the freezing front. This clearly indicates that moisture migration occurred through the frozen soil. These results are in agreement with Hoekstra's findings (1969), and with the previous experiments in chapter IV. In the case of Fig. 53 (test No. 6), the flux of water through the plane at the depth of $1 \mathrm{~cm}$, with a thickness of $2.4 \mathrm{~mm}$, was calculated. The calculation was performed as follows for

$$
T_{\text {mean }}=-2.13^{\circ} \mathrm{C}:
$$

the water content $=46.94 \%$ after 42 hours

the water content $=49.92 \%$ at 0 hour 


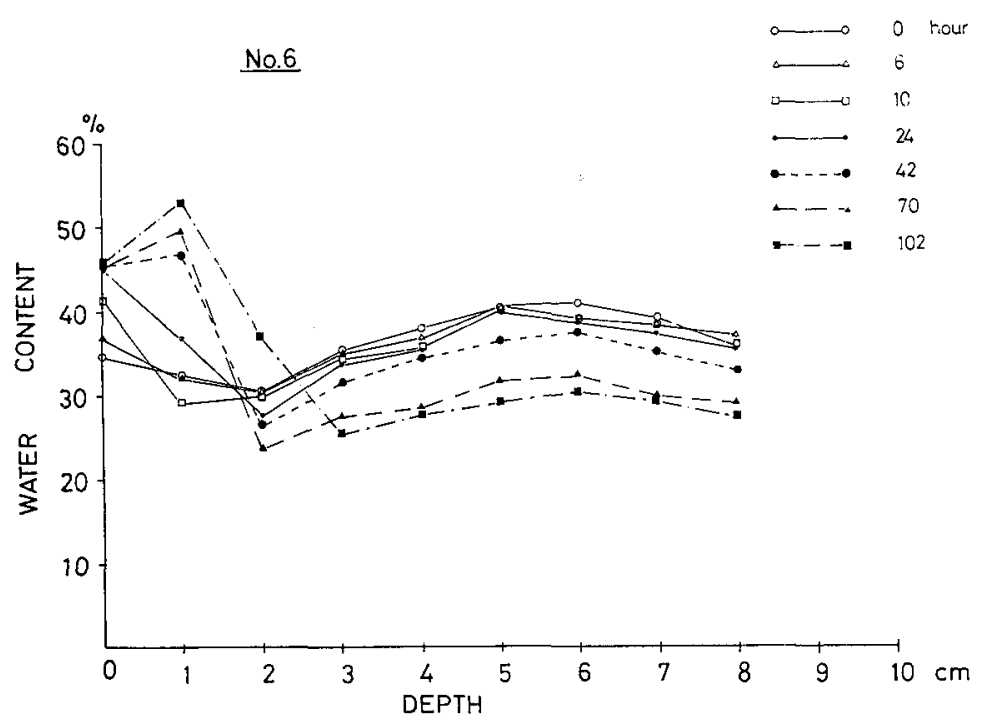

Fig. 53 Water content fluctuations as a function of depth at various times after initiation of freezing, test No. 6.

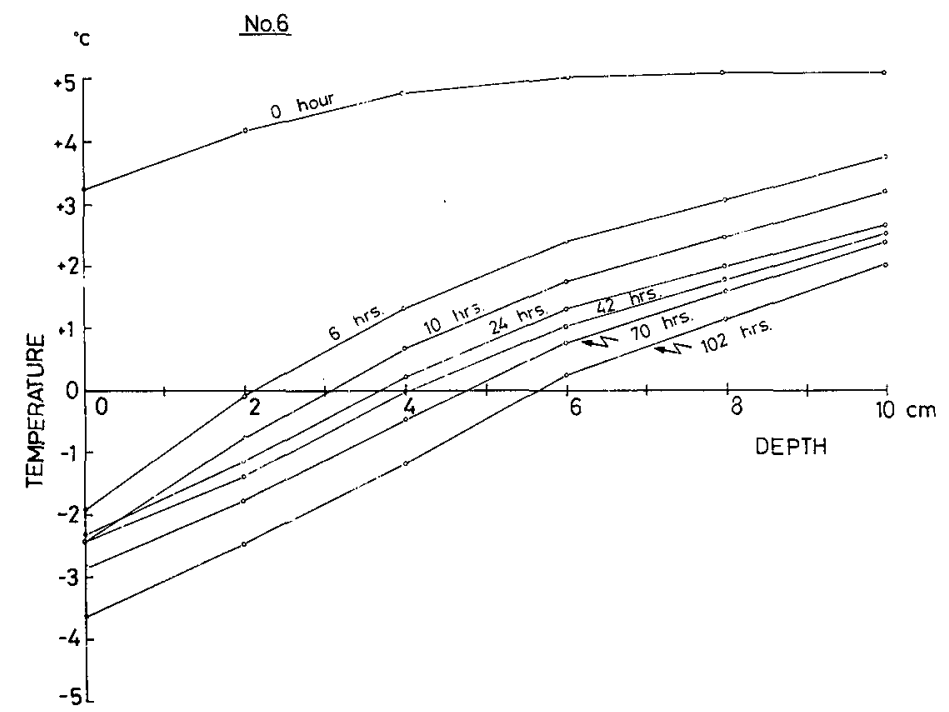

Fig. 54 Temperature distribution for Fig. 53.

An increase in water content is $2.98 \%$ or it is $0.00298 \mathrm{~g}$ per unit volume of soil. Since the time interval is 28 hours, the flux per unit area is $2.98 \times 10^{-2} / 28 \times 60 \times 60=2.95 \times 10^{-7} \mathrm{~g} / \mathrm{sec}$. $\mathrm{cm}^{2}$.

The results are shown in Table II. Using Fig. 54, the temperature gradient between 1 
and $2 \mathrm{~cm}$ in depth were calculated. The unfrozen water contents at each temperature were estimated by the masured temperature profile. According to empirical equation (16) and the characteristic curves (Fig. 51), the total hydraulic gradients were calculated (Table II). During the period between 42 and 70 hours, the average total hydraulic gradient of unfrozen water is $4.1 \times 10^{3} \mathrm{~cm} / \mathrm{cm}$; hydraulic gradient being calculated from the flux value and gradient as follows :

$$
K=Q / \frac{\partial \phi}{\partial x}
$$

where $Q=$ flux $=2.95 \times 10^{-7} \mathrm{~g} / \mathrm{cm}^{2} \cdot \mathrm{sec}$

$$
\frac{\partial \phi}{\partial x}=\text { gradient }=4.1 \times 10^{3} \mathrm{~cm} / \mathrm{cm}
$$

Table 2 Estimation of hydraulic conductivity of frozen soil.

No. 6

\begin{tabular}{|c|c|c|c|}
\hline $\begin{array}{l}\text { Elapsed } \\
\text { time hours }\end{array}$ & $\frac{\partial T}{\partial x}(. \mathrm{C} / \mathrm{cm})$ & $\frac{\partial \phi}{\partial x}(\mathrm{~cm} / \mathrm{cm})$ & Flux $\mathrm{g} / \mathrm{cm}^{2} \cdot \mathrm{sec}$ \\
\hline 42 & 0.54 & $4.25 \times 10^{3}$ & $2.95 \times 10^{-7}$ \\
\hline 70 & 0.55 & $3.89 \times 10^{3}$ & $2.069 \times 10^{-7}$ \\
\hline 90 & 0.66 & $4.16 \times 10^{3}$ & $2.045 \times 10^{-7}$ \\
\hline 102 & 0.59 & $3.49 \times 10^{3}$ & 2 \\
\hline
\end{tabular}

$42 \mathrm{~h}-70 \mathrm{~h}$

$$
\left(\frac{\partial \phi}{\partial x}\right)_{\text {mean }}=4.1 \times 10^{3}
$$

$$
\begin{aligned}
K=7.38 \times 10^{-11} \mathrm{~cm} / \mathrm{sec} \quad K(\varphi) & =9.04 \times 10^{-9} \\
\varphi & =2.47 \times 10^{4}
\end{aligned}
$$

$70 \mathrm{~h}-90 \mathrm{~h}$

$$
\begin{aligned}
\left(\frac{\partial \phi}{\partial x}\right)_{\text {mean }}=4.0 \times 10^{3} & \\
K=6.73 \times 10^{-11} \mathrm{~cm} / \mathrm{sec} \quad K(\varphi) & =8.68 \times 10^{-9} \\
\varphi & =2.79 \times 10^{4}
\end{aligned}
$$

$90 \mathrm{~h}-102 \mathrm{~h}$

$$
\begin{aligned}
\left(\frac{\partial \phi}{\partial x}\right)_{\text {mean }}=3.8 \times 10^{3} & \\
K=5.38 \times 10^{-11} \mathrm{~cm} / \mathrm{sec} \quad K(\varphi) & =3.46 \times 10^{-9} \\
\varphi & =3.0 \times 10^{4}
\end{aligned}
$$




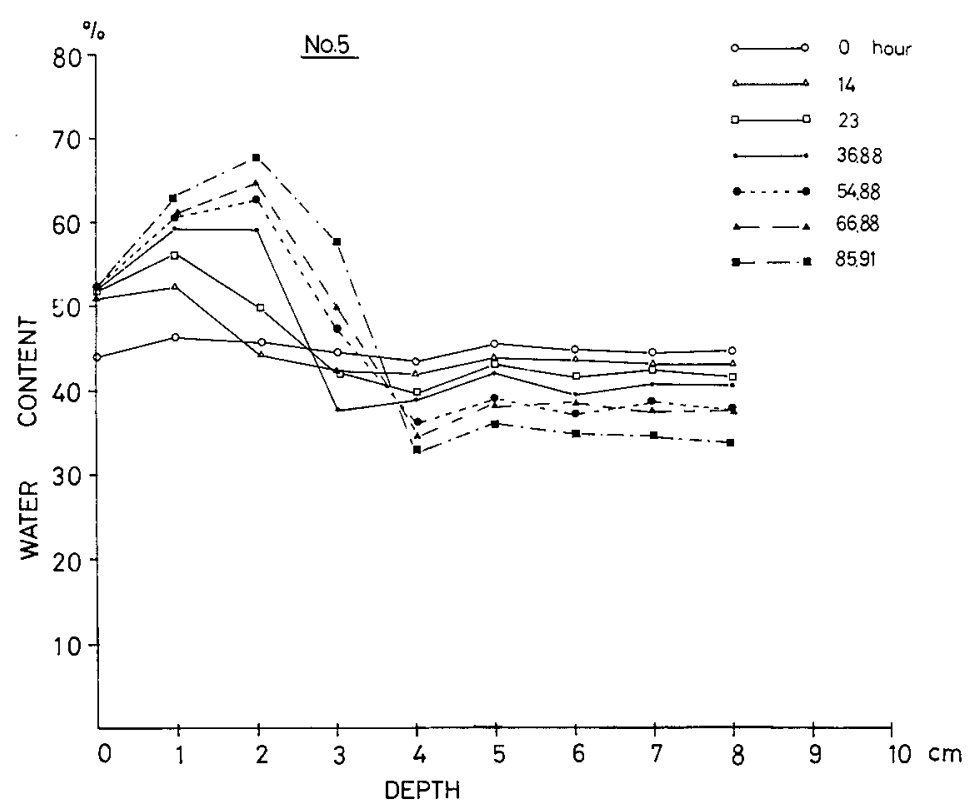

Fig. 55 Water content fluctuations as a function of depth at various times after initiation of freezing, test No. 5 .

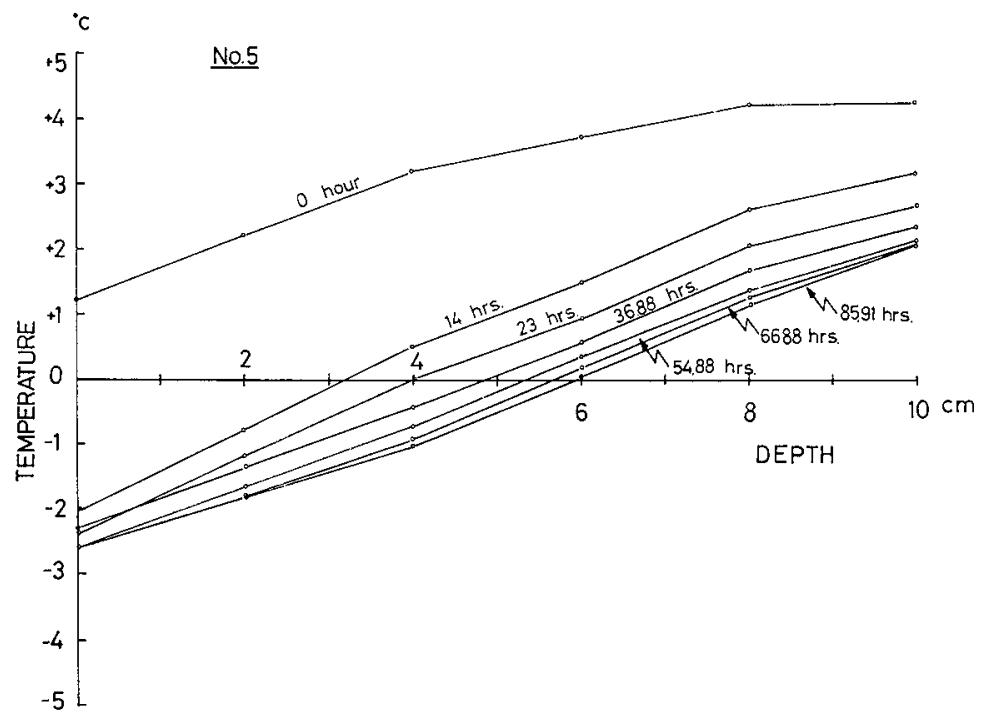

Fig. 56 Temperature distribution for Fig. 55. 


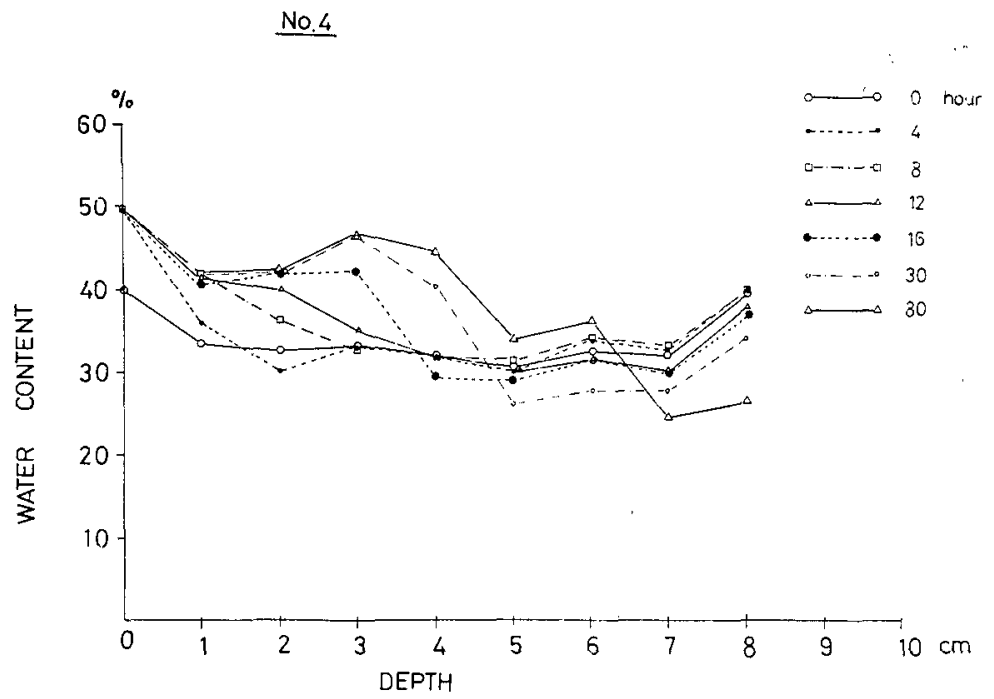

Fig. 57 Water content fluctuations as a function of depth at various times after initiation of freezing, test No. 4.

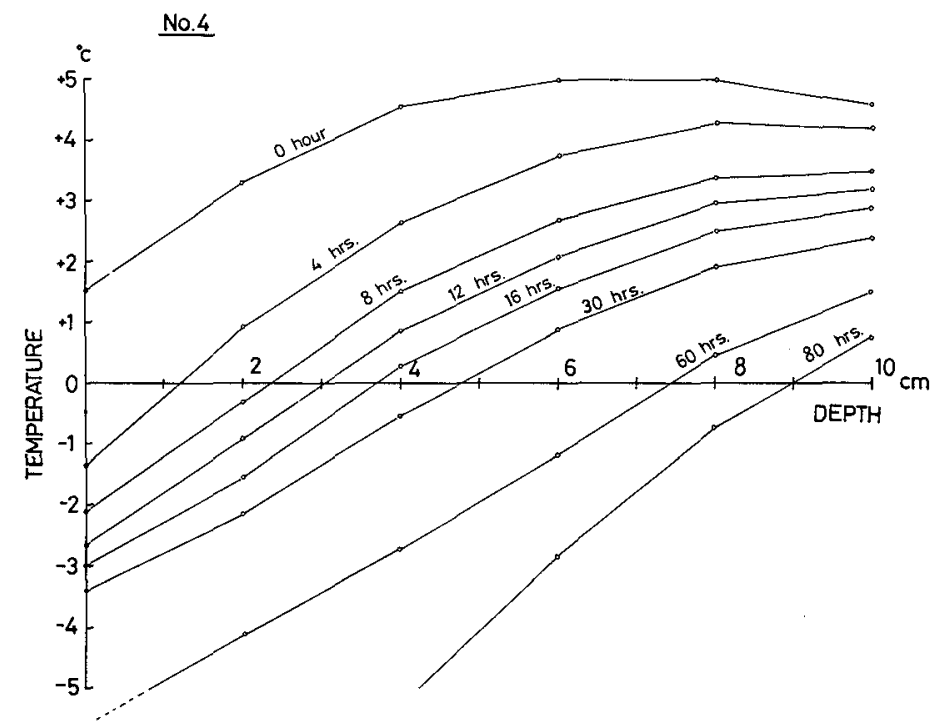

Fig. 58 Temperature distribution for Fig. 57. 
The estimated hydraulic conductivity is $7.38 \times 10^{-11} \mathrm{~cm} / \mathrm{sec}$. If one assumes that the unfrozen water in the frozen soil migmates as the unsaturated, unfrozen water, the hydraulic conductivity is estimated by empirical equation (2). This conductivity is $9.04 \times 10^{-9} \mathrm{~cm} / \mathrm{cm}$, which is 100 times greater than the previous estimated value. It means that the ice-impeding factor for the hydraulic conductivity is $10^{-2}$. In other cases, for a period between 70 and 90 hours and a period between 90 and 102 hours, the ice-impeding factors are $10^{-2}$. Burt and Williams (1978) suggested that the hydraulic conductivity of unsaturated and frozen soil is $1 /$ $100-1 / 1000$ times smaller than that of unfrozen soil. This finding of the ice-impeding factor is considerably important for a numerical analysis, which will be discussed in the next chapter.

The effect of the advancing rate of the freezing front will be shown in Figs. 55 and 57. Under different boundary conditions, two experimental runs were carried out (Figs. 55 and 57). If we compare Fig. 56 with Fig. 58 , it is obvious that the advancing rate of front of test No. 4 is faster than that of test No. 5. Also, a comparison between Figs. 55 and 56 shows that the initial water contents are close to each other. However, the water content in the frozen layer of test No. 5 is much larger than that of test No. 4. The discontinuity in water content profile (test No. 5 after freezing) is more distinct than in test No. 4. The difference of test conditions between No. 4 and 5 is only a difference in advancing rate. A decrease in advancing rate results in a greater increase in water content in the frozen soil.

Using Figs. 55 and 56 , changes in water content and unfrozen water content at depths of $1,2,3 \mathrm{~cm}$ were shown as variables of elapsed time. At the depth of $2 \mathrm{~cm}$, during a

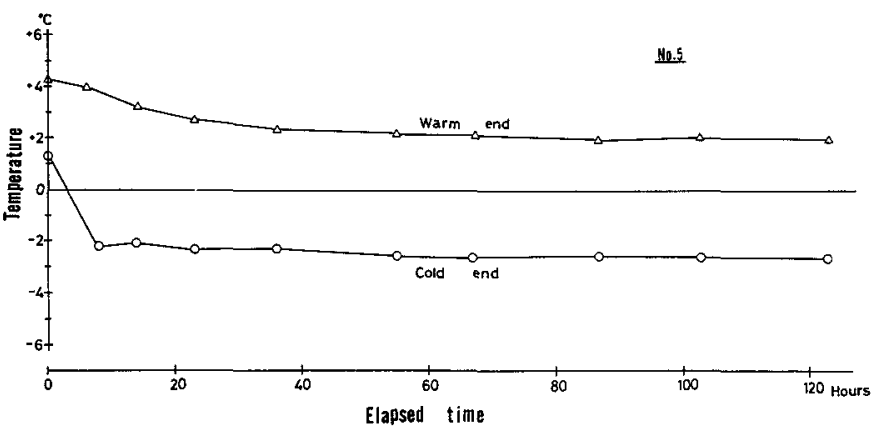

Fig. 59 Temperature change at both ends of a soil sample in test No. 5 .

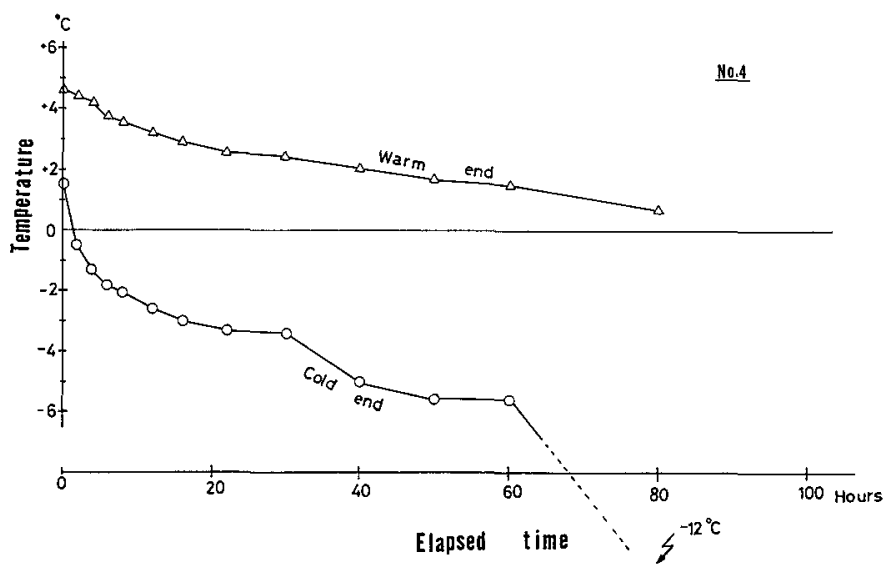
period from 20 to 40 hours, the Fig. 60 Temperature changes at both ends of a soil sample in test No. 4 . water content increased and the 
flux of migrated water is calculated. Also the average total hydraulic gradients between 2 and $3 \mathrm{~cm}$ in depth is estimated. These two values estimated make it possible to calculate the hydraulic conductivity of the unsaturated and frozen soil. On the assumption that the same amounts of unfrozen water of soil have the same hydraulic conductivity regardless of the coexistance of ice, the hydraulic conductivity is also estimated according to empirical equation (2). If we compare these two values of hydraulic conductivity (Fig. 61), it is obvious that the

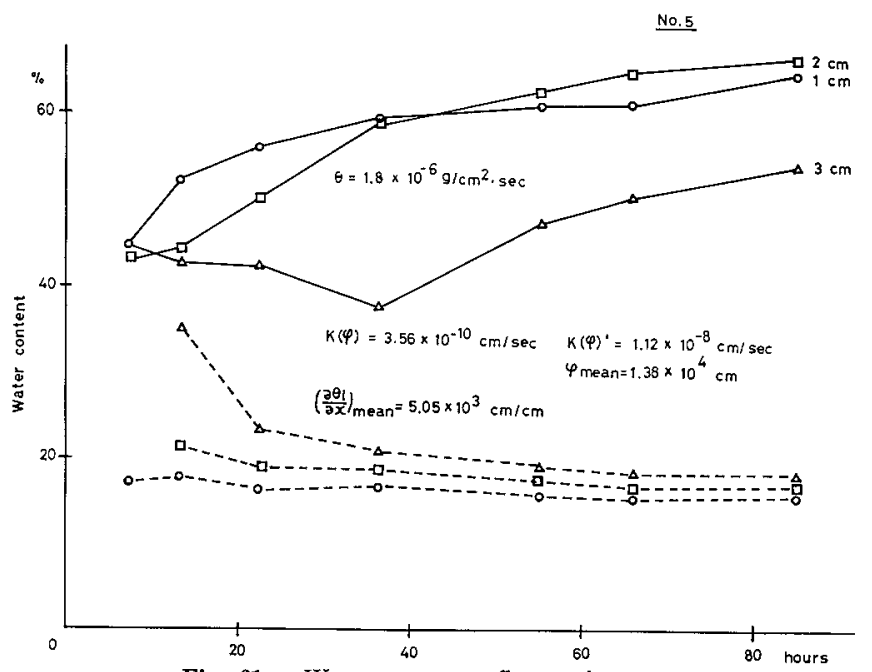

Fig. 61 Water content fluctuation as a function of elapsed time at various depths. Solid lines indicate unfrozen water content fluctuations. ice-impeding factor is nearly of the order of $10^{-2}$ in this case.

Water contents and temperature profiles in the freezing unsaturated soil were obtained by the gamma ray attenuation method. Water migration to both unfrozen and frozen soil layers were monitored with an adequate accuracy. The flux rate of water through the frozen layers was obtained by direct measurements. The moisture flow rate depends upon the speed with which the freezing front advances. The hydraulic conductivity of the unsaturated and frozen soil is also estimated from the obtained water content profiles. The profiles of water content and temperature provide data to be applied to a computer model. These considerations will be discussed in the next chapter.

\section{Numerical analyses of coupled heat and moisture transfer in a soil}

\section{during freezing}

\section{1. Introduction}

The objective of this chapter is to present simulation analyses of heat and water flow during soil freezing. A mathematical model for simulating heat and water flow in a freezing soil was presented earlier in the introductional chapter of this paper. Similar attempts were made by Jame and Norum (1977) and Taylor and Luthin (1978) ; both simulation models were based on the concept proposed by Harlan (1973). Despite that the simulation model itself has 
been developed, few experimental results have been yielded to verify it. The author carried out experiments of measuring the heat and moisture flows simultaneously, as described in the previous chapter. The results obtained are applied to the numerical analysis to verify the model in this chapter. It is because no attempts have been made to verify the model on the basis of the results from the dual gamma beam attenuation method.

\section{2. Procedure}

The basic equations used in the model are given below. Details of derivation of these equations are presented by Harlen (1973), Taylor and Luthin (1978) and Sheppard, Kay and Loch (1978).

The heat transfer equation is

$$
C_{s} \frac{\partial T}{\partial t}=\frac{\partial}{\partial x}\left(\lambda \frac{\partial T}{\partial x}\right)+L \rho_{i} \frac{\partial \theta_{i}}{\partial t}
$$

where $\lambda=$ thermal conductivity $\left(\mathrm{w} / \mathrm{cm}^{2} \cdot{ }^{\circ} \mathrm{C}\right)$

$T=$ temperature $\left({ }^{\circ} \mathrm{C}\right)$

$X=$ position coordinate $(\mathrm{cm})$

$t=$ time (seconds)

$L=$ specific heat of fusion of water $(\mathrm{erg} / \mathrm{g})$

$\rho_{i}=$ density of ice $\left(\mathrm{g} / \mathrm{cm}^{3}\right)$

$C_{s}=$ heat capacity of soil $\left(\mathrm{erg} / \mathrm{cm}^{3} \cdot{ }^{\circ} \mathrm{C}\right)$

$\theta_{i}=$ volumetric soil ice content $\left(\mathrm{cm}^{3} / \mathrm{cm}^{3}\right)$

In equation (17), the first set of terms accounts for the value of thermal conduction due to a temperature gradients, while the second set represents the amount of heat from a heat source (or sink) due to a water-ice phase transition.

The water transport equation is

$$
\frac{\partial \theta_{l}}{\partial t}=\frac{\partial}{\partial x}\left(K \frac{\partial \psi}{\partial x}\right)-\frac{\rho_{i}}{\rho_{i}} \frac{\partial \theta_{i}}{\partial t}
$$

Applying the relation, $D=K / C_{\theta} \quad C_{\theta}=\frac{\mathrm{d} \theta_{l}}{d \varphi}$ to equation (18), we obtain the equation :

$$
\frac{\partial \theta_{l}}{\partial t}=\frac{\partial}{\partial x}\left(D \frac{\partial \theta}{\partial x}\right)-\frac{\rho_{i}}{\rho_{l}} \frac{\partial \theta_{i}}{\partial t}
$$

where $\quad K=$ hydraulic conductivity $(\mathrm{cm} / \mathrm{sec})$

$D=$ soil water diffusivity $\left(\mathrm{cm}^{2} / \mathrm{sec}\right)$

$\rho_{w}=$ density of water $\left(\mathrm{g} / \mathrm{cm}^{3}\right)$

$\theta_{L}=$ volumetric soil water content $\left(\mathrm{cm}^{3} / \mathrm{cm}^{3}\right)$

$C_{\theta}=$ specific moiisture capacity $(1 / \mathrm{cm})$

$\varphi=$ total soil water potential ( $\mathrm{cm}$ of water)

These two equations are coupled at temperature below freezing in the following manner: the water contents calculated by equation (19) are related to temperatures calculated by 
equation (18). The relationship is given by the temperature versus water content curve for the soil (Fig. 47). This relationship for the tested Tomakomai silt was experimentally obtained (Ishizaki and Kinosita, 1980). Thus, the coupling equation below freezing is

$$
\theta_{l}=\mathbf{a} \cdot T^{b}
$$

where $\quad \theta_{L}=$ volumetric unfrozen water centent $\left(\mathrm{cm}^{3} / \mathrm{cm}^{3}\right)$

$T=$ absolute value of temperature $\left(\left|{ }^{\circ} \mathrm{C}\right|\right)$

$a=$ constant $=0.1978$

$b=$ constant $=-0.3046$

Equations (18) and (19) were solved numericaly by the finite difference method. The boundary conditions to be used in the solutions are

$$
\begin{aligned}
& T=T_{1}, X=0 \quad t \geqq 0 \\
& T=T_{2}, X=L_{0} \quad t \geqq 0 \\
& \frac{\partial \theta_{l}}{\partial x}=0, X=0 \quad t \geqq 0 \\
& \frac{\partial \theta_{l}}{\partial x}=0, X=L_{o} \quad t \geqq 0
\end{aligned}
$$

Wher $T_{1}$ and $T_{2}$ are the specified temperatures at the ends of the soil column, and $L_{0}$ is the length of it. Both $T_{1}$ and $T_{2}$ may be time dependent. Equations (22) and (23) imply that the system is closed with regard to liquid water transport; so, no water flows into or out of the system.

The initial conditions are

$$
\begin{array}{lll}
T=T_{0}(X) & 0 \leqq X \leqq L_{0} & \mathrm{t}=0 \\
\theta_{l}=\theta_{0}(X) & 0 \leqq X \leqq L_{0} & \mathrm{t}=0
\end{array}
$$

where $T_{0}(X)$ and $\theta_{0}(X)$ are the known values of temperature and water content along the soil column at $t=0$, respectively, and they can be either constants or functions of $x$.

\section{V1. 3. Soil properties}

The following list includes the relevant properties of the soil material (Tomakomai silt) used in this study.

(a) Thermal conductivity

Direct measurements were made to determine the thermal conductivity of both the frozen and unfrozen soil by means of a transient flow using a thermal probe (Woodside and Messmer, 1961). The author already measured the thermal conductivities of the frozen and unfrozen using Tomakomai silt, and obtained the following empirical equations (Fukuda, 
1977) :

$$
\begin{aligned}
& \lambda_{u}=A_{0}+A_{1} \theta_{l}+A_{2} \theta_{l}{ }^{2}+A_{3} \theta_{l}{ }^{3} \\
& \lambda_{f}=A_{0}{ }^{\prime}+A^{\prime}{ }_{1} \theta_{i}+A^{\prime}{ }_{2} \theta_{i}{ }^{2}+A^{\prime}{ }_{3} \theta_{i}{ }^{3}
\end{aligned}
$$

where $\quad \lambda_{u}=$ thermal conductivity of unfrozen Tomakomai silt

$$
\text { (mcal } / \mathrm{cm} \cdot \mathrm{sec} \cdot{ }^{\circ} \mathrm{C} \text { ) }
$$

$\lambda_{f}=$ thermal conductivity of frozen Tomakomai silt

$$
\text { (mcal } / \mathrm{cm} \cdot \mathrm{sec} \cdot{ }^{\circ} \mathrm{C} \text { ) }
$$

$\theta_{l}, \theta_{i}=$ volumetric water and ice content $\left(\mathrm{cm}^{3} / \mathrm{cm}^{3}\right)$

$$
\text { respectively }
$$

$$
A_{0}-A_{3}=\text { constant }
$$

$A_{0}{ }^{\prime}-A_{3}{ }^{\prime}=$ constant

These empirical equations, which were plotted as functions of $\theta_{l}$ or $\theta_{i}$ in Figs. 62 and 63, were used in the numerical analysis.

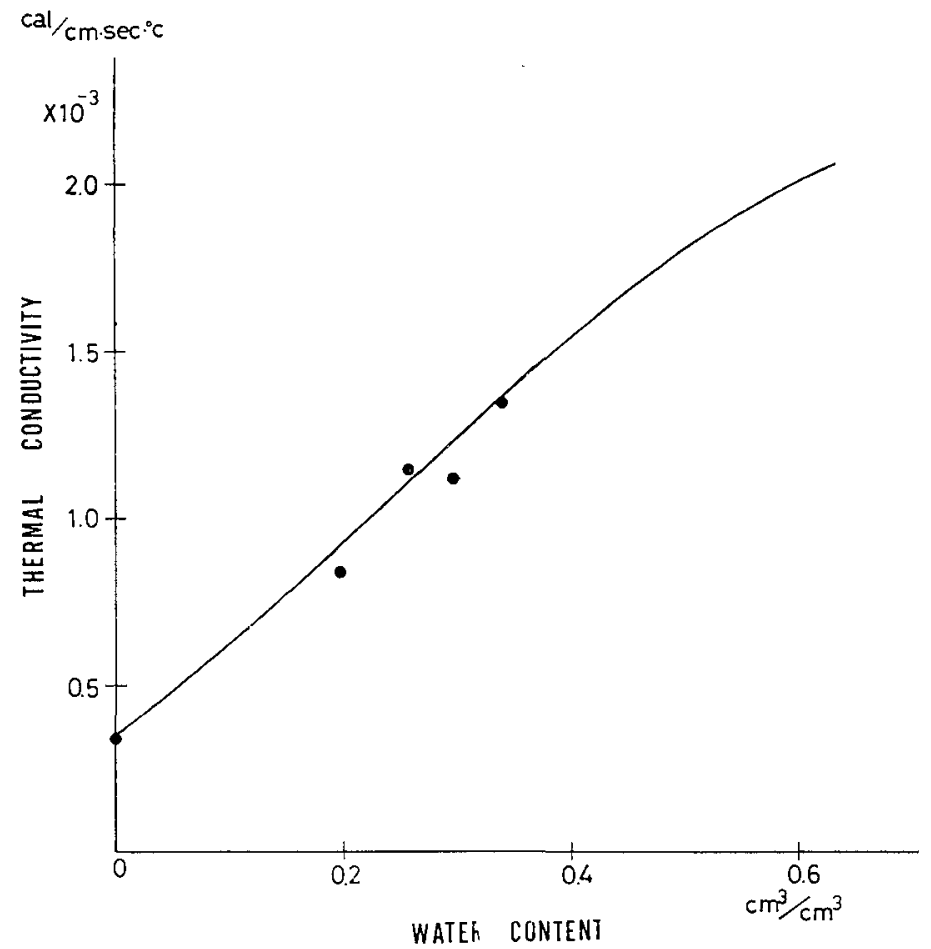

Fig. 62 Plots of thermal conductivity of unfrozen soil as a function of water content. 


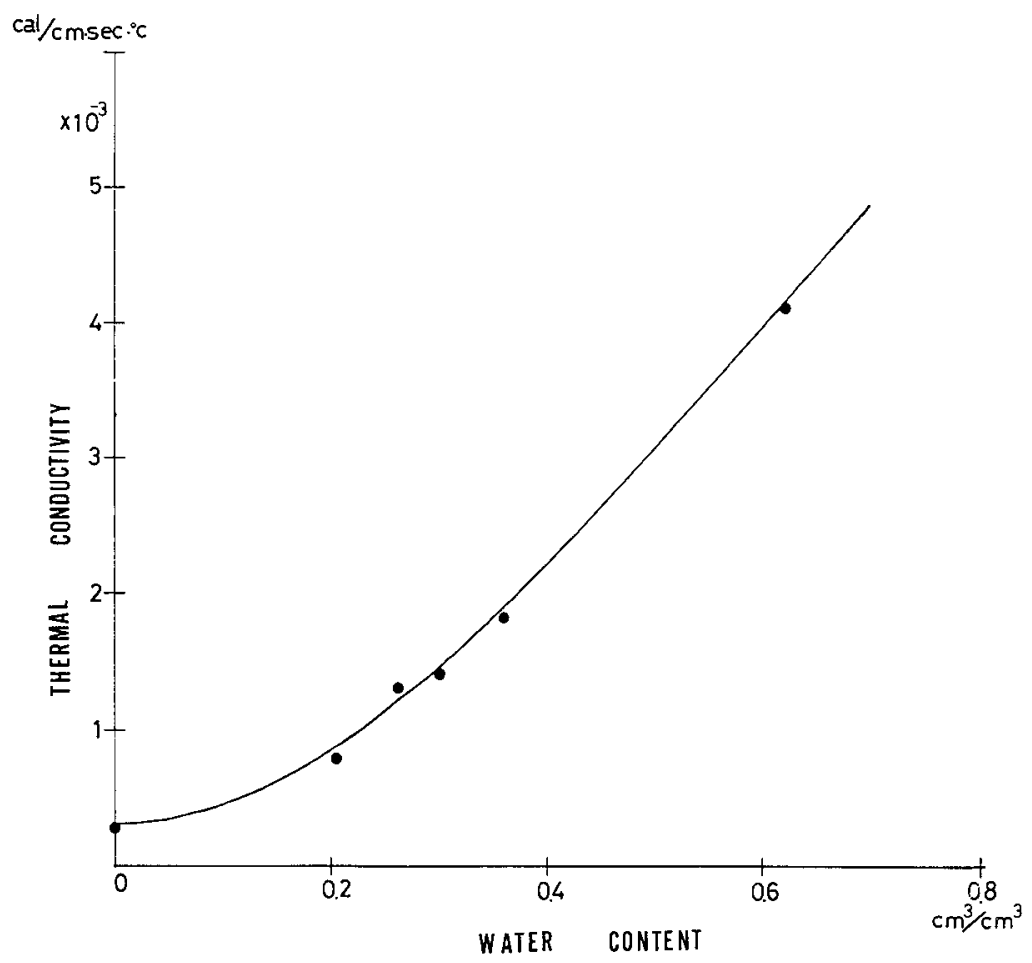

Fig. 63 Plots of thermal conductivity of frozen soil as function of water content.

(b) Soil-water diffusivity

An experimental equipment was not available to permit direct measurements of soilwater diffusivity. Hence, a trial and error method was adopted to approximate these values. As previously described, soil-water diffusivity was estimated by the hydraulic conductivity $(K)$ and specific moisture capacity $\left(C_{\theta}\right)$. The unfrozen and unsaturated hydraulic conductivty was already obtained as the function of pore-water pressure (Fig. 10). The specific moisture capacity is defined as follows :

$$
C_{\theta}=\frac{\mathrm{d} \theta}{\mathrm{d} \varphi}
$$

The relationship between water content $(\theta)$ and pore-water pressure $(\varphi)$ was obtained by the previous experiment as the soil mosture characteristic curve (Fig. 51). This curve may be expressed using the polynominal or other curve fittings as the function of pore-water pressures $(\varphi)$, and one may differentiate water content $(\theta)$ with respect to the pore-water pressure $(\varphi)$. Thus, the diffusivity may be estimated as the function of pore-water pressure or water content. The author obtained two types of empirical equations. 


$$
\begin{aligned}
& D(\theta)=D_{0} \exp \left(D_{1} \cdot \theta\right) \\
& D(\theta)=D_{0}^{\prime}+D_{1}^{\prime} \cdot \theta
\end{aligned}
$$

where $\quad D_{0}=$ constant $=1.06 \times 10^{-4}$

$$
\begin{aligned}
D_{1} & =4.54 \\
D^{\prime} & =-2.61 \times 10^{-4} \\
D^{\prime} & =0.0025
\end{aligned}
$$

In the numerical analysis, equation (30) was used.

In case of a soil in the frozen state, the diffusivity value reduces from the value in the unfrozen state. As described in the previous chaper, the factor impeding water transport by the presence of ice is $10^{-2}$ of the hydraulic conductivity of the soil in the unfrozen state. Taylor and Luthin also assumed the ice-impeding factor as the funciton of ice content. In this study, it is assumed that the soil water diffusivity of the frozen soil is as small as $1 / 100$ times the value of unfrozen diffusivity of the same water content.

\section{4. Scheme of numerical analysis}

The overall scheme is to first equations (17) and (19) in a finite-difference form. The flow region is then depicted by a series of grid point. Quantities given in both equations are assigned to each grid point. Some values are known and applied to the time $(t-\Delta t)$ or $t$, while others are unknown and applied to the advanced time $(t+\Delta t)$.

The finite-difference form of both equations is given by equations (31) and (32), respectively in Fig. 64. Each of the latter represents the sum of two finite-difference equations. The flows of the calculation are shown in Figs. 65 and 66 . The ice content $\theta_{i}$ is determined at the beginning of each time step by equation (33) agrees with the value given by the temperaturewater content relationship (equation 16). When $R$ is unity, equation (33) is used on the assumption that a net heat loss by thermal conduction at a grid point is exactly compensated

$$
\begin{aligned}
& \frac{2 \lambda_{n+1 / 2}}{\left(\Delta X_{1}+\Delta X_{2}\right)}\left\{\frac{T_{n+1}-T_{n}}{\Delta X_{2}}\right\}+\frac{2 \lambda_{n+1 / 2}}{\left(\Delta X_{1}+\Delta X_{2}\right)}\left\{\begin{array}{c}
T_{n+1}{ }^{0}-T_{n}^{0} \\
\Delta X_{2}
\end{array}\right\}-\frac{2 \lambda_{n-1 / 2}}{\left(\Delta X_{1}+\Delta X_{2}\right)}\left\{\frac{T_{n+1}{ }^{0}-T_{n}}{\Delta X_{1}}\right\} \\
& -\frac{2 \lambda_{n-1 / 2}}{\left(\Delta X_{1}+\Delta X_{2}\right)}\left\{\frac{T_{n}-T_{n-1}}{\Delta X_{1}}\right\}-\frac{2 \lambda_{n-1 / 2}}{\left(\Delta X_{1}+\Delta X_{2}\right)}\left\{\frac{T_{n}^{0}-T_{n-1}^{0}}{\Delta X_{1}}\right\}+2 L\left(\frac{\theta_{i n}^{0}-\theta_{i n}^{\infty}}{\Delta t}\right\}\left\{C_{n}+C_{n}^{0}\right\}\left\{\frac{T_{n}-T_{n}^{0}}{\Delta t}\right\} \cdots-(31) \\
& \frac{D_{n+1 / 2}}{\left(\Delta X_{1}+\Delta X_{2}\right)}\left\{\frac{\theta_{n+1}-\theta_{n}}{\Delta X_{2}}\right\}+\frac{D_{n+1 / 2}}{\left(\Delta X_{1}+\Delta X_{2}\right)}\left\{\frac{\theta_{n+1}-\theta_{n}^{0}}{\Delta X_{2}}\right\}-\frac{D_{n-1 / 2}}{\left(\Delta X_{1}+\Delta X_{2}\right)}\left\{\frac{\theta_{n}-\theta_{n-1}}{\Delta X_{1}}\right\} \\
& -\frac{D_{n}-1 / 2^{\circ}}{\left(\Delta X_{1}+\Delta X_{2}\right)}\left\{\frac{\theta_{n}^{\circ}-\theta_{n}-1}{\Delta X_{1}}\right\}-\frac{\rho_{i}}{\rho_{w}}\left\{\frac{\theta_{i n}^{\circ}-\theta_{i n}^{\infty}}{\Delta t}\right\}=\left\{\frac{\theta_{n}-\theta_{n}^{\circ}}{\Delta t}\right\}
\end{aligned}
$$

Fig. 64 Finite-difference form of equation (17) and (19). 
HEAT MASS FLOW SIMULATION

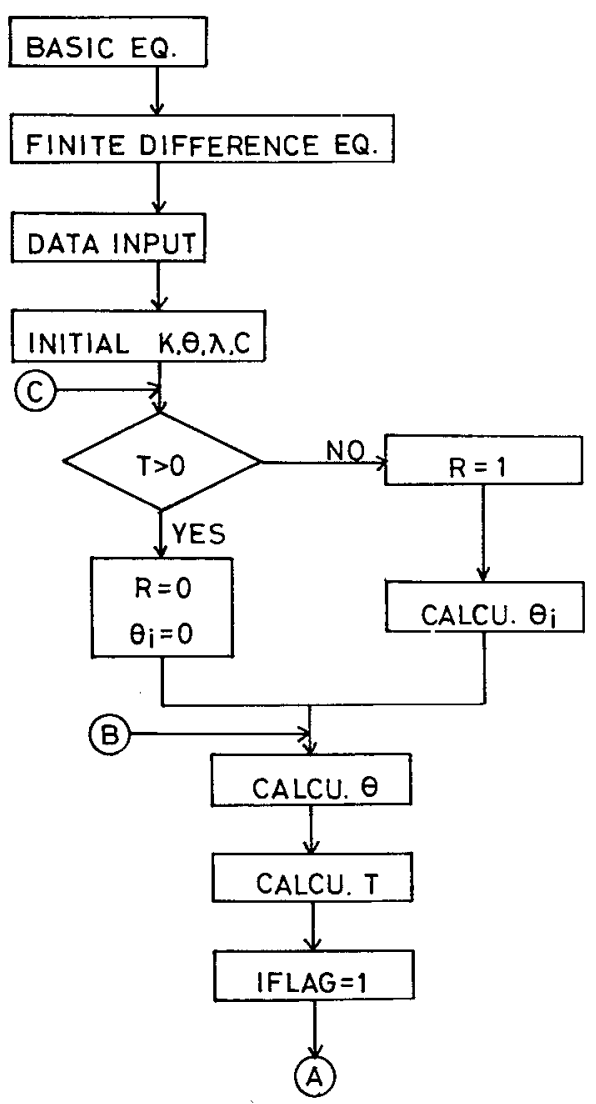

Fig. 65 Flow chart of finitedifferential equations - Part I -

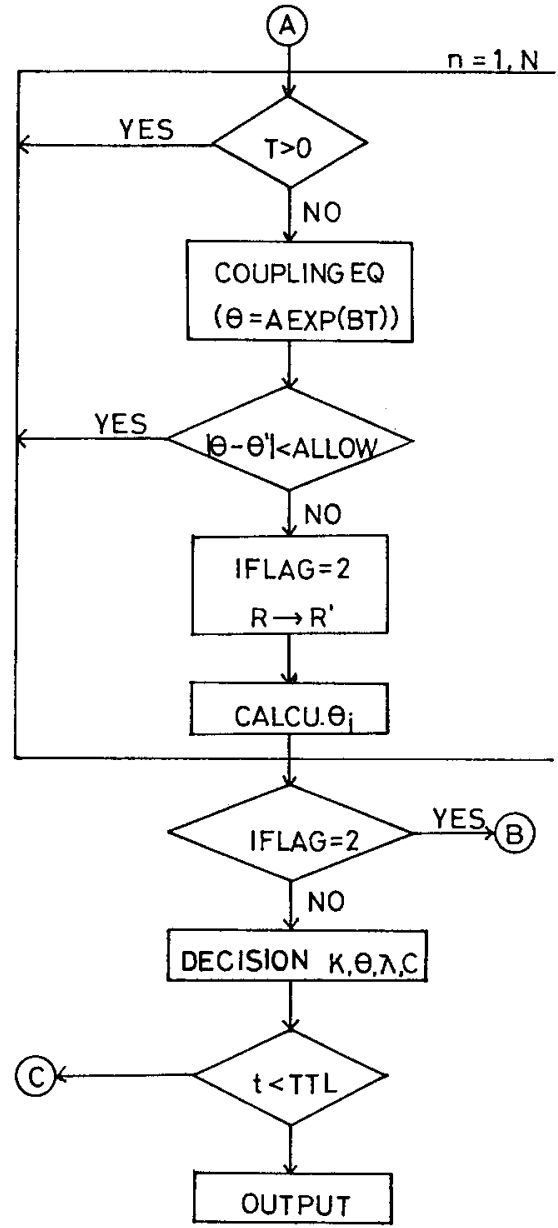

Fig. 66 Flow chart of finitedifferential equations - Part II -

by a heat released during the phase change. (Fig. 67) The magnitude of $R$ is permitted to range from $0-1.05$, but usually resides in the interval $(0.95 \leqq R \leqq 1.05)$. If temperatures are above freezing and the soil is ice free, then $R$ is automatically set to zero. Otherwise, $R$ is initially set to unity. In subsequent time steps, small adjustments are made in its magnitude so that the value of computed by eqation (33) will approach the value calculated by equation (16). Using the scheme mentioned above, a series of simulations was made. Each run corresponds to the experimental result in the previous chapter, obtained by the dual beam gamma attenuation method. 
ICE CONTENT $\theta_{i}$

$$
\begin{aligned}
\theta_{i}^{0}=\theta_{i}^{*}-\frac{2 R \Delta t}{L P_{i}\left(\Delta X^{\top}+\Delta X^{2}\right)}\left\{\lambda_{n}^{0}+1 / 2\left(\frac{T_{n}^{\circ}+1-T_{n}^{0}}{\Delta X_{2}}\right)\right. \\
\quad-\lambda_{n}^{\circ}-1 / 2\left(\frac{T_{n}^{\circ}-T_{n}^{\circ}-1}{\Delta X_{1}}\right) \ldots(\text { (33) }
\end{aligned}
$$

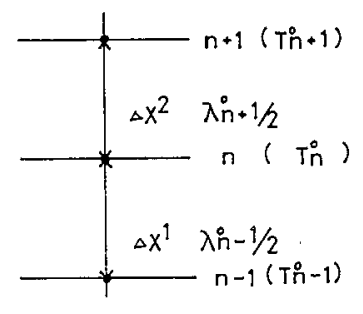

$$
\begin{aligned}
& 0: t=t \\
& x: t=t-1
\end{aligned}
$$

Fig. 67 Schematics of determining ice content using finite-difference form.

\section{5. Results and discussion}

Two experimental tests presented in the previous chapter were chosen for a simulation analysis to scrutinize the reliability of the proposed model as well as the developed numerical techiques. Tests No. 4 and 5 are the chosen examples, which had the similar initial water content but the different advancing rates of the freezing front.

A comparison of temperature changes of test No. 5 between the direct and simulated measurements is shown in Figs. 68-a and 68-b. Two of each temperature profile at each elapsed time from both figures coincide with each other.

The water content profiles of test No. 5 are compared between Figs. 69-a and 69-b. The directly measured initial water contents were not uniform throughout the soil sample, but the simulated profile was assumed to be uniform. At the beginning, the surface water content increased in the simulated case, but it was not a significant increase. This difference is due to a transitional change in temperature at the beginning of the experiment. Such a transitinal change was not established in this computer simulation. At the end of the experimental run, both water content porfiles did not coincide with each other well. However, the indicated discontinuities in water content profiles which formed near the freezing front were located at the similar positions. If the ice-impeding factor of the diffusivity of frozen soil becomes larger, the accumulation of water in the frozen layer decrease (Fig. 69-c). It means that the deqree of accumulation of water in the frozen layer is fairly sensitive to the impeding factor.

Compared with test No. 4, the simulated measurements have simpler profiles of water content than the direct measurements. (Figs. 70-a and 70-b). Like test No. 5, discontinuities 


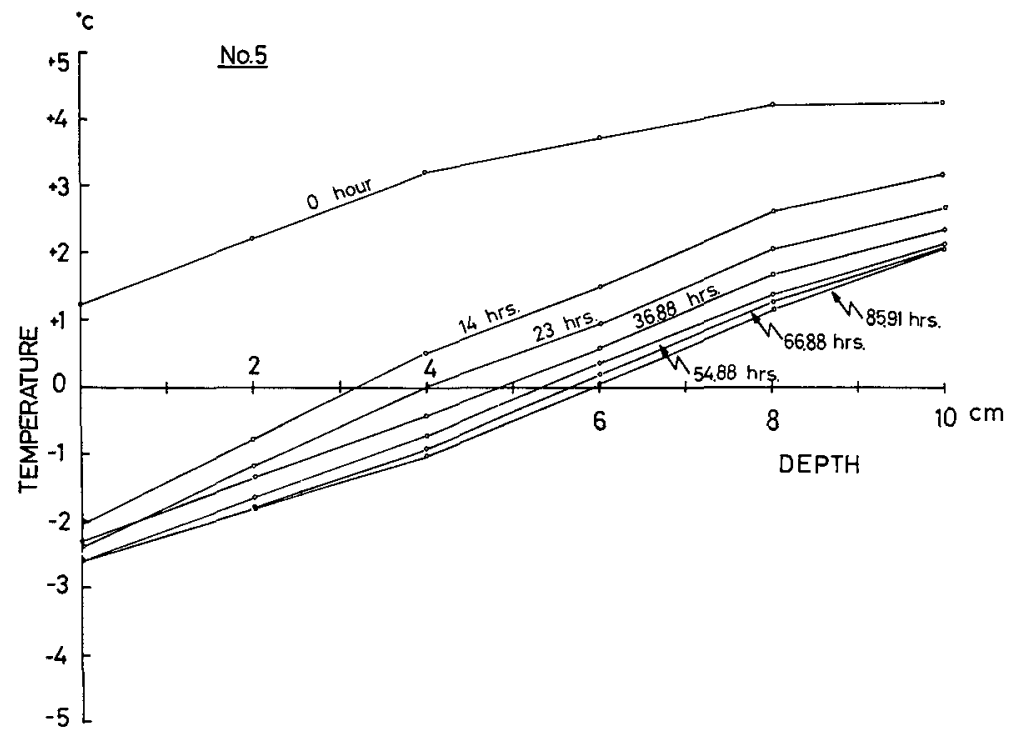

Fig. 68-a Temperature distributions as a function of depth at various elapsed times, directly measured by Dual gamma method.

TEMP. (C)

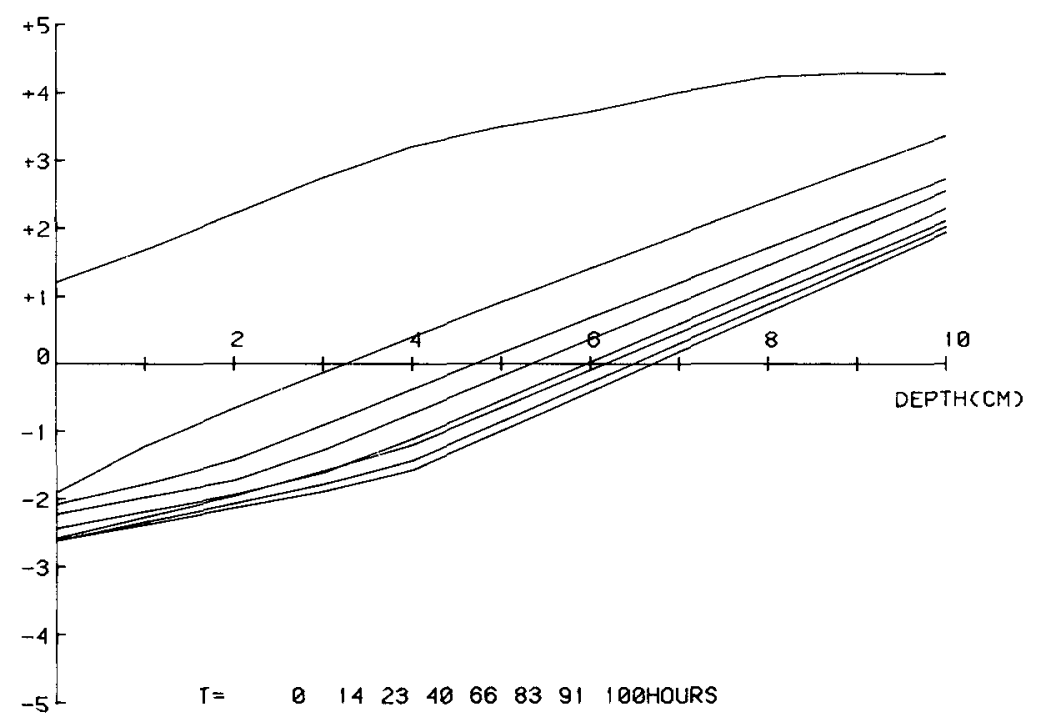

Fig. 68-b Temperature distribution of simulated results, test No. 5. 


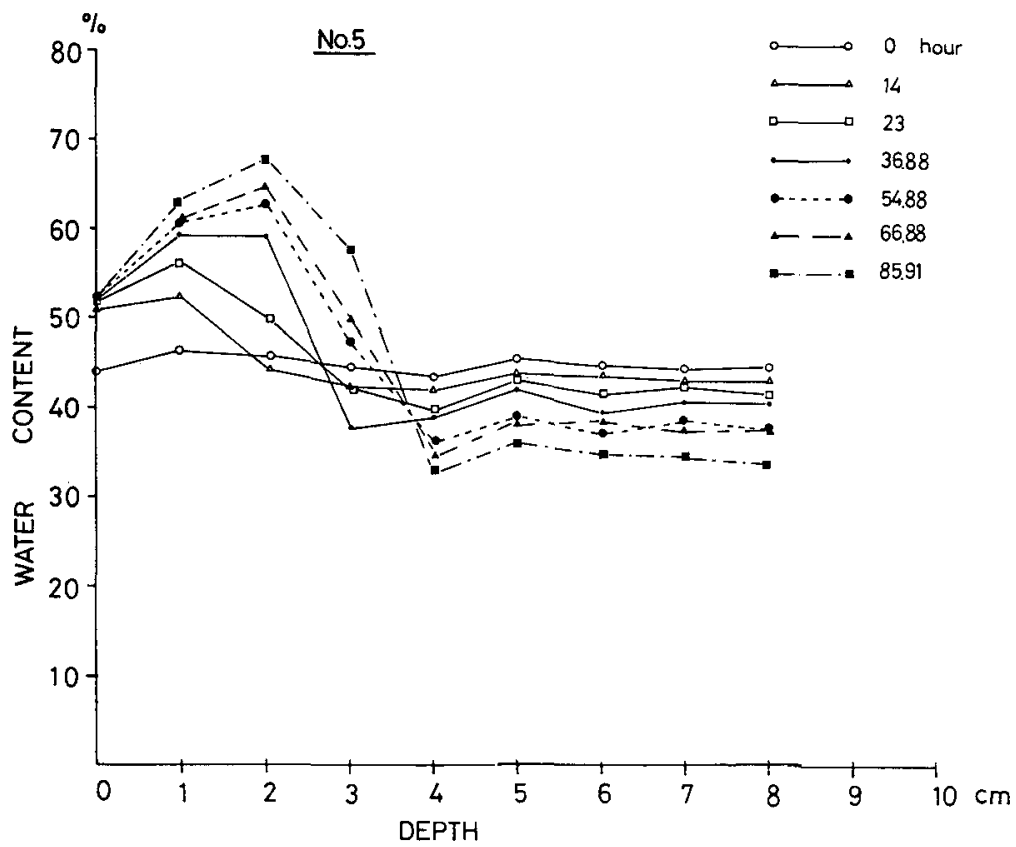

Fig. 69-a Water distribution of test No. 5 ; directly measured by dual gamma method.

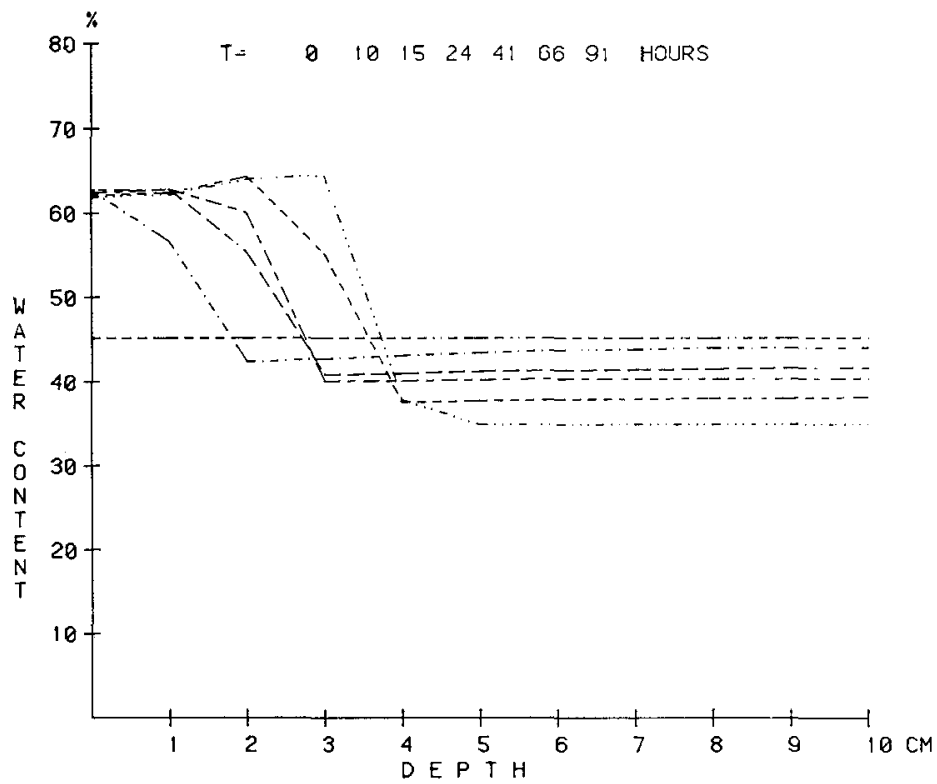

Fig. 69-b Water distribution of simulated results, test No. 5 ; small values of ice impeding factor used. 


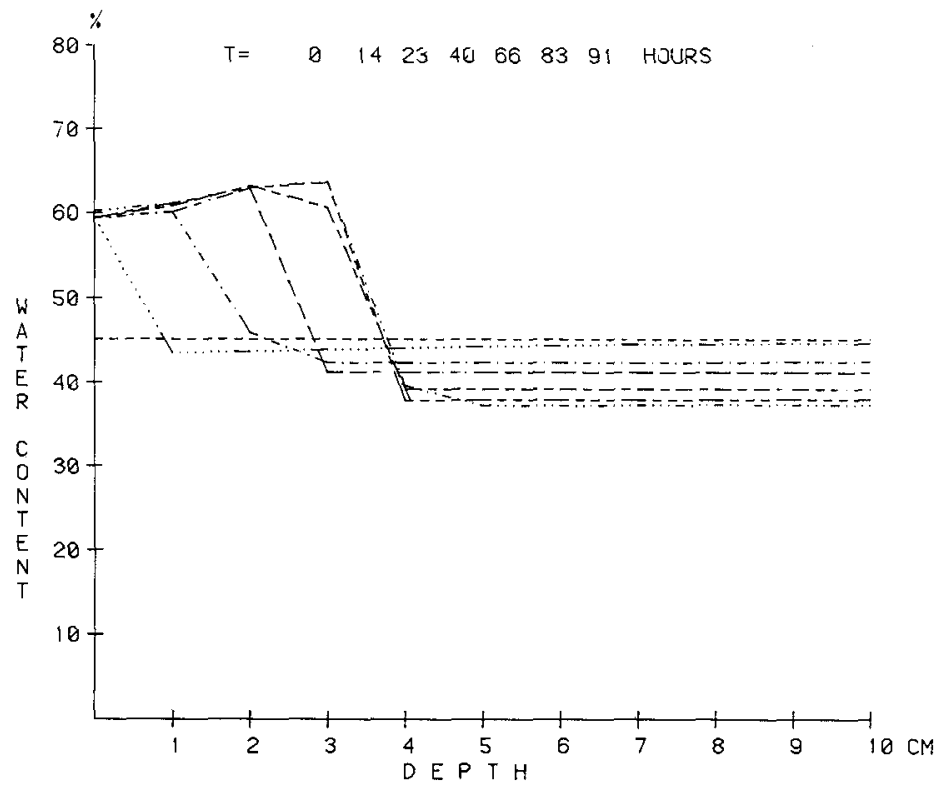

Fig. 69-c Water distribution of simulated result, test No. 5 ; large values of ice impeding factor used.

№. 4

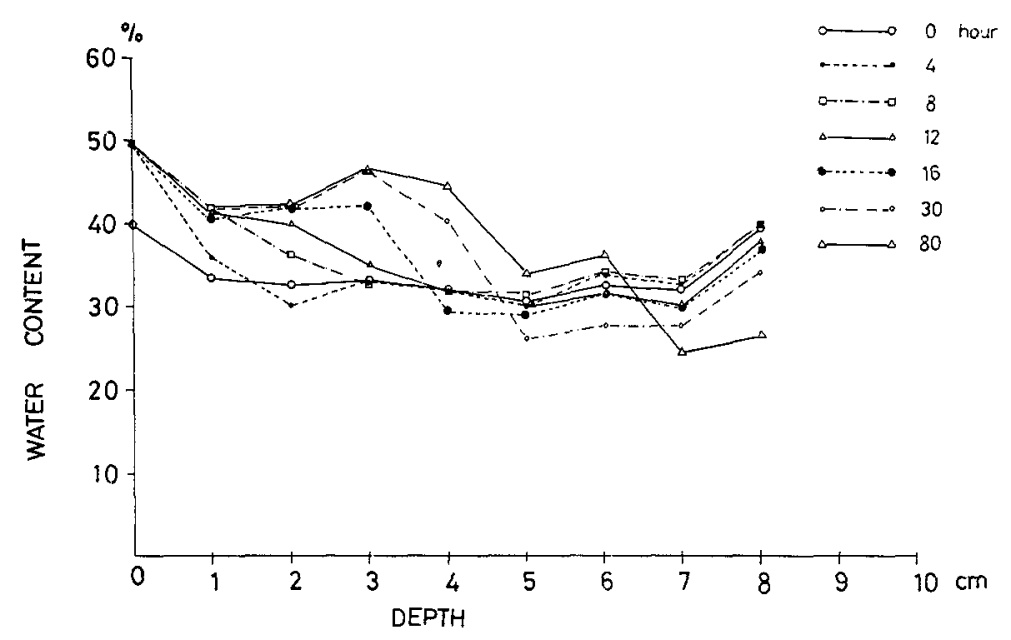

Fig. 70-a Water distribution of test No. 5 ; directly measured by dual gamma method. 


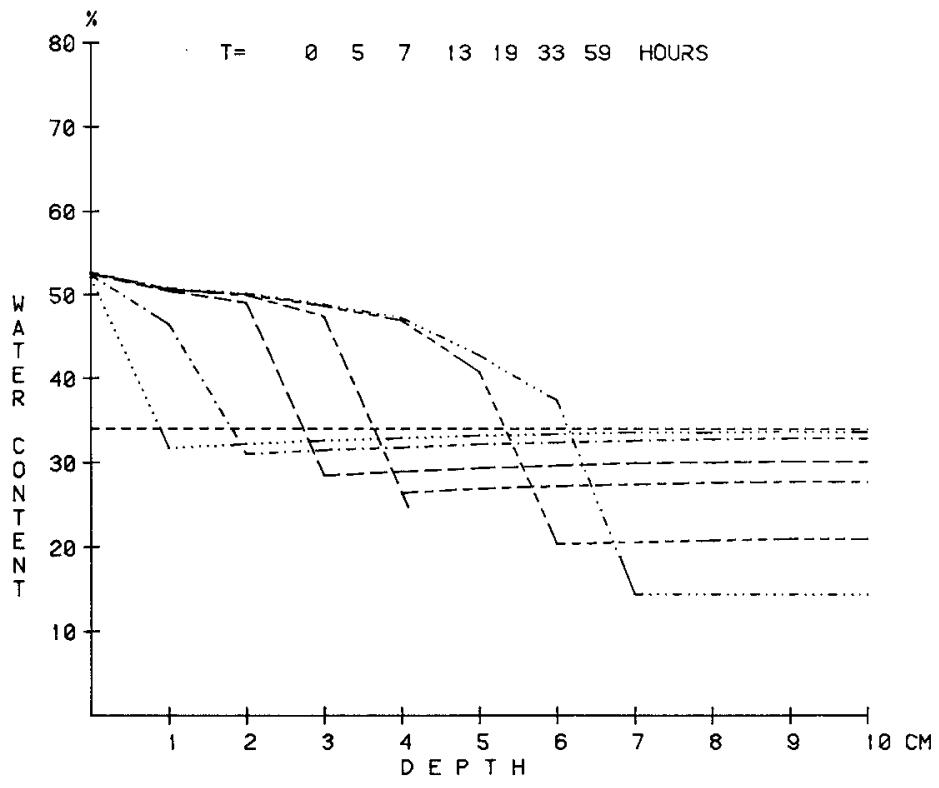

Fig. 70-b Water distribution of simulated results, test No. 4 ; small values of ice impeding factor used.

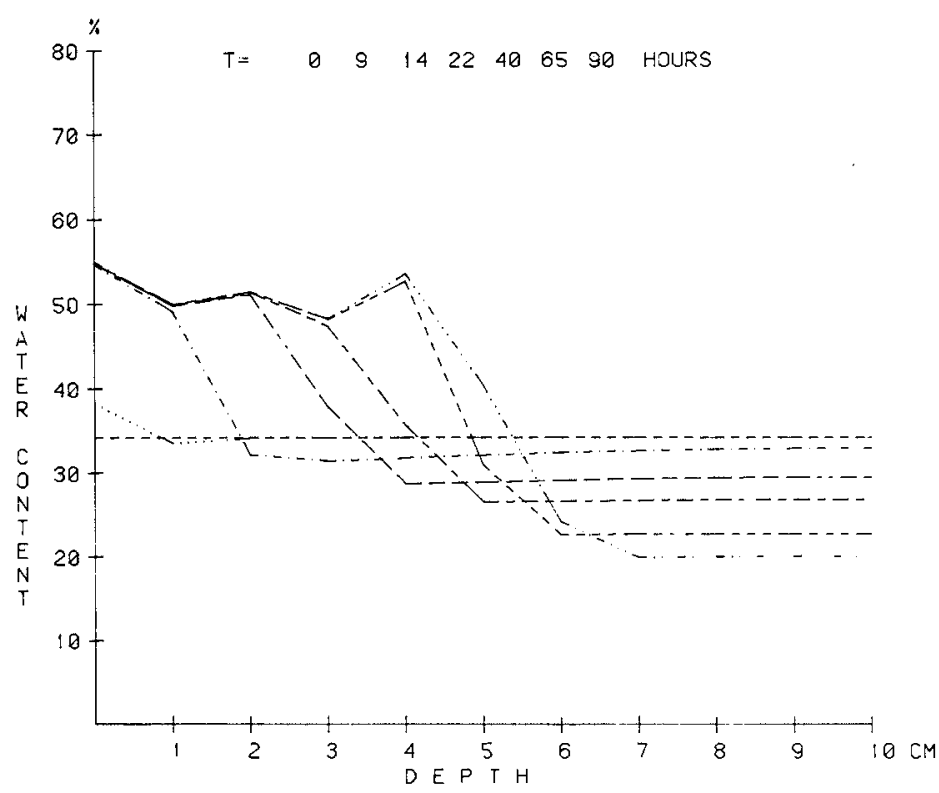

Fig. 70-c Water distribution of simulated result, test No. 4 ; large values of ice impeding factor used. 
in water content profiles at the end of test were located at the similar positions. If the iceimpeding factor becomes small, which means much water accumulation is expected, the profile of water content exceeds the measured values (Fig. 70-c).

From the simulation analysis the following conclusions were reached.

1. The numerical results obtained from the model agree fairly well with the experimental data for both profiles of temperature and moisture content under different conditions imposed on the system. Thus, this agreement will verify the coupled heat and moisture transfer model as well as the numerical solution used in this study.

2. For the model to be used successfully in practice, it is necessary to develop techniques for the measurements of the thermal conductivity and soil-water diffusivity of a soil both in the frozen and unfrozen states. The thermal conductivity was measured with an adequate accuracy by the thermal probe method, which was developed by the author. The value of diffusivity was evaluated by the results of direct measurements of water migration in the frozen layer by means of the dual gamma ray attenuation method.

3. Differences were observed between the simulated and measured water contents in the frozen layer. They might be due to the nonuniform thermal and hydraulic properties of soil in the experiments. Difficult as it may be to incorporate such nonuniformity of soil properties into the simulation and condition, the numerical results obtained from the proposed model agree, in general, very well with the experimental data concerning profiles of both temperature and water content.

\section{Acknowledgements}

The author wishes to acknowledge profound suggestions with Dr. S. Kinosita, Y. Suzuki (Institute of Low Temperature Science). And special thanks are due to late Professor J. N. Luthin (University of California) for his encouragements and assistances throughout the experimental studies in Davis.

With regard to the experimental works, warm acknowledgement is made of the contributions of Mr. A. Orhun (University of California).

The author is pleased to acknowledge typewriting manuscript by Mrs. A. Kono, and revising manuscript by $\mathrm{Mr}$. T. Ohe. 


\section{References}

Anderson, D. M. and Morgenstern, N. R. 1973 Physics, chemistry and mechanics of frozen ground : A review, 2nd International Conference of Permafrost, N. American Contribution, Nat. Acad. Sci., 257-288.

Burt, T. P. and Williams, P. J. 1976 Hydraulic conductivity in frozen soils, Earth Surface Processes, 1, 349-360.

Chalmers, B. and Jackson, K. A. 1970 Experimental and theoretical studies of the mechanism of frost heaving, Research report No. 199, CRREL, pp 22.

Dorsey, N. E. 1940 Properties of ordinary water substances, Reinhold Publishing Co., N. Y. pp 466.

Edlefsen, N. E. and Anderson,A. B. C. 1943 Thermodynamics of soil moisture, Hilgaida. 15, 31-298.

Everett, K. H. 1961 The thermodynamics of frost damage to porous solids, Trans. Faraday Soc. 57, 1541-1551.

Fritton, D. D. 1969 Resolving time, mass absorpion coefficient and water content with gamma-ray attennuation, Soil. Soc. Amer. Proc., 33, 651-655.

Fukuda, M. 1976 Measurements of thermal conductivity of frozen soils by the thermal probe method, Low Temp. Sci Series A., 34, 249-252.

Fukuda, M., Orhun, A. and Luthin, J. N. 1980 Experimental studies of coupled heat and moisture transfer in soil during freezing, Cold Regions Sci. Tech., 3, 223-232.

Fukuda, M. and Luthin, J. N. 1980 Pore-water pressure profile of a freezing soil, Frost I Jord, 21, $31-36$.

Gardner, W. H., Champbell, G. S. and Calissendorf, C. 1972 Systematic and random errors in dual gamma energy soil bulk density and water content measurements, Soil Sci. Soc. Amer. Proc., 36, 393-398.

Goit, J. B., Groenvalt, P. H. and Kay, B. D. 1978 The applicability of dual gamma scanning to freezing soil and the problems of stratification, Soil Sci. Soc. Amer. Proc., 42, 858-862.

Guymon, G, L. and Luthin, J. N. 1974 A coupled heat and moisture transport model for artic soils, Water Resources Res., 10, 995-1003.

Harlan, R. L. 1973 Analysis of coupled heat-fluid transport in partially frozen soil-water transfer, Water Resources Res., 9, 99-102. * ...

Hoekstra, P. 1969 Water movement and freezing pressures, Soil Sci. Soc. Amer. Proc., 33, 512-518.

Jame, Y. W. and Norum, D. I. 1976 Heat and mass transfer in freezing unsaturated soil in a closed system, Edmonton Conference on Soil-water Problems in Cold Regions, Am. Geo. Union, 4662.

Jame, Y. W. and Norum, D. I. 1977 Heat and mass transfering freezing unsaturated soil, presented at A G U annual meeting, San Francisco.

Kinosita, S. and Ishizaki, I. 1980 Freezing point depression in moist soil, The 2nd Intl. Symp. on Ground freezing Troheim, Norway, Preprints pp 640-646.

Klute, A. 1965 Laboratory measurement of hydraulic conductivity of unsaturated soil, Methods of soil analysis, ed by Black, C. A. American Soc. of Agronomy, 210-221.

Koopmans, R. W. R. and Miller, R. D. 1966 Soil freezing and soil water characteristic curves, Soil Sci. Soc. Amer. Proc., 30, 680-685.

Loch, J. P. G. and Kay, B. D. 1978 Water redistribution in partially frozen, saturated silt under several temperature gradients and overburden loads, Soil Sci. Soc. Amer. Proc., 42, 400-406.

Nofziger, D. L. and Swartzendruber, D. 1974 Material content of binary physical mixtures as measured with a dual-energy beam of gamma rays, $J$. Appl. Phys., 45, 5443-5449.

Sheppard, M. I., Kay, B. D. and Loch, J. P. G. 1978 Development and testing of a computer model 
for heat and mass flow in freezing soils, Proc. 3rd International Conference of Permafrost, $76-81$.

Taylor, G. S. and Luthin, J. N. 1976 Numeric results of coupled heat mass flow during freezing and thawing, Proc. 2nd Conference Soil-Water Problems in Cold Region, 155-172.

Taylor, G. S. and Luthin, J. N. 1978 A model for coupled heat and moisture transfer during soil freezing, Canad. Geotech., 15, 548-555.

Woodside, W. and Messmer, J. H. 1961 Thermal conductivity of porous media. I. Unconsolidated sands, J. Appl. Phys., 32, 1688-1699. 